\title{
Afraid of being disliked : from distorted cognitions to interpersonal problems in social phobia
}

Citation for published version (APA):

Voncken, M. J. (2006). Afraid of being disliked : from distorted cognitions to interpersonal problems in social phobia. [Doctoral Thesis, Maastricht University]. Datawyse / Universitaire Pers Maastricht. https://doi.org/10.26481/dis.20060203mv

Document status and date:

Published: 01/01/2006

DOI:

10.26481/dis.20060203mv

Document Version:

Publisher's PDF, also known as Version of record

\section{Please check the document version of this publication:}

- A submitted manuscript is the version of the article upon submission and before peer-review. There can be important differences between the submitted version and the official published version of record.

People interested in the research are advised to contact the author for the final version of the publication, or visit the DOI to the publisher's website.

- The final author version and the galley proof are versions of the publication after peer review.

- The final published version features the final layout of the paper including the volume, issue and page numbers.

Link to publication

\footnotetext{
General rights rights.

- You may freely distribute the URL identifying the publication in the public portal. please follow below link for the End User Agreement:

www.umlib.nl/taverne-license

Take down policy

If you believe that this document breaches copyright please contact us at:

repository@maastrichtuniversity.nl

providing details and we will investigate your claim.
}

Copyright and moral rights for the publications made accessible in the public portal are retained by the authors and/or other copyright owners and it is a condition of accessing publications that users recognise and abide by the legal requirements associated with these

- Users may download and print one copy of any publication from the public portal for the purpose of private study or research.

- You may not further distribute the material or use it for any profit-making activity or commercial gain

If the publication is distributed under the terms of Article $25 \mathrm{fa}$ of the Dutch Copyright Act, indicated by the "Taverne" license above, 


\section{Afraid of Being Disliked}

From Distorted Cognitions to Interpersonal Problems in Social Phobia 
Cover design

Addy Corstiaensen

Druk

Datawyse / Universitaire Pers Maastricht

ISBN-10: $90-9020269-2$

ISBN-13: $978-90-9020269-3$

(c) Marisol Voncken, Maastricht 2006 


\section{Afraid of Being Disliked}

From Distorted Cognitions to Interpersonal Problems in Social Phobia

\section{PROEFSCHRIFT}

ter verkrijging van de graad van doctor aan de Universiteit Maastricht, op gezag van de Rector Magnificus, Prof. mr. G. P. M. F. Mols

volgens het besluit van het College van Decanen, in het openbaar te verdedigen op vrijdag

3 februari 2006 om 14.00 uur

door:

Marisol Jannie Voncken 


\section{Promotor:}

Prof. Dr. A. Arntz

Co-promotores:

Dr. S. M. Bögels

Prof. Dr. L. E. Alden (University of British Columbia, Vancouver)

\section{Beoordelingscommissie:}

Prof. Dr. A. T. M. Jansen (voorzitter)

Prof. Dr. E. S. Beckers (Radboud Universiteit, Nijmegen)

Prof. Dr. N. Heinrichs (Technische Universität Braunschweig)

Prof. Dr. P. J. de Jong (Universiteit Groningen)

Dr. M. L. Peters

These studies were supported by an ASPASIA grant from the Netherlands Organization for Scientific Research (NWO: 015.000.069) 


\section{Contents}

1. Introduction 7

2. Interpretation and judgmental biases in social phobia 15

3. Interpretation and judgmental biases in social phobia versus depression

4. Physiological responses, anxious appearance and social skills in social phobia

5. Hiding anxiety versus acknowledgment of anxiety in social interaction: relationship with social anxiety

6. Changing interpretation and judgmental biases in social phobia: a pilot of a short, highly structured cognitive treatment

7. Conclusion and discussion

8. Summary 133

9. Samenvatting (Dutch summary)

10. Dankwoord (Acknowledgments)

11. Curriculum Vitae 

Chapter 1 
Social phobia, or social anxiety disorder, is a persistent and excessive anxiety about being negatively evaluated by others. Researchers agree that social phobia is under diagnosed and incorrectly regarded as simple shyness (see Kessler, 2003). In fact, social phobia is the most prevalent anxiety disorder (Netherlands: 8\% life-time, Bijl, van Zessen, \& Ravelli, 1997; western society $7 \%-13 \%$, Kessler, 2003) and the third most prevalent mental disorder after the major depressive and substance abuse disorders. Moreover, social phobia severely affects quality of life (Simon et al., 2002). The economic cost of social phobia in the form of educational underachievement, increased financial dependency, decreased work productivity, social impairment (e.g. isolation), and family impairment (e.g. divorce, staying single) is huge (Lipsitz \& Schneier, 2000).

In terms of mental health, social phobia, if left untreated, often results in comorbid depression and alcohol abuse. Moreover, social phobia as a comorbid disorder, also leads to behavioral problems, suicide and psychosis (Bögels \& Tarrier, 2004; Carrigan \& Randall, 2003; Kessler, 2003; Stein, Torgrud, \& Walker, 2000). In addition, parents with social phobia are at risk of transmitting the disorder to the next generation (Rapee \& Spence, 2004). Mean age of onset of social phobia is between 10 and 17 years, and new cases are rarely seen after the age of 25 (see Wittchen \& Fehm, 2003). Without treatment the course of this disorder is chronic (mean of 20 to 25 years, Turner, Beidel, Dancu, \& Keys, 1986; DeWit, Ogborne, Offord, \& MacDonald, 1999). Retrospective data by DeWit et al. (1999) show that only $50 \%$ of social phobic patients (SPs) in the general population recover from their illness. Thus, there is need to understand the factors that maintain social phobia and to develop effective treatments for this impairing disorder.

Over the last two decades, mounting evidence implicates cognitive biases as a pivotal factor in the maintenance of social phobia (see reviews by Heinrichs \& Hofman, 2001 and Hirsch \& Clark, 2004). In this thesis, three different types of cognitive biases are investigated, interpretation and judgmental biases, biases regarding social performance and biases concerning interpersonal behavior. In addition, a cognitive treatment is evaluated that was developed specifically to address the core cognitive biases in social phobia.

\section{Interpretation and Judgmental Biases}

In 1976, A. T. Beck developed a cognitive model for the emotional disorders. His basic assumption was that individuals with such disorders process information in a more negative way than individuals without emotional disorders. More precisely, he postulated that these processing biases were content specific, i.e., restricted to key areas related to the disorder. Moreover, these biases are not simply a side effect of the disorder but rather operate to 
maintain the disorder, and if corrected, reduce complaints. Subsequently, researchers started investigating these assumptions in the depressive disorders. As interest in anxiety disorders developed, the content specificity model was tested in anxious patients. In the area of anxiety disorders, three types of biases were identified: attention, memory, and interpretation and judgmental biases (Mathews \& MacLeod, 1994). After social phobia was added as an official diagnosis in the DSM-III (APA, 1980), the study of cognitive biases was extencled to this condition. In their critical review Heinrichs and Hofman (2001) concluded that little evidence was found for memory bias in social phobia but that SPs do suffer from attentional, and interpretation and judgmental biases regarding potentially threatening social stimuli.

In this thesis, both interpretation and judgmental biases will be investigated. Interpretation refers to the meaning assigned to an event (Heinrichs \& Hofman, 2001). Judgment refers to the perception of threat, and can be subdivided into the estimation of the probability that an event would happen and the cost of the event if it were to happen (Carr, 1974). These biases are assumed to play an important or even pivotal role in the maintenance of social phobia (Foa \& Kozak, 1986). For example, Heinrichs and Hofman (2001), in their review of cognitive biases in social phobia, state that "the meaning assigned to a social situation may influence attentional and memory processes". Moreover, contemporary cognitive models of social phobia regard negative interpretation of a social event as the starting point for various cognitive and behavioral problems (Clark, 2001; Clark \& Wells, 1995; Rapee \& Heimberg, 1997). Lucock and Salkovskis (1988) were the first to test the content-specificity of judgmental bias in social phobia, and Amir, Foa, \& Coles (1998) were the first to examine the specificity of interpretation bias in this disorder. Since then, many researchers have addressed this issue.

Chapter 2 adds to the research on content specificity of interpretation and judgmental biases by refining the assessment of these biases in social phobia and testing them in a large patient sample. In chapter 3 the content specificity of these biases is tested in comparison to depressive disorder. As depression is highly comorbid with social phobia depression might have contaminated findings in SPs. Analyzing contributions of depression and social phobia to cognitive biases in social and non-social situations is a good test of the content specificity model proposed by Beck (1976).

\section{Biases Regarding Social Performance}

Not only do recent cognitive models of social phobia (Clark, 2001; Clark \& Wells, 1995; Rapee \& Heimberg, 1997) assume that SPs have cognitive biases regarding the meaning they assign to social events, they propose that SPS also 
suffer from a biased perception regarding their social performance. Thus, they predict that SPs do not necessarily have problems in social performance, like heightened physiological responses, anxious appearance and social skills, but rather overestimate the visibility of their physiological reactions and underestimate their social skills. Such cognitive biases are assumed to contribute to problems SPs experience in social interactions (Clark, 2001; Rapee \& Heimberg, 1997). In chapter $4_{f}$ studies that assessed physiological responses, anxious appearance and social skills during social interactions are reviewed. Next, the negatively biased perceptions of physiological reactions, anxious appearance and social performance believed to be characteristic of social phobia are investigated. SPs and normal controls' engage in two social interactions and predict how they expect to be evaluated by their interaction partners. The actual responses and behawior of the participants are also actually evaluated by the interaction partners.

\section{Biases Regarding Interpersonal Behavior}

Cognitive writers also assume that SPS suffer from dysfunctional interpersonal beliefs that perpetuate negative interaction cycles (Alden \& Taylor, 2004; Clark, 2001). A growing body of evidence indicates that SPs create negative interaction cycles as witnessed by the finding that they evoke more negative reactions from others than do non-socially anxious individuals (see the review by Alden \& Taylor, 2004). It might well be that the use of safety behaviors by SPs contribute to these negative social outcomes (Alden \& Taylor, 2004; Clark, 2001). For example, trying to conceal one's anxiety by avoiding eye contact or turning away from one's interaction partner might have a negative impact on that person. Possibly, that the belief that safety behavior forestalls a negative impression motivates SPs to engage in such behaviors (Alden \& Taylor, 2004; Clark, 2001). In addition, it may be that SPs fail to engage in behaviors that elicit positive responses from others, such as self-disclosure (see review by Collins \& Miller, 1994) because they erroneously believe this will evoke negative responses. In chapter 5 we investigate beliefs concerning safety behaviors and self-disclosure that might contribute to the negative interaction cycles observed in social phobic people.

\section{Cognitive Treatment}

In addition to investigating different cognitive biases in social phobia, this thesis also presents a study of short, highly structured treatment to address core cognitive biases in social phobia. Over the last decade, treatments for social phobia evolved from social skills training to a combination of behavioral and cognitive techniques. Ingredients of the most recent and effective treatment protocol (Clark et al., 2003; Stangier, Heidenreich, Peitz, 
Lauterbach, \& Clark ${ }^{2}$ 2003) are cognitive restructuring, redirection of selffocused attention, testing the effect of dropping of safety behavior, addressing distorted self-imagery, and identifying anticipatory and post event processing. The cognitive model (Clark, 2001; Clark \& Wells, 1995; Rapee \& Heimberg, 1997) of social phobia, however, postulates that cognitive and behavioral problems such as self-focused attention and safety behavior are the result of the meaning assigned to a social event. If this is indeed the case, a treatment regimen that focuses solely on interpretation and judgmental biases should be sufficient to reduce complaints. Therefore, we developed a treatment aimed to specifically address these core cognitive biases. In chapter 6 the effect of this treatment on social phobic complaints is investigated.

Finally, in chapter 7 the implications of these 5 studies for our understanding of the cognitive biases that characterize social phobia are discussed. This discussion concludes with a cognitive interpersonal model of social phobia that has implications for treatment. 


\section{References}

Alden, L. E., \& Taylor, C. T. (2004). Interpersonal processes in social phobia. Clinical Psychology Review, 24(7), 857-882.

Amir, N., Foa, E. B., \& Coles, M. E. (1998). Negative interpretation bias in social phobia. Behaviour Research and Therapy, 36(10), 945-957.

American Psychiatric Association (1980). Diagnostic and Statistical Manual of Mental Disorders (3rd edition). Washington, DC: American Psychiatric Association.

Beck, A. T. (1976). Cognitive therapy and the emotional disorders. Oxford, England: International Universities Press.

Bijl, R. V., van Zessen, G., \& Ravelli, A. (1997). Psychiatrische morbiditeit onder volwassenen in Nederland: het NEMESIS-onderzoek. II. Prevalentie van psychiatrische stoomissen. Nederlands tijdschtrift voor geneeskunde.

Bögels, S. M., \& Tarrier, N. (2004). Unexplored issues and future directions in social phobia research. Clinical Psychology Review, 24(7), 731-736.

Carr, A. T. (1974). Compulsive neurosis: A review of the literature. Psychological Bulletin, 81(5), 311-318.

Carrigan, M. H., \& Randall, C. L. (2003). Self-medication in social phobia: a review of the alcohol literature. Addictize behaviors, 28(2), 269-284.

Clark, D. M. (2001). A cognitive perspective on social phobia. In W. R. Crozier \& L. E. Alden (Eds.), (2001). International handbook of social anxiety: Concepts, research and interventions relating to the self and shymess. (pp. 405-430). New York, NY, US: John Wiley \& Sons Ltd.

Clark, D. M., Ehlers, A., McManus, F, Hackmann, A., Fennell, M., Campbell, H., Flower, T., Davenport, C., \& Louis, B. (2003). Cognitive Therapy Versus Fluoxetine in Generalized Social Phobia: A Randomized Placebo-Controlled Trial. Joumal of Consulting and Clinical Psychology, $71(6), 1058-1067$.

Clark, D. M., \& Wells, A. (1995). A cognitive model of social phobia. In R. G. Heimberg \& M. R. Liebowitz \& D. A. Hope \& F. R. Schneier (Eds.), Social Phobia: diagnosis, assessment and treatment (pp. 69-93). New York: The Guilford Press.

Collins, N. L., \& Miller, L. C. (1994). Self-disclosure and liking: A metaanalytic review. Psychological Bulletin, 116(3), 457-475. 
DeWit, D. J., Ogborne, A., Orford, D. R., \& MacDonald, K. (1999). Antecedents of the risk of recovery from DSM-III-R social phobia. Psychological Medicine, 29(3), 569-582.

Foa, E. B., \& Kozak, M. J. (1986). Emotional processing of fear: Exposure to corrective information. Psychological Bulletin, $99(1), 20-35$.

Heinrichs, N., \& Hofman, S. G. (2001). Information processing in social phobia: A critical review. Clinical Psychology Review, 21(5), 751-770.

Hirsch, C. R. \& Clark, D. M. (2004). Information-processing bias in social phobia. Clinical Psychology Review, 24(7), 799-825.

Kessler, R. C. (2003). The impairments caused by social phobia in the general population: Implications for intervention. Acta Psychiatrica Scandinavica, 108(Suppl417), 19-27.

Lipsitz, J. D., \& Schneier, F. R. (2000). Social phobia. Epidemiology and cost of illness. PhamacoEcomomics, $18(1), 23-32$.

Lucock, M. P., \& Salkovskis, P. M. (1988). Cognitive factors in social anxiety and its treatment. Behwour Research and Therapy, 26(4), 297-302.

Mathews, A., \& MacLeod, C. (1994). Cognitive approaches to emotion and emotional disorders. Annual Review of Psychology, 45, 25-50.

Rapee, R. M., \& Heimberg, R. G. (1997). A cognitive-behavioral model of anxiety in social phobia. Behaviour Research and Therapy, 35(8), 741-756.

Rapee, R. M., \& Spence, S. H. (2004). The etiology of social phobia: empirical evidence and an initial model. Clinical psychology review, 24(7), 737-767.

Simon, N. M., Otto, M. W., Korbly, N. B., Peters, P. M., Nicolaou, D. C. \& Pollack, M. H. (2002). Quality of life in social anxiety disorder compared with panic disorder and the general population. Psychiatric Senvices, $53(6), 714-718$.

Stangier, Un, Heidenreich, T., Peitz, M., Lauterbach, W., \& Clark, D. M. (2003). Cognitive therapy for social phobia: Individual versus group treatment. Behaoiour Resench and Therapy, 41(9), 991-1007.

Stein, M. B., Trorgrud, L. J., \& Walker, J. R. (2000). Social phobia symptoms, subtypes, and severity: Findings from a community survey. Archioes of General Psychiatry, 57(11), 1046-1052.

Turner, S. M., Beidel, D. C., Dancu, C. V.\& Keys, D. J. (1986). Psychopathology of social phobia and comparison to avoidant personality disorder. Journal of Abnormal Psychology, 95(4), 389-394. 


\section{Chapter 2}

Interpretation and Judgmental Biases in Social Phobia

Marisol J. Voncken

Susan M. Bögels

K. de Vries

This section was published as:

Voncken, M. I., Bögels, S. M., de Vries, K. (2003). Interpretation and judgmental biases in social phobia. Behaviour Research and Therapy, 41(12), $1481-1488$ 



\begin{abstract}
Previous research demonstrated that social phobia is characterized by content specific interpretation and judgmentall biases. The present study investigated whether this interpretation bias occurs not only in ambiguous but also in positive and negative social events, and whether social phobic patients (SPs) are more characterized by a judgmental bias in costs than in probability. Besides, we argued that the judgmental bias observed in former studies could also be attributed to accurate estimations of SPs (of, for example, stuttering). Therefore, we assessed judgmental bias by the ratings of probability and costs of a negative evaluation (e.g., "people dislike me") and not, as in previous studies, of negative social events (e.g., "stuttering"). SPs $(n=228)$ and normal controls $(n=33)$ were presented social and non-social events ranging from positive to profoundly negative, they ranked four different interpretations on likelihood to assess interpretation bias, and rated the profoundly negative interpretation on probability and cost to assess judgmental bias. SPS demonstrated content specific interpretation and judgmental biases that also occurred in positive and negative social events. In contrast with expectations, SPs were characterized by a judgmental bias in both costs and probability.
\end{abstract}




\section{Introduction}

Interpretation and judgmental biases are said to play an important role in the maintenance of anxiety disorders (Foa \& Kozak, 1985; Rapee \& Heimberg, 1997). Amir, Foa and Coles (1998) state that interpretation bias, the interpretation of ambiguous events as negative, may be specifically involved in those anxiety disorders in which ambiguous information needs to be disambiguated, such as social phobia. Three studies investigated interpretation bias in social phobia (Amir et al., 1998; Constans, Penn, Ihen, \& Hope, 1999; Stopa \& Clark, 2000). All three studies indicate that the interpretation bias in social phobia is content specific. That is, social phobic patients (SPs) show a negative interpretation bias only for social but not for non-social events, compared to normal subjects and to patients with other anxiety disorders. Not only ambiguous but also non-ambiguous mildly negative events (e.g., "... he is not really interested in what you're saying") are catastrophized by SPS (Stopa \& Clark, 2000). This suggests that nonambiguous events are also subject to interpretation bias, and it can be hypothesized that SPs interpret all kinds of social events in a negative way. even positive and profoundly negative social events. To our knowledge no research has been carried out into interpretation bias of SPS in positive and profoundly negative socilal events.

Judgmental bias refers to the overestimation of the costs and/or probability of a negative event (Foa, Franklin, Perry, \& Herbert, 1996). Four studies examined judgmentall bias in social phobia compared to normall and anxious controls (Foa et al., 1996; Lucock \& Salkovskis, 1988; McManus, Clark, \& Hackmann, 2000; Poulton \& Andrews, 1996). Results suggest that social phobics have a judgmental bias, which is a content specific phenomenon. However, for two reasons it can be questioned whether SPs in these studies overestimated probability and costs of mildly negative social events or were actually accurate in their ratings. First, the social events sometimes involved symptoms that SPS display more often than controls, such as "feeling shy" or "blushing" (Foa et al., 1996), which affects the estimations of probability. Second, some of the events were not objective but open to interpretation, such as "I will make a mistake in front of my colleagues" (McManus et al., 2000). SPs might have interpreted "mistake" as for example, "stutter slightly in a conversation" whereas normals might have interpreted "mistake" as "letting a valuable object fall to pieces." Such differences in interpretation do influence estimations of cost and probability. Therefore, we argue that judgmental bias in social phobia should be assessed by the overestimation of probability and cost of negative evaluation (e.g., "people dislike me") and not of negative social events (e.g., "making a mistake" or "stuttering"). 
Regarding differences in overestimation in cost and probability, Foa and Kozak (1985) argue that SPs are afraid of highly probable events such as stuttering, whereas patients with other anxiety disorders are afraid of less probable events such as getting a heart attack (panic disorder) or having an accident (obsessive compulsive disorder). Therefore, they expect that social phobia is distinguished by exaggerated cost estimations, whereas anxiety disorders such as panic disorder or obsessive-compulsive disorder will be more distinguished by exaggerated probability estimations. Results, however, are conflicting: Foa et al. (1996) found that decrease in cost estimates in treatment for social phobia mediated improvement in therapy more than decrease in probability estimates, whereas McManus et al.(2000) found partial support for a more prominent role of decrease in probability estimates.

In the present study we addressed the former issues by adjusting previouslly used questionnaires. To study whether objective social events are subject to interpretation bias we presented 228 SPs and 33 control persons social and non-social events ranging from positive, ambiguous and mildly negative to profoundly negative. To assess interpretation bias, subjects were asked to arrange four different interpretations on likelihood. These interpretations ranged from positive, neutral and mildly negative to profoundly negative. Judgmental bias was assessed by the estimation of probability and costs of the profoundly negative interpretation (e.g., in social events "negative evaluation by others"). These estimations were converted to a threat score, as threat can be seen as a joint product of probability and cost of a negative event (Carr, 1974). Furthermore, we investigated the psychometric properties of this questionnaire to expand previous research.

We hypothesized that SPs show content specific interpretation and judgmental biases. That is, compared to normals, SPs (Ia) will interpret social events as more negative; (Ib) will give higher probability and cost ratings of a profoundly negative interpretation in social events (that is, "a negative evaluation) and thus judge social events as more threatening; and (Ic) will not differ in their ratings of non-social events. Also, we expect (II) SPs to show interpretation and judgmental biases in social events of different valence: positive, ambiguous, mildly negative and profoundly negative. Finally, we hypothesized that (III) the difference between SPs and normals will be more pronounced for cost ratings than for probability ratings of "a negative evaluation" in social events. 


\section{Method}

\section{Participants}

Members $(n=720)$ of the Dutch "Association of Shy People" were sent a booklet of questionnaires, 256 returned the questionnaires. All members $(n=$ $228,89 \%$ ) with a score above 88 on the social phobia scale of the Dutch Social Phobia and Anxiety Inventory (SPAl; Turner, Beidel, Dancu, : Stanley, 1989) were included in our SPS group. This cut-off point was based on data of Boggels and Reith (1999): a score above 88 corresponded with $91 \%$ correct diagnoses of social phobia. The SPs group reported a history of social anxiety for a mean of $16.3 \mathrm{SD}=11.6 \%$ years and $85 \%$ of the subjects received a form of treatment, varying from self-hellp groups to psychotherapy. The normal control group ( $n=33$ ) was selected out of 75 volunteers who responded to an advertisement in national newspapers. 26 volunteers were not included in order to match with the SP group on sex, age and education level, 5 had too many missing values, and 11 had a score above the SPAI cut-off point.

All subjects completed the SPAI, the Beck Depression Inventory (BDI; Beck, Ward, Mendelson, Mock and Erbaugh, 1961), the brief Fear of Negative Evaluation (FNE; Leary, 1983) and the Social Phobic Belief Scale (SPB; Bögels, unpublished). The SPB is based on statements of SPS $\mathrm{S}_{s}$ for example, "If I show my weaknesses in sociall events, I will be rejected." In this study the internal consistency was high (Cronbach's alpha: 97). Subject characteristics, mean scores and standard deviations for each of the questionnaires are given in Table 2-1. Because the SP group and the normals show differences in means for depression $(p<.001)$ and education level $(p=.13)$, the analyses were corrected for these variables.

Table 2-1. Subjects characteristics and questionnaire data

\begin{tabular}{|c|c|c|}
\hline & \multicolumn{2}{|c|}{ Group } \\
\hline & $\begin{array}{c}\text { Social phobic patients M (SD) } \\
\qquad(n=228)\end{array}$ & $\begin{array}{l}\text { Mormals } M(S D) \\
\qquad D=33)\end{array}$ \\
\hline Agge & $36.4(9.5)$ & $39.5(14.4)$ \\
\hline Sex & $43 \%$ male $(n)=99)$ & $39 \%$ male $(n=13)$ \\
\hline Education level" & $83(20)$ & $7.8(1.6)$ \\
\hline Socilal phobla scale of the SPA & $127(21,6)$ & $60.7(21)^{*}$ \\
\hline Beck Depression Inventory (BDi) & $14.0(9.4)$ & $7.7(5.1)^{*}$ \\
\hline Fear of Negalive Evaluation (FNE) & $33.9(10.5)$ & $12.9(19.1)^{*}$ \\
\hline Social Phobic Beliefs (SPB) & $54.4(18.8)$ & $20.3(17.4)^{n}$ \\
\hline
\end{tabular}

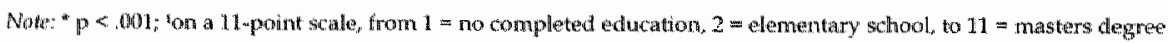




\section{Materials}

The Interpretation and Judgmental Questionnaire (IJO), modelled after questionnaires developed by Butler and Mathews (1983), Foa et al. (1996), McManus et al. (2000) and Stopa \& Clark (2000), consists of brief scripts of 20 social events and 4 non-social control events, ranging from positive (e.g. "Someone makes a compliment about your looks"), ambiguous (e.g." "Somebody you know looks in your direction"), mildly negative (e.g" "The newly introduced person doesn't say anything to you") to profoundly negative (e.g." "A friend tells you that a colleague dislikes you"). Care was taken that the scripts did not consist of any SP" symptoms and contained only objective information. Events such as: "... they appear to be offended by something you said" were rephrased as "... they say they are offended by something you said."

To assess interpretation bias, subjects were instructed to arrange the four kinds of interpretations, varying from positive, neutral and mildly negative (Mld-Neg) to profoundly negative (Pf-Neg), in order of likeliness $(4=$ most likely, 1 = least likely). The interpretations were designed so that normals would most likely choose the neutral interpretation in each event. To assess judgmental bias, subjects rated on visual analogue scales the probability (0$100 \%)$ and the cost (0-100) of each Pf-Neg interpretation. For each event a threat score was calculated by multiplying the probability and costs ratings. "This product was divided by 100 to ensure a range from 0 to 100 . For an example see Figure 2-1.

\section{Results}

Psychometric Properties of the Interpretation and Judgnental Questionnaire (IJQ)

We calculated the internal consistency and internal validity of the 110 and correlated the IJQ with social phobic beliefs measures, using all 306 subjects that returned the questionnaires. High Cronbach alphas were found for the social events $(n=20)$ for the position of the positive (.90), neutral (.84), MldNeg (.82), Pf-Neg interpretation (.91), the probability (.92), costs (.93) and threat (.94) estimates. The same ratings for the non-social events $(n=4)$ showed low internal consistency $(34 ; .19 ; .29 ; .43 ; .58 ; .58$ and .58$)$. 


\section{Middly negative social event:}

You made an appointment with an acquaintance to go to the movies. Shortly before, this person leaves a message on your answering machine that the appointment has to be cancelled.

Why does this acquaintance cancel the appointment?
A This acquaintance doesn't like me (profoundly negative interpretation).
B This acquaintance made another appointment and considers the appointment with me not important enough (mildy negative interpretation).
C This acquaintance likes to go to the movies with me but couldn't cancel another, tedious, appointment (positive interpretation).
D This acquaintance feels sick (neutral interpretation).

1 st....... 2nd ....... 3rd....... 4 th ....... (fill in $A, B, C$ and D)

How probable is it that this acquaintance really doesn't like you?

$0 \%$

$100 \%$

How bad would it be for you if this acequaintance rally didn't like you?

not bad

very bad

at all

Figure 2-1. Example of a mildly negative social event used in the Interpretation and Judgmental Questionnaire

The position of the Pf- $\mathrm{Neg}$ interpretation correlated substantially with the threat scores (social: $r=55, p<.01$; non-social: $42, p<.01$ ). The SPB and FNE correlated highly with the different ratings of the social events (SPB with interpretation $r=.64$, with threat 68 ; FNE with interpretation .58 , with threat $.59)$, and only moderately with the different ratings of the non-social events (SPB with interpretation .35, with threat .34; FNE with interpretation .37, with threat .27) (all $p^{\prime} s<.01$ ).

The questionnaire was designed so that in all events, independent of the valence, a neutral interpretation was the most likely interpretation for normals. Nomals indeed ranked the neutral interpretation as more likely than the SP group (mean normals: $3.5(S D=.27)$; mean SPs: $3.2(S D=.38)$; $\mathrm{t}(255)=4.4, \mathrm{p}<.001,4=$ most likely) . 


\section{Content Specific Interpretation and Judgnental Biases (Mypothesis D)}

To examine whether SPs show content specific interpretation and judgmental biases we used a MANOVA with SPs vs normals as the between group variable and the social vs non-social events as the within group variable. The predicted interaction effect for position of the Pf-Neg interpretation, $F_{\text {wilk }}(1,255)=11.0, p<.01$, and threat scores, $F_{\text {wilk }}(1,257)=14.4, p<.001$, occurred. In line with the idea that interpretation and judgmental biases are content specific, follow-up t-tests revealed that for social events SPS had higher ratings than normals (position: $t(108.9)=10.8, p<.001$; threat: $t(68.4)=$ $6.3, p<.001)^{1}$, whereas for non-social events no difference was found between the two groups (position: $t(256)=2.2$; threat: $t(259)=.4)^{1}$. See also Table $2-2$.

\section{Binses in Social Events of Different Valence (hypothesis II)}

We used post-hoc $t$-tests to test whether interpretation and judgmental biases are present in social events of different valence (positive, ambiguous, mildly negative and profoundly negative). These tests supported our hypothesis (for position: positive: $t(245)=9.1, p<.001$; ambiguous: $t(70.9)=10.2, p<.001$; Mid-Neg: $t(75.4)=7.1, p<.001$; Pf-Neg: $t(78.9)=8.0, p<.001)$; for threat: positive: $t(62.5)=3.3, p<.005$; ambiguous: $t(53.8)=5.0, p<.001$; Mld-Neg: $t(65.5)=5.2, p<.001 ;$ Pf-Neg: $t(53.5)=3.0, p<.05)^{1}$. These $t$-tests were Bonferroni corrected for 6 used contrasts. See also Table $2-2$

\section{Costs versus Probability Ratings (Mypothesis III)}

To examine whether SPs differed in overestimation of costs vs probability we conducted a MANOVA with SPs vs normals as the between group variable, and probability vs costs of social events as the within group variable. No interaction effect was found, $F_{\text {ind }}(1,257)=9$, suggesting that SPs did not have the tendency to overestimate costs over probability of negative social evaluation compared to normals (means: probability SPs: $31.3(\mathrm{SD}=15.3$ ), normals: $19.8(10.0)$ and cost SPs: $66.4(16.6)$ and normals $53.5(18.2)$ ) .

Differences in degrees of freedom are due to the choice of using the thest for different variance estimates, because of the violation of the assumption the equality of means. 
Table 2-2. Means of social phobic patients and normals of position of the profoundly negative interpretation and threat in social and non-social events. Means with different superscripts differ significantly $(p<.05)$

\begin{tabular}{|c|c|c|c|c|}
\hline & \multicolumn{2}{|c|}{ position } & \multicolumn{2}{|c|}{ threat (probability $x \cos t$ ) } \\
\hline & social phobia & normals & social phobia & nomals \\
\hline posilive social events & $1.48(.63)^{\circ}$ & $1.06(1.12)^{\mathrm{fo}}$ & $15.9(13.6)$ & $10.5(7.7)^{\mathrm{t}}$ \\
\hline ambiguous social events & $2.27(68)^{a}$ & $1.48(.36)^{\circ}$ & $26.5(46.2)^{*}$ & $15.6(10.6)^{\mathrm{b}}$ \\
\hline mildly negative social events & $1.86(.79)^{3}$ & $1.24(.40)^{\mathrm{b}}$ & $22.2(16.5)^{\pi}$ & $12.1(9.0)^{\mathrm{b}}$ \\
\hline profoundly negative social events & $1.83(.68)^{\mathrm{a}}$ & $1.24(.34)^{\mathrm{b}}$ & $22.2(15.8)^{a}$ & $15.7(10.4)^{b}$ \\
\hline all social events & $1.86(.357)^{a}$ & $1.26(.23)^{\mathrm{b}}$ & $21.9(41.2)^{a}$ & $11.5(7.7)^{\mathrm{b}}$ \\
\hline non-social events & $1.75(.61)^{\mathrm{a}}$ & $1.54(.56)^{\mathrm{a}}$ & $18.8(13,9)^{\mathrm{a}}$ & $18.7(13.6)^{\mathrm{a}}$ \\
\hline
\end{tabular}

Nols: position of the profoundly negative interpretation. Range $1-4,1=$ least likely, $4=$ most likely; ; of the profoundly negative interpretation

\section{Discussion}

Hypothesis I - interpretation and judgmental biases in social phobia are content specific - was confirmed: compared to normals, SPs interpreted social events as more negative and judge social events as more threatening but do not differ from normals in their ratings of non-social events. These results are in line with those of Amir et al. (1998), Foa et al. (1996), Stopa and Clark (2000) and McManus et al. (2000) but provide a stronger support for the role of interpretation and judgmental biases, since we assessed judgmental bias by negative evaluation (e.g., "people think I" $\mathrm{m}$ stupid") and not, as in previous studies, by negative social events (e.g. "stuttering"). We argued that it is not clear whether the results in those former studies indeed indicate a judgmental bias in social phobia or also represent accurate estimations of social phobics, since some of the used items measure symptoms of social phobia and/or are open to interpretation. 
Furthermore, we found (hypothesis II) interpretation and judgmental biases for social events of different valence: positive, ambiguous, milly negative and profoundly negative. Where interpretation bias in social phobia used to be defined as the negative interpretation of only ambiguous social events our findings argue for a new definition. Interpretation bias in social phobia can be seen as a negative interpretation of all social events, irrespective of vallence.

Finally, in contrast to hypothesis III, we did not find a more pronounced overestimation of cost over probability of negative evaluation by SPs. This is in contradiction with the argument of Foa and Kozak (1985) that SPs would overestimate costs and not so much probability of mildly negative social events. Our results do not support this idea. A possible explanation is that people in general do not seem to find negative evaluation likely (we found probability ratings of $20 \%$ for normals) but find negative evaluation rather severe (we found ratings of 54 for normals, scale range 0-100).

This study had several limitations. First, the SP group in this study was. unusual because it did not consist of patients, in the sense that they were referred for treatment. However, we only included participants in the SP group who scored higher than the cut-off point of the Dutch SPAI (Bögels \& Reith, 1999). Therefore, our SPs can be considered equally severe as patients referred for treatment. In addition, $85 \%$ of the participants in the SP group received previous treatment for their social phobia. Post-hoc t-test indicated no difference between the treated and the not-treated group in SPAI scores (means: treated $128(\mathrm{SD}=22)$; not-treated $124(21) ; t(176)=0.7)$ and in interpretation and judgmental biases (Pf-Neg interpretation: treated $1.9(.59)$; non-treated $1.8(.49) ; t(174)=-0.8$, and threat: treated $22(14)$; not-treated 24 (14); $t(175)=-.5)$. This suggests that either the treatments they received were not successful or the treated patients had more severe social phobic symptoms before treatment than the non-treated ones. In any case, the participants of the present study clearly had severe social phobic complaints. The second limitation of this study was the lack of a control group of patients with other anxiety disorders. Consequently, we cannot rule out that the results represent anxious patients and not especially SPs. However, studies of McManus al. (2000) and Stopa and Clark (2000) already showed that interpretation and judgmental biases in social events is specific for SPS and do not occur in patients with other anxiety disorders. Note also that we did include non-social events and found no interpretation or judgmental biases of SPs in non-social events. The third limitation of this study is the ecological validity of written scripts. It can be questioned whether responses to written scripts are comparable to reactions in real life events. Further research will have to clarify this. 
Finally, this study extended previous research by investigating the psychometric properties of the questionnaire used to assess interpretation and judgmental biases. The internal consistencies of the IJQ were satisfactory for the social but not for the non-social events, possibly due to the smaller number of non-social events $(n=4)$ compared to the social events $(n=20)$. Furthermore, the IJQ showed a good internal validity. Therefore, this questionnaire could be used to evaluate individual cognitive change of social phobic patients during therapy.

\section{Acknowledgements}

This research was supported by a grant from the Netherlands Organization for Scientific Research (NWO: 015,000,069). The authors wish to thank the Dutch Association of Slly People, especially Rian Baremans, John Hommersom and Erik van Brink for their assistance in the recruitment of participants. 


\section{References}

Amir, N., Foa, E. B., \& Coles, M. E. (1998). Negative interpretation bias in social phobia. Behaviour Research and Therapy, 36(10), 945-957.

Beck, A. T., Ward, C. H., Mendelson, M., Mock, J., \& Erbaugh, J. (1961). An inventory for measuring depression. Archives of General Psychintry, 4 . $561-571$

Bögels, S. M., \& Reith, W. (1999). Validity of two questionnaires to assess social fears: The Dutch Social Phobia and Anxiety Inventory and the Blushing, Trembling and Sweating Questionnaire. foumal of Psychopathology and Behavioral Assessment, 21(1), 51-66.

Butler, G. \& Mathews, A. (1983). Cognitive processes in anxiety. Advances in Behaviour Research and Therapy, 5(1), 51-62.

Carr, A. T. (1974). Compulsive neurosis: A review of the literature. Psychological Bulletin, 81(5), 311-318.

Constans, J. I., Penn, D. L., Then, G. H., \& Hope, D. A. (1999). Interpretive biases for ambiguous stimuli in social anxiety. Behaviour Research and Therapy, $37(7), 643-651$.

Foa, E. B., Franklin, M. E., Perry, K. J, \& Herbert, J. D. (1996). Cognitive biases in generalized social phobia. Jounal of Abnormal Psychology, 105(3), 433439.

Foa, E. B., \& Kozak, M. J. (1985). Treatment of anxiety disorders: Implications for psychopathology. In A. H. Tuma \& J. D. Maser (Eds.), Anxiety and the anxiety disorders (pp. 421-452). Hillsdale, NI, US: Lawrence Erlbaum Associates, Inc.

Leary, M. R. (1983). A brief version of the Fear of Negative Evaluation Scale. Personality and Social Psychology Bulletin., 9(3), 371-375.

Lucock, M. P. \& Salkovskis, P. M. (1988), Cognitive factors in social anxiety and its treatment. Behaviour Research and Therapy, 26(4), 297-302.

McManus, F., Clark, D. M., \& Hackmann, A. (2000). Specificity of cognitive biases in social phobia and their role in recovery. Behwoiounal and Cognitive Psychotherapy, 28(3), 201-209.

Poulton, R. G., \& Andrews, G. (1996). Change in danger cognitions in agoraphobia and social phobia during treatment. Behaviour Researd and Therapy, 34(5-6), 413-421.

Rapee, R. M., \& Heimberg, R. G. (1997). A cognitive-behavioral model of anxiety in social phobia. Behaviour Research and Therapy, 35(8), 741-756. 
Stopa, L., \& Clark, D. M. (2000). Social phobia and interpretation of social events. Behaviour Research and Therapy, 38(3), 273-283.

Turner, S. M., Beidel, D. C., Dancu, C. V., \& Stanley, M. A. (1989). An empirically derived inventory to measure social fears and anxiety: The Social Phobia and Anxiety Inventory. Psychological Assessment, 1(1), 3540. 


\section{Chapter 3}

Specificity of Interpretation and Judgmental Biases in Social Phobia versus Depression

Marisol J, Voncken

Susan M. Bögels

Frenk Peeters

This section is submitted for publication as:

Voncken, M. I., Bögels, S. M., Peeters, F. Specificity of interpretation and judgmental biases in social phobia versus depression. 



\begin{abstract}
A body of studies shows that social phobia is characterized by content specific interpretation and judgmental biases. That is, they show these biases in social situations but not in non-social situations. Comorbid depression, one of the major comorbid disorders in social phobia, might account for these biases in social phobia since depression also is characterized by cognitive distortions in social situations. This study investigated interpretation bias (using openended responses and forced-interpretations) and judgmental bias in social. and non-social situations in four groups: Social phobic patients with high $(n=$ 38) and low $(n=47)$ depressive symptoms, depressed patients $(n=22)$ and normal controls $(n=33)$. In line with the content-specificity hypothesis of Beck (1976), we found both social phobic groups to interpret social situations more negatively and judge social situations as more threatening than nonsocial situations relative to depressed patients and normal controls. However, we found this pattern for the interpretation bias, forced choice, and judgmental bias but not for the open-ended measure of interpretation bias. As expected, depressive symptoms related to elevated general interpretation and judgmental biases across social and non-social situations. Moreover, the content-specific biases characterizing social phobia were independent of the general biases related to depressive symptoms.
\end{abstract}




\section{Introduction}

Interpretation and judgmental biases are said to play an important rolle in the maintenance in anxiety disorders, amongst those social phobia (Foa \& Kozak, 1985). A body of research found content specific interpretation and judgmental biases in social phobia (Amir, Foa, \& Coles, 1998; Constans, Penn, Then, \& Hope, 1999; Foa, Franklin, Perry, \& Herbert, 1996; Lucock \& Salkovskis, 1988; McManus, Clark, \& Hackmann, 2000; Poulton \& Andrews, 1996; Stopa \& Clark, 2000; Voncken, Bögels \& de Vries, 2003). That is, social phobic patients compared to normal controls and other anxiety disorders showed more negative interpretations and overestimated probability and costs of negative social outcome, i.e., judgmental bias, in social scripts but not in non-social scripts. This is in line with the content-specificity hypothesis of the cognitive model of (Beck, 1976), assuming that biases of each disorder differ in content (e.g., social phobia is characterized by biases regarding social events, panic disorder is characterized by biases regarding bodily symptoms).

Although one of these studies corrected for depression (i.e., Voncken et al., 2003), the question still remains whether the interpretation and judgmental biases found in social phobia are not caused by depression since depression is one of the major co-morbid diagnoses in social phobia (Brunello et al., 2000; Chartier, Walker, \& Stein, 2003). Moreover, depression has a remarkable overlap with socially anxious symptoms and cognitive distortions found in social phobia. For instance, depressed patients, like social phobic patients, report social distress and avoidance as well as poor social performance (Ducharme \& Bachelor, 1993). Not only do depressed patients report the same complaints in social interaction as socially anxious patients but they also show biases in their perceptions of themselves in social interaction (Gotlib \& Meltzer, 1987) and have a negative cognitive style in social interaction in the sense of being self-critical, self-blaming and having negative expectations regarding other responses like socially anxious patients (see overview of Alden, Bieling, \& Meleshko, 1995). Therefore, the assumed content-specific interpretation and judgmental biases in social phobic patients could as well be the result of elevated depressive symptoms and not specifically the result of social phobia..

Following the content-specificity model of Beck (1976), depressed patients are assumed to show cognitive distortions in both social and non-social situations whereas social phobic patients only show these distortions in social and not in non-social situations. In line, Taylor and Wald (2003) found high correlations between depressive symptoms and judgments about negative outcomes for both social and non-social events, whereas social anxiety symptoms 
correlated highly with social events but not with non-social events. However, this study only used patients with anxiety disorders and no patients with depression as primary diagnosis. Thus, because of the high comorbidity of depression in social phobia it can still not be ruled out that elevated depressive symptoms are responsible for these biases. Due to this comorbidity problem it is difficult to find a clinical sample of social phobia without depressive symptoms. Fortunately, in our previous study (Voncken et al., 2003) we recruited a large sample $(n=228)$ of individuals from a self-help organization for shy people in the clinical range of social phobia. We also assessed depressive symptoms in this group. Therefore, it was feasible to select two sub samples of sufficient size: one with high depressive symptoms (group I: $\mathrm{SP}+\mathrm{D}, n=38$ ) and one with low depressive symptoms (group II: SP$\mathrm{D}, n=47$ ). To our knowledge this was the first study that was able to select such sub samples in social phobia. In addition to these social phobia sub samples, we recruited a clinical sample with depression as primary diagnosis (group III, $n=22$ ) and reused the data of the normal control group (group IV, $n=33$ ). All the subjects in these four groups interpreted social and non-social scripts by answering open-ended questions and ranking four different interpretations (ranging form positive to profoundly negative) in order of likeliness. To assess judgmental bias, all the subjects estimated the probability and costs of a negative outcome in each script.

We hypothesized individuals with social phobia to show (I) content specific interpretation and judgmental biases. That is, compared to the normal control group and the depression group, we expect the social phobia groups to give more negative responses to (Ia) the open-ended questions in the social situations $(\mathrm{Ib})$, position a negative interpretation as more likely in social situations (forced-interpretation) (Ic) and judge social situations as more threatening (the product of probability and costs estimations) than non-social situations. Second, we expected (II) that elevated depressive symptoms would be related with general biases across social and non-social situations. Therefore, the depression group would show interpretation and judgmental biases across the social and non-social situations compared to the normal control group. Moreover, we expected (III) these general biases related to depressive symptoms to be independent of content-specific biased in social phobia. Therefore, interpretation and judgmental biases would be elevated in the same extent across social and non-social situations in the SP+D group compared the SP-D group. 


\section{Method}

\section{Participants}

Two groups of social phobia patients were created: patients with high versus low depressive symptoms. These groups were selected out of the 228 members of the Dutch "Association of Shy People", who participated in the Voncken et al. (2003) study, with a score above 88 on the social phobia scalle of the Dutch Social Phobia and Anxiety Inventory (SPAI; Tumer, Beidel, Dancu, \& Stanlley, 1989). This cut-off point was based on data of Bögels and Reith (1999): a score above 88 corresponds with $91 \%$ correct diagnoses of social phobia when discriminating between social phobic patients and normal controls.

To create the social phobia group with low depressive symptoms (SP-D) of sufficient size we selected subjects with the bottom $15 \%$ scores on the Beck Depression Inventory (BDI; Beck, Ward, Mendelson, Mock and Erbaugh, 1961). The BDI scores of this group $(n=47)$ ranged from 0 to 6 . The social phobia group with high depressive symptoms $(S P+D)$ consisted of subjects $(n$ $=38$ ) with the top $15 \%$ scores on the BDI (range 24 to 45 ). Four subjects of this group only marked one interpretation and thus did not rank order the four interpretations in the interpretation part of the IJQ (see below). Therefore, their ratings could not be used.

The normal control group $(n=33)$, that participated in the Voncken et al. (2003) study, was selected out of 75 volunteers who responded to an advertisement in national newspapers and were matched with the social phobia group on sex, age and education level. They were only included in the normal control group if they had a score beneath the SPAI cut-off point. The depression group $(n=20)$ consisted of patients who were just before or during their start of treatment for depression in the ambulant mental health centre in Maastricht, the Netherlands. These patients fulfilled the DSM-IV criteria of major depression and/or dysthymia according to postgraduate trained therapists who routinely diagnose patients as part of the normal assessment procedure of the mental health centre. Of the 27 patients who were willing to participate 5 did not return the questionnaires, 4 did not rank order the interpretations in the interpretation part of the IIQ (see below) and 2 of them also failed to fill out the probability and costs questions correctly (e.g., only marked the extreme values of the scale). 


\section{Materials}

All participants completed the SPAI, the Beck Depression Inventory (BDI: Beck, Ward, Mendelson, Mock and Erbaugh, 1961), the brief Fear of Negative Evaluation (FNE; Leary, 1983) and the Social Phobic Beliefs Scale (SPB: Boggels, unpublished). The SPB is based on statements of social phobia patients, for example, "If I show my weaknesses in social events, I will be rejected." and has a high internal consistency (Cronbach's alpha: 97, Voncken et al., 2003). See Table 3-1 for subjects' characteristics.

Table 3-1. Subjects' characteristics. Means with different superscripts differ significantly $(\beta$ $<.05$ )

\begin{tabular}{|c|c|c|c|c|}
\hline & $\begin{array}{c}\text { Normal } \\
\text { controls } \\
(n=33) \\
\text { Mean }(S D)\end{array}$ & $\begin{array}{l}\text { Social phobic } \\
\text { patients } \\
\text { low depression } \\
(n=47) \\
\text { Mean }(S D)\end{array}$ & $\begin{array}{l}\text { Social phobic } \\
\text { patients } \\
\text { high depression } \\
(n=38) \\
\text { Mean }(S D)\end{array}$ & $\begin{array}{l}\text { Depressive } \\
\text { patients } \\
(n=20) \\
\text { Mean }(S D)\end{array}$ \\
\hline Age & $39.5(14.4)^{a b}$ & $36.0(8.4)^{2}$ & $35.5(9.7)^{\mathrm{a}}$ & $45.0(12.2)^{19}$ \\
\hline Sex & $39 \%$ male & $49 \%$ male & $42 \%$ male & $36 \%$ male \\
\hline Education level & $7.8(1.6)^{\mathrm{ab}}$ & $8.6(2.2)^{b}$ & $7.5(1.7)^{\mathrm{a}}$ & $6.6(2.6)^{a}$ \\
\hline $\begin{array}{l}\text { SPAI, social } \\
\text { phobia subscale }\end{array}$ & $60.7(21)^{\mathrm{a}}$ & $114.6(16)^{b}$ & $141.9(24.4)^{\mathrm{C}}$ & $112.3(23.2)^{2}$ \\
\hline $\mathrm{BDI}$ & $7.7(5.1)^{\mathrm{a}}$ & $3.6(1.6)^{b}$ & $30.4(5.7)^{\circ}$ & $25.6(8.9)^{\circ}$ \\
\hline FNE & $12.9(11.1)^{2}$ & $28.7(10.2)^{\mathrm{b}}$ & $38.0(11.1)^{c}$ & $29.3(10.2)^{\mathrm{D}}$ \\
\hline SPB & $20.3(17.4)^{2}$ & $46.3(12.9)^{b}$ & $63.0(19.4)^{c}$ & $49.6(21.2)^{b}$ \\
\hline
\end{tabular}

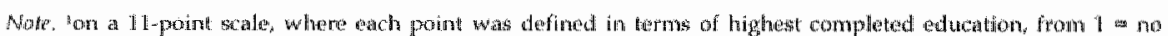
completed education, 2 = elementary school, 1011 masters degree

The Interpretation and Judgmental Questionnaire (IJQ; Voncken et al., 2003), consists of brief scripts of 20 social events (e.g. "you" re being introduced to a friend of one of your best friends. The new person doesn't say anything to you") and 4 non-social control events (e.g. "you bought a new TV. You're programming this TV at home. You push a button and suddenly the TV doesn't work anymore"). The social and non-social situations were presented in mixed order. 
The questionnaire consists of two parts to assess interpretation bias. In part I the subjects are asked in each of the 24 situations to respond to an open-ended question (e.g." why does this person doesn't say anything to you?"). In part II subjects were insitructed to rank the four kinds of interpretations, varying from positive, neutral and mildly negative to profoundly negative (e.g.s "This person doesn't like me"), in order of likeliness ( $4=$ most likely, $\mathbb{1}=$ least likely). The order of interpretations was randomised. To assess judgmental bias, subjects rated on visual analogue scales the probability $(0-100 \%)$ and the cost $(0-100)$ of each profoundly negative interpretation. For an example see Figure 2-1 in the previous chapter.

\section{Psychometric Properties of the IJQ}

The IJQ was shown to have a good internal consistency and congruent validity (Voncken et al., 2003) for part II, the forced interpretations and the probability and cost estimations. In this study we additionally analyzed part $\mathrm{I}_{s}$ the open-ended responses. The inter-rater reliability, indexed by the intra class coefficient (ICC), for the open-ended responses for the social situations. was .95 and for the non-social situations 88 . The correlation between the proportion of negative open-ended responses (part $D$ and the order of likeliness of the profoundly negative interpretation (forced interpretation of part II) was for the social situations .81, $p<.001$ and for the non-social situations $.47, p<.001$. The smaller correlation for the non-social situations is probably due to the smaller number of non-social situations $(n=4)$ than the social situations $(n=20)$. The moderate to high correlations indicate that subjects initial response in part $I$ is consistent with their response to the forced choices of interpretations of part II.

\section{Data Reduction and Analysis}

For the analyses concerning interpretation bias we used two dependent variables. The first variable ('open-interpretation') consisted of the responses to the open-ended questions in part I of the questionnaire. This variable was constructed as follows. Blind raters judged the open-ended responses from positive, neutral, mildly negative to profoundly negative. Because $39 \%$ of the participants did not respond with any profoundly negative interpretations, the proportion of these responses was not normal distributed. Therefore, we added the proportion of profoundly negative responses (with a weight of 1.5) to the proportion of mildly negative responses (with a weight of 1.0 ). The second variable for the analyses of interpretation bias ('forced-interpretation') consisted of the ranking of the profoundly negative interpretation in part III of the questionnaire. For this variable the average of the position of the 
profoundly negative interpretation in the social and non-social situations was calculated.

For the analyses concerning judgmental bias we used one variable ("threatjudgement'). This variable was constructed out of the ratings of the probability and costs for the profoundly negative interpretation in part II of the questionnaire. For the social and non-social situations a mean threat score was calculated by multiplying these probability and costs ratings for the respective situations. To ensure a range form 0 to 100 this product was divided by 100 .

For data analysis we used ANOVA, repeated measures, with 2 between subject factors (social phobia vs. non-social phobia and depressed versus nondepressed) and 1 within subject factor (social vs. non-social). We first included age, sexe and education as covariates. Age and sex did not show an interaction whereas education did in the analyses of threat-judgment. Therefore, education was included as a covariate for this ANOVA. Significant interaction effects were followed up with post hoc $t$-tests, which were Bonferoni corrected for the number of tests.

A side effect of dividing the social phobia group into subjects with high or low depressive symptoms was that the SP+D had higher SPAI scores than the SP-D group (see Table 3-1). In addition, the depressive group showed elevated SPAI scores compared to the normal control group. Finding differences between the groups could, therefore, be the result of the elevate SPAI scores and not of elevate depressive symptoms. Therefore, we repeated the ANOVAs with the same 2 within subject factors (social vs. non-social). However, instead of using social phobia and depression as between subject factors, SPAI and BDI scores were included as covariates. Thus, SPAI and BDI were analyzed as continuous variables. Significant effects were followed up with post hoc partial correlations, corrected for either SPAI or BDI. 
Table 3-2. Means and standard dewiations of proportion of negative responses to the openended questions, position of the profoundly negative interpretation and threat scores, across situations and for social and non-social situations

\begin{tabular}{|c|c|c|c|c|}
\hline \multirow{2}{*}{$\begin{array}{l}\text { Type of } \\
\text { situation }\end{array}$} & \multicolumn{4}{|c|}{ Group } \\
\hline & $\begin{array}{l}\text { Normal } \\
\text { controls }\end{array}$ & $\begin{array}{l}\text { Social phobia } \\
\text { low depression }\end{array}$ & $\begin{array}{l}\text { Social phobia } \\
\text { high depression }\end{array}$ & Depression \\
\hline \multicolumn{5}{|c|}{ Proportion of negative responses } \\
\hline Across situations & $0.28(0.28)$ & $0.40(0.17)$ & $0.53(0.20)$ & $0.37(0.14)$ \\
\hline Sacial & $0.26(0.14)$ & $0.39(0.16)$ & $0.54(0.23)$ & $0.31(0.10)$ \\
\hline Non-social & $0.29(0.27)$ & $0.40(0.25)$ & $0.52(0.27)$ & $0.44\{0.24\}$ \\
\hline \multicolumn{5}{|l|}{$\begin{array}{l}\text { Position of the profoundly } \\
\text { regative interpretation }\end{array}$} \\
\hline Across situations & $1.39(0.37)$ & $1.63(0.34)$ & $2.11(0.69)$ & $1.71(0.36)$ \\
\hline Socilal & $1.26(0.23)$ & $1.67(0.36)$ & $2.19(0.77)$ & $1.51(0.32)$ \\
\hline Non-social & $1.52(0.58)$ & $1.60(0.47)$ & $2.04(0.77)$ & $1.94(.63)$ \\
\hline \multicolumn{5}{|c|}{ Threat scores (probability x costs) } \\
\hline Across situations & $14.6(9.0)$ & $15.9(8.4)$ & $26.3(14.6)$ & $21.1(10.4)$ \\
\hline Social & $11.6(7.7)$ & $17.1(9.3)$ & $27.5(16.1)$ & $15.9(8.73)$ \\
\hline Nan-social & $17.7(12.2)$ & $15.4(12.1)$ & $25.2(15.3)$ & $26.4(15.9)$ \\
\hline
\end{tabular}

\section{Results}

\section{Content Specific Interpretation Bias, Forced-Interpretations}

Means and SDs are displayed in Table 3-2. The ANOVA, with the 2 between subject factors (social phobia versus non-social phobia and depressed versus non-depressed), on the position of the profoundly negative interpretation revealed a small main effect for situation, $F(1,128)=4.53, p<.05$; the nonsocial situations were interpreted more negatively than the social situations. Regarding social phobia, the expected interaction effect between situation and social phobia appeared, $F(1,128)=18.34 p<.001$. Follow-up $t$-tests indicated that individuals with social phobia interpreted social situations more negatively than the individuals without social phobia, $t(130)=5.82, p<.001$, whereas for the non-social situations these groups did not differ, $t(130)=1.03$, ns. Thus, social phobia was accompanied by a content-specific bias. The data also showed social phobia to relate to a more negative bias in general, across social and non-social situations, $F(1,128)=14.51, p<.001$. Note that the follow-up $t$-tests indicate that this was mainly due to the social phobia effect 
within the social situations. Regarding depression, in line with expectations, no interaction between depression and situation, $F(1,128)=0.09$, ns, but a main effect for depression occurred $F(1,128)=22.00, p<.001$. This indicates that depressive symptoms were related to an increase in negative interpretations across social and non-social situations. That is, elevate depressive symptoms were characterized with a general blas across situations. No interaction between situation, social phobia and depression occurred, $F(1,128)=1.34, n s$, what indicates that the content-specific bias related to social phobia was independent of the general bias characterizing depression. See Figure 3-2 for illustration.

The ANOVA, with SPAI and BDI as covariates, revealed the same pattern. An interaction between SPAI and situation, $F(1,129)=10.5, p<.005$, occurred indicating that a higher SPAI related to a greater contrast between social and non-social situations: partial correlation $r=.28, p<.005$. This greater contrast reflected higher ratings for social than for non-social situations. In other words, the more socially anxious the more negative the social situations were interpreted compared to the non-social situations. The ANOVA also showed an interaction between BDI and situation, $F(1,129)=$ $4.29, p<.05$. However, a higher BDI related to a greater contrast between social and non-social situations in the other direction than for SPAI. $(r=-18$, $p<.05$ ): reflecting lower rating for social than for non-social situations. Thus, the more depressive symptoms the more negative the non-social situations were interpreted compared to the social situations.

\section{Content Specific Judgmental Bias, Threat-Judgment}

Means and SDs are displayed in Table 3-2. The threat-judgment (probability times costs estimations) results showed exactly the same pattern as the forcedinterpretation data for both the ANOVA, with the 2 between subject factors, and the ANOVA with SPAI and BDI as covariates. See Figure 3-2 for illustration.

\section{Content Specific Interpretation Bias, Open-Interpretations}

Means and SDs are displayed in Table 3-2. The open-interpretations showed the same pattern as the forced-interpretation data for the ANOVA with the 2 between subject factors. However, the interaction between social phobia and situation failed to reach significance, $F(1,129)=3.41, p<.07$. Moreover, the ANOVA with SPAI and BDI as covariates revealed no interactions between SPAI and type of situation and BDI and type of situation. In short we did not find strong evidence for a content specific interpretation bias for social phobia for the open-interpretations. 

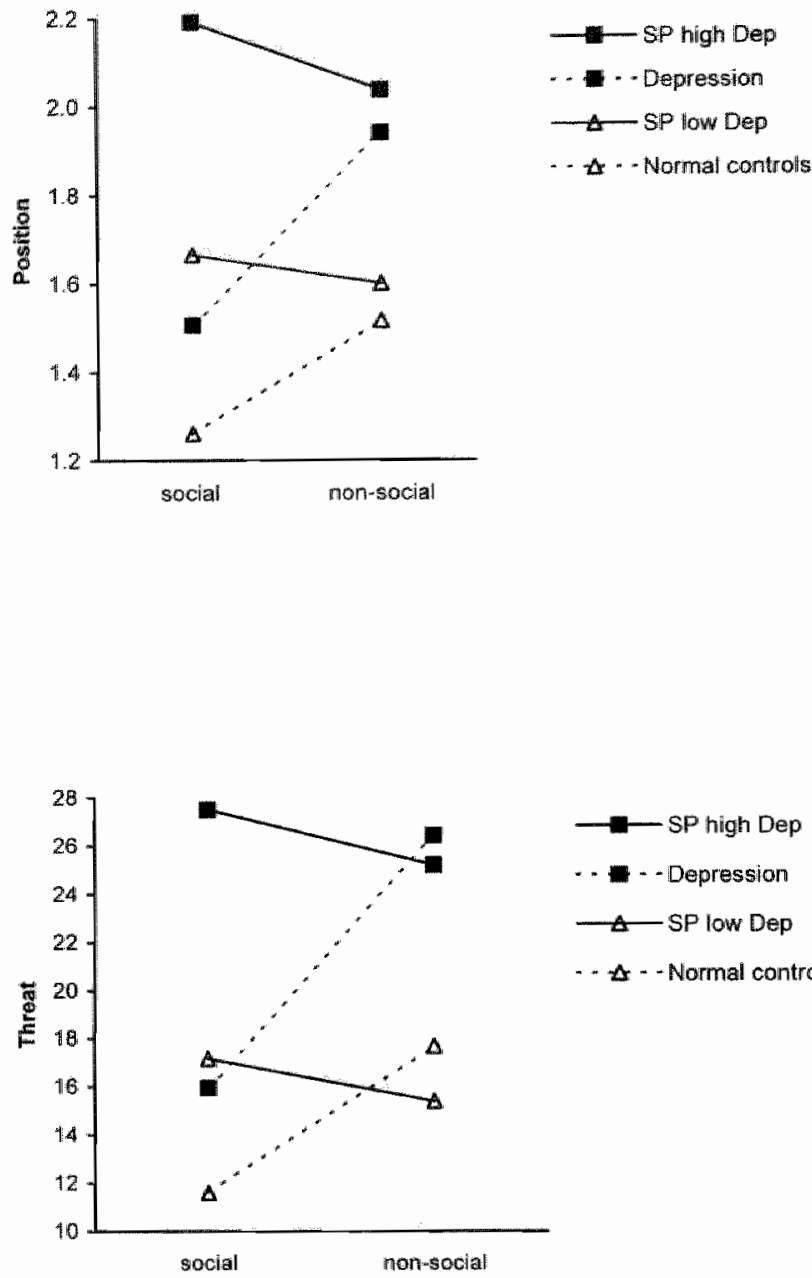

- - - Normal controls

Figure 3-2. Position of the profoundly negative interpretation and threat (probability $x$ cost) scores in social and non-social situations for the social phobic group with high depressive symptoms, the social phobic group with low depressive symptoms, the depression group and the normal control group 


\section{Discussion}

This study investigated whether the content specific interpretation and judgmental biases in social phobia are the result of elevated depressive symptoms, as depression is also marked by cognitive distortions in social situations. In line with the content-specificity hypothesis of Beck (1976), the results indicate that, in spite of depressive symptoms, social phobia patients show content specific biases for social situations. First, we found social phobic patients with high and low depressive symptoms to make negative interpretations in social situations and judge social situations as more threatening than non-social situations relative to normal controls and depressed patients. This indicates that social phobia is characterized by a content-specific interpretation and judgmental bias. Second, depressive symptoms were accompanied by general biases across social and non-social situations. Moreover, the content-specific biases characterizing social phobia were independent of the general biases related to depressive symptoms. We can conclude that an underlying difference in content of interpretation and judgmental biases distinguishes patients with social phobia from those with depression, even if their social anxiety levels are equally high.

In contrast to Stopa and Clark (2000), the open-ended responses to the social and non-social situations did not confirm our content-specificity hypothesis. That is, the more structured or forced-interpretations seem to differentiate better between the four groups than open-responses. The first explanation for this non-finding could be that the open-ended responses were not valid. However, we found moderate to high correlations between open-ended responses and likeliness of negative interpretations. Second, it might be that that the open answers of the subjects produced more measurement error than the forced interpretations because subjects" responses did not always fit into the rating format (e.g., behavior rather than interpretation). Third, the patient groups were possibly more avoidant of negative feelings and therefore produced less negative responses in their open answers than in the forced answers. Fourth, the way of eliciting the interpretation of the subjects differed between the two parts of the IJQ. In the open-ended part subjects were asked to write down "the first thing that comes to mind" whereas in the forced interpretation part subjects were asked to "arrange the four answers in order of likelihood". It could be that the first thing that comes to ones mind does not reflect the likelihood of the interpretation. 


\section{Clinical Implications}

The content-specific cognitive bias, that distinguishes social phobic patients from depressed patients, speaks for the importance of establishing the primary diagnosis in patients with mixed depression and social anxiety complaints. Without such a primary diagnosis therapists might not focus their treatment specifically on biases in social situations in patients with primary social phobia. However, this study also indicates that the general negative biases of such patients should not be neglected, as depressive symptoms in social phobic patients increase biases in social as well as non-social situations. Therefore, therapists should be aware that these general biases across situations might still need intervention after biases in social situations are addressed.

\section{Linitations of the Study}

In the social phobia group we did not have a formal DSM IV diagnosis because we were not able to conduct diagnostic interviews as in the depression group. On the other hand, being a member of an "Association for Shy People" gives a strong indication that social phobia is a serious problem, as these people only become members when they describe themselves as being shy. Moreover, we only included subjects that scored above the cut-off point of the Dutch SPAI (Bögels \& Reith, 1999) implying that $91 \%$ of these subjects fulfilled the criteria of social phobia. Moreover, $85 \%$ of the subjects sought treatment for social anxiety what indicates that these subjects had severe social phobic complaints (see as well Voncken et al., 2003). Another shortcoming of this study is that the depressive group was recruited under different conditions that might have resulted in a different way of responding to the questionnaire than for the other groups. For instance, this group might suffer from more severe psychopathology in general because they were seeking treatment than the members of the "Association of Shy People". However, the depressive group did not respond more negatively to the questionnaires. Last, we only used scripts to investigate interpretation and judgmental biases. It can be questioned whether responses to scripts are equivalent to responses in real life. Further studies will be needed to investigate the ecological validity of these findings. 


\section{Acknowledgment}

This research was supported by a grant from the Netherlands Organization for Scientific Research (NWO: 015.000.069). The authors wish to thank the therapists of the depression team at the ambulant health centre in Maastricht, Sarah Verkennis and the Dutch Association of Shy People, especially Rian Baremans, John Hommersom and Erik van Brink for their assistance in the recruitment of participants. We are also grateful to Suzanne Mol with her assistance in the data-entry. 


\section{References}

Alden, L. E., Bieling, P. J., \& Meleshko, K. G. A. (1995). An interpersonal comparison of depression and social anxiety. In K. D. Craig \& K. S. Dobson (Eds.), Anxiety and depression in adults and children (pp. 57-81). USA: Sage Publications, Inc.

Amir, N., Foa, E. B., \& Coles, M. E. (1998). Negative interpretation bias in social phobia, Behaviour Research and Therapy, 36(10), 945-957.

Beck, A. T. (1976). Cognitive therapy and the emotional disorders. Oxford, England: International Universities Press.

Bögels, S. M., \& Reith, W. (1999). Validity of two questionnaires to assess social fears: The Dutch Social Phobia and Anxiety Inventory and the Blushing, Trembling and Sweating Questionnaire. Journal of Psychopathology and Behavioral Assessment, 21(1), 51-66.

Brunello, N., den Boer, J. A., Judd, L. L., Kasper, S., Kelsey, J. E., Lader, M., et al. (2000). Social phobia: Diagnosis and epidemiology, neurobiology and pharmacology, comorbidity and treatment. Journal of Affective Disorders, 60(1), 61-74.

Chartier, M. J., Walker, J. R., \& Stein, M. B. (2003). Considering comorbidity in social phobia. Soc Psychiatry Psychiatr Epidemiol, 38(12), 728-734.

Constans, J. I., Penn, D. L., Ihen, G. H., \& Hope, D. A. (1999). Interpretive biases for ambiguous stimuli in social anxiety. Behaxiour Research and Therapy, 37(7), 643-651.

Ducharme, J., \& Bachelor, A. (1993). Perception of social functioning in

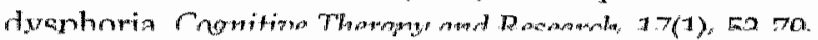

Foa, E. B., Franklin, M. E., Perry, K. J., \& Herbert, J. D. (1996). Cognitive biases in generalized social phobia. Joumal of Abnormal Psychology, 105(3), 433439.

Foa, E. B., Kozak, M. J. (1985). Treatment of anxiety disorders: Implications for psychopathology. In A. H. Tuma \& J. D. Maser (Eds.), Anxiety and the anxiety disorders (pp. 421-452). Hillsdale, NJ, US: Lawrence Erlbaum Associates, Inc.

Gotlib, I. H., \& Meltzer, S. J. (1987). Depression and the perception of social skill in dyadic interaction. Cognitive Therapy and Research, 11(1), 41-53.

Lucock, M. P., \& Salkovskis, P. M. (1988). Cognitive factors in social anxiety and its treatment. Behaviour Research and Therapy, 26(4), 297-302. 
McManus, F., Clark, D. M., \& Hackmann, A. (2000). Specificity of cognitive biases in social phobia and their role in recovery. Behnviournl and Cognitioe Psychotherapy, 28(3), 201-209.

Poulton, R. G., \& Andrews, G. (1996). Change in danger cognitions in agoraphobia and social phobia during treatment. Behaviour Research and Therapy, 34(5-6), 413-421.

Stopa, L., \& Clark, D. M. (2000). Social phobia and interpretation of social events. Behaviour Research and Therapy. 38(3), 273-283.

Taylor, S., \& Wald, J. (2003). Expectations and attributions in social anxiety disorder: Diagnostic distinctions and relationship to general anxiety and depression. Cognitive Behaviour Therapy, 32(4), 166-178.

Voncken, M. J., Bögels, S. M., \& de Vries, K. (2003). Interpretation and judgmental biases in social phobia. Behaviour Research and Therapy, $41(12), 1481-1488$. 



\section{Chapter 4}

Physiological Responses, Anxious Appearance and Social Skills in Social Phobia

Marisol J. Voncken

Susan M. Bögels

This section uas submitted for publication as:

Voncken, M. J., Bögels, S. M. Physiological responses, anxious appearance and social skills in social phobia 



\begin{abstract}
Cognitive models emphasize that social phobia is mainly characterized by biased estimations of their physiological responses, anxious appearance and social skills. This study reviews the literature concerning actual differences between social phobic patients (SPs) and control groups. Moreover, physiological responses, anxious appearance, social skills and biased estimations of social performance are examined in SPs $(n=48)$ and normal controls $(n=27)$ during a speech and a conversation situation. SPs showed a higher blush level (cheek blood flow) prior to the tasks but showed no other differences in level or responsiveness to the tasks for blushing and arousal (skin conductance) compared to the normal control group. Across both tasks independent observers rated SPs as higher on anxious appearance than controls. Interestingly, no differences in social skills between the groups were observed during the speech, but during the conversation SPs were rated as less socially inapt than controls. Next to this actual difference in blushing, anxious appearance and social inadequacy, SPs also overestimated their anxious appearance and social inadequacy compared to normal controls. The actual impairment of SPs during social interactions is argued to be of importance in the maintenance of social phobia.
\end{abstract}




\section{Introduction}

Social phobic patients ( $\mathrm{SP}$ ) are concerned about heightened physiological response (e.g., blushing), an anxious appearance (e.g., looking nervous) and poor social performance (e.g, not knowing what to say). Although cognitive models emphasize that social phobia is foremost characterized by an overestimation of an anxious appearance and physiological responses and an underestimation of their skills (Clark, 2001; Clark \& Wells, 1995; Rapee \& Heimberg, 1997), SPs might also suffer from actual deficits in arousal and performance in social interaction. Such deficits can subsequently confirm their assumption of being negatively evaluated. For instance, Papsdorf and Alden (1998) found a negative relation between liking and an observed anxious appearance.

We review social anxiety studies that assessed physiological blushing and general arousal responses (i.e., skin conductance, heart rate and blood pressure). As SPs might either suffer from more intense physiological responses to social tasks or suffer from a higher physiological arousal level in social situations, we address these two different physiological problems in the review. Next, we review the literature concerning social skills deficits and an anxious appearance in social anxiety. We will address type of participants: analogue or patient samples, and type of situations: speech or conversation. The latter seems important as assumed deficits in social phobia might be more pronounced in certain situations.

\section{Physiological Differences in Blushing in Analogue and Patient Samples}

Blushing has the potential to be visible to others and therefore can be evaluated by an interaction partner. As social phobia is characterized by excessive concern about negative evaluation by other people if others see their embarrassment and anxiety, blushing could be a specific marker for social phobia.

Analogue santples. Six studies assessed blushing in analogue samples. Two studies (Mulkens, De Jong, \& Bögels, 1997; Mulkens, de Jong, Dobbelaar, \& Bögels, 1999) did not find differences in responsiveness of cheek blood flow and cheek temperature in high versus low blushing fearful or blushing propensity groups while watching video fragments inducing embarrassment. In line, Drummond (1997) did not find differences between high and low blushing propensity groups in forehead blood flow responses during a mental arithmetic, singing and moderate physical exercise. 
In contrast, three other analogue studies did detect differences in blushing between socially anxious participants and their non-socially anxious counterparts. Drummond (2001) assessed forehead blood flow responses of high and low blushing propensity groups during embarrassment inducing singing tasks. They found high blushing propensity participants to have greater increases in forehead blood flow during the first of three singing tasks than low blushing propensity participants. In a second study (Drummond et al., 2003), the participants were given false feedback that they were blushing. Subsequently, the high blushing propensity group increased in fore head blood flow in the successive tasks (e.g., singing and reading aloud and listening to audiotapes of their performance) whereas no change was detected in the low blushing propensity group. These two previous studies assessed changes in blood flow but did not analyze overall level of blushing. The study of Bögels, Rijsemus and De Jong (2002) was the only study including level analyses as well. They found high socially anxious persons to have a higher level of blood flow in the cheek overall during a conversation (that is, during baseline, conversation and recovery) than low socially anxious persons while no differences in blushing responsiveness occurred.

Patient samples. Two studies assessed blushing in patient samples. Gerlach, Wilhelm, Gruber and Roth (2001) found SPs to have higher changes of blood flow (responsiveness) in their cheek than normal controls while watching an embarrassment inducing video. Surprisingly, these differences were not found in a conversation and a speech situation. This study did not compare overall levels of blushing between SPs and normal controls. Edelmann and Baker (2002) did not assess blood flow but measured level and reactivity of face and neck temperature in SPs and controls in three non-social tasks and a conversation. No differences in blushing level and reactivity between the groups were found. This might be due to the type of situations studied, as they combined results on the three non-social tasks with the one social task in their analyses.

Conclusion. Of the eight studies that investigated physiological blushing in social anxiety, three analogue and one patient study point in the direction that blushing is a marker for social phobia. Note that none of the three studies that assessed cheek temperature found this to be specific for social anxiety. However, blood flow in cheek or forehead in four out of seven studies discriminated socially anxious from non-socially anxious participants. Thus, there is some evidence for blushing to be a marker for social phobia, especially blood flow in cheek or forehead. It is striking that the only one study that compared level and responsiveness of blushing found level (but not responsiveness) differences between high and low socially anxious 
participants (Bogels et al., 2002). Maybe, blushing level rather than responsiveness is a potential physiological marker in social phobia.

Concerning differences in blushing between speech or conversation. situations, two of the five performance studies found differences between socially anxious and non-socially anxious participants. Regarding conversation situations, one out of three studies found differences in blushing between socially anxious and non-socially anxious participants. Thus, there is no clear evidence that type of situation differentiates physiological blushing in social anxiety.

\section{Other Physiological Differences}

Larger numbers of studies investigated internal physiological arousal, like, skin conductance, heart rate and blood pressure in social anxiety. Although these physiological responses might not be visible to others, they may contribute to the distress and performance of SPs in social interaction.

Analogue Sannples. Three studies in analogue samples failed to detect differences between high and low socially anxious participants for arousal level and/or response. Two studies (Mulkens et al, 1997; Mulkens et al., 1999) did not find differences in responsiveness of skin conductance in high versus low blushing fearful or propensity participants while watching video fragments inducing embarrassment or control fragments. In line, Bögells et al. (2002) did not detect differences in skin conductance during a conversation; this was true for overall level as well as responsiveness.

In contrast, two analogue studies did find differences in physiological responses though they did not assess level of physiology. Beidel, Turner and Dancu (1985) found socially anxious individuals to have increased physiological blood pressure and heart rate reactivity during a speech and two conversations. Moreover, Eckman and Shean (1997) showed socially anxious participants to not physiologically habituate to speeches as high socially anxious students slower decreased in skin conductance and heart rate level from a first speech to a third speech than low socially anxious students.

Patient Samples. Four studies did not find differences in internal physiological level and/or responses between SPs and normal controls. The study of Edelmann and Baker (2002) failed to find differences in level and reactivity of skin conductance and heart rate across three non-social tasks and a conversation. Also no heart rate differences in level and physiological reactivity were found by Levin, Saoud, Strauman, Gorman and colleagues (1993) comparing generalized $S_{S}$ with normal control persons during a speech. Moreover, Hofmann, Newman, Ehlers and Roth (1995) did not detect significant baseline and reactivity differences in heart rate between social 
phobic participants and normal controls during a speech. Also the study of Gerlach, Wilhelm and Roth (2003) found no differences in skin conductance reactivity between SPs and normal controls while watching a videotape of themselves singing, but did not analyze differences in skin conductance level.

In contrast, three studies showed differences in internal physiological level and/or responses between SPs and normal controls. Gerlach et al. (2001) found a higher heart rate overall level for SPs than for normal controls across three social tasks. However, they did not find differences in heart rate reactivity and level and reactivity of skin conductance between the groups. In line, Davidson, Marshall, Tomarken and Henriques (2000) detected SPs to have a higher heart rate level during a speech compared to normal controls but found no reactivity differences. In addition, SPs showed a higher blood pressure level during a speech than normal controls, however this did not reach significance. Turner, Beidel and Larkin (1986) found SPs and high socially anxious participants to have higher blood pressure reactivity than low socially anxious participants during a speech but not for a conversation, but no differences were present with respect to reactivity of heart rate. Physiological arousal level was not assessed in this study.

Conclusion. More than $40 \%$ of the studies so far (two out of five analogue and three out of seven patient studies) implicate some sort of physiological arousal problems in social anxiety. Looking at the assessment of arousal level versus responses, two out of six studies indicate a higher arousal level for SPs or high socially anxious individuals than control groups. Concerning responsiveness, only two of the ten studies found SPs and high socially anxious participants to be more responsive than control participants. In addition, one analogue study found socially anxious participants to slower decrease in arousal than non-socially anxious participants. It seems that the evidence for social anxiety to be marked with a higher arousal level is stronger than for a greater responsiveness to social situations.

When differentiating between speech and conversations situations it is notable that all the five studies (two analogue and three patient studies) that did find differences in physiological level or reactivity included speeches in their assessment. Remarkably, the study of Turner et al. (1986) only found physiological differences during a speech and not during two conversations. In contrast, out of the seven studies (three analogue and four patient studies) that did not find differences only two included speeches in their assessment whereas the other five used social situations like, conversations or watching video fragments. Therefore, it seems that individuals with social anxiety foremost suffer from problems in physiological arousal during a speech and not so much during a conversation. 


\section{Observed Social Skills and Anxious Appearance}

Besides gaining insight in physiological reactions in social phobia, we need to investigate whether others detect SP's' anxiety or social skills deficits. This knowledge helps to estimate how realistic their fear of coming across as anxious and socially inapt for SPs is.

Analogute samples. To our knowledge, nine studies examined social skills and anxious appearance in analogue samples of high and low socially anxious individuals. Bogels et al. (2002) found, in first instance, a difference in observed social skills between high and low socially anxious students in a conversation. However, in a factor analysis two factors emerged in the social skills rating scale: skilled behavior (e.g., smiling) versus showing anxiety symptoms (e.g. stuttering). In post-hoc analyses differences in behavior were explained by high socially anxious students appearing more anxious than low socially anxious students; no differences between the groups were found on the variable comprised of solely social skills. Also Clark and Arkowitz (1975) found that high and low socially anxious male students did not differ in social skills during two conversations but in contrast differed in observed anxiety symptoms. In line, a third analogue study that investigated solely social skills and no anxiety symptoms (Strahan \& Conger, 1998) found equal social skills across high and low socially anxious men during a simulated job interview. In sum, these three studies detected no social skills deficits in social anxiety and the two studies that investigated visible anxiety confirm that social anxiety is marked by an actual anxious appearance.

In contrast, the study of Halford et al. (1982) found socially anxious individuals to be foremost marked by inadequate social skills and not by visible anxiety across 16 role-plays (e.g., initiating conversations, refusing requests, giving and receiving compliments). In line, the data of Beidel et al. (1985) support the supposed lack of social skills in social anxiety in two conversations and a speech, and did not clearly support the presence of more visible anxiety symptoms in social anxiety. Also the study of Twentyman and McFall (1975) found socially anxious students to be rated as less skillful but also as more anxious than non-anxious students across six role-plays (e.g., initiating conversations). Moreover, three other studies that rated solely social skills in analogue samples contribute to the evidence of lack in social skills in social anxiety. Observers in the study of Thompson and Rapee (2002) rated socially anxious individuals as less socially skilled in general (e.g, voice quality, conversational skill) than non-socially anxious individuals during two conversations. In the study of Daly, Twentyman and McFall (1978) high socially anxious students made less eye contact and were less talkative than non-anxious students during an interview and a role-play. In addition, socially anxious participants in the study of Lewin, McNeil and Lipson (1996) 
paused more often and for a longer duration than non-socially anxious participants during a speech. Thus, according to these six studies social anxious individuals suffer from a social skills deficit and less by an anxious appearance.

Patient Samples. A total of eight studies observed social skills and/or anxiety symptoms in social phobic patients (SPs) and control groups. Two studies (Fydrich, Chambless, Perry, Buergener, \& Beazley, 1998; Stopa \& Clark, 1993) observed a worse performance of SPs on one hand and anxious patients and non-patient controls on the other hand during conversations. However, these studies did not distinguish between social skills and anxiety when observing the performance. In the study of Fydrich et al. (1998) participants were rated on items such as gaze, tone and discomfort and by Stopa and Clark (1993) on negative items like showing anxious symptoms, being awkward or uncomfortable and positive items like, friendly, assertive and warm. Therefore differences between SPs and clinically anxious and normal control groups in these studies might be due to deficits in social skills, showing anxiety symptoms or both. A third study by Alden and Wallace (1995) did examine anxiety symptoms separately from social skills. They showed SPs to both appear more anxious and to be less socially skilled (e.g., conveying interest and warmth in partner, extent of self-disclose) than normal controls across two conversations. In line, the study of Levin et al. (1993), that did not assess social skills, confederates rated SPs as more anxious (e.g., sweating, trembling, stammering and flushing) than normal controls during a speech. In a fifth study (Baker \& Edelmann, 2002), independent raters observed, during a conversation, SPs to exhibit less eye contact, show more inadequate gestures, were less fluent in speaking and were overall less adequate than a clinical anxious and a normal control group. No separate anxiety symptoms were rated in this study.

Also Hofmann, Gerlach, Wender and Roth (1997) and Gerlach et al. (2001) found social skills differences between SPs and normals. However, these two studies did not measure social skills in general, but speak disturbances such as frequency and duration of pauses. In these studies SPs showed more speak disturbances than normal controls during a speech and conversation. Additionally, SPs also blushed and appeared more anxious during a speech, but not during a conversation (Gerlach et al., 2001).

All these seven patient studies detected differences between SPs and normal controls in skills, anxious appearance or both. Only Rapee and Lim (1992) did not detect differences between social phobic patients and normal controls, but this study did not assess anxious appearance and did not include a conversation. 
Conclusions. Concerning social skills, two-third of the analogue and most patient studies detected social skills deficits. This was especially true for conversation situations. Concerning anxiety symptoms, three out of the five analogue studies detected differences and all three studies that explicitly observed anxiety symptoms in patient samples point in the direction of SPs showing more of these symptoms than normal controls. This anxious appearance of SPs was most pronounced during speech situations.

\section{Cognilive Biases}

Cognitive models predict that SPs are not so much characterized by poor social skills or an anxious appearance but more by an underestimation of their skills and an overestimation of their anxious appearance. Two studies indeed found SP's to show these biases (Rapee \& Lim, 1992; Stopa \& Clark, 1993) and two analogue studies found the same pattern (Clark \& Arkowitz, 1975; Mellings \& Alden, 2000). However, Bögels et al. (2002) were not able to replicate this in analogue samples; in their study high and low socially anxious students underestimated their social skills in the same extend.

Note that these prior studies estimated biases in skills and anxious appearance by the discrepancy between observer ratings and ratings of participants ${ }^{\prime}$ own experience. However, instead of using participants own experience of the social situation it would be more valuable to have them estimate how observers perceive them. That is, it is assumed that SPs do not specifically suffer from distorted self-perception (also characteristic for depression) but from distorted perceptions of how others view them. The study of Strauman (1989) nicely illustrates this by showing that social phobia is characterized by a discrepancy between how patients perceive themselves and what they believe others want them to be. In other words, not living up to perceived standards of other people is related to social anxious feelings. Therefore, a more precise assessment of cognitive discrepancies in social phobia is to have participants rate how they estimate the observers perceive them.

\section{General Conclusion}

Overall, more than half of the studies show blushing to be a marker of social phobia, for cheek and forehead blood flow but not for skin temperature. There is no clear evidence that type of situation (speech or conversation) differentiates physiological blushing in social anxiety. Although it is common to investigate blushing responsiveness, the single study that also analyzed level of cheek blood flow did detect social anxious individuals to blush more than their non-anxious counterparts. This could signify that not only blushing responsiveness but also a higher blushing level is a marker for social phobia. 
Apart form blushing, almost half of the studies provide evidence that social phobia is marked with general physiological arousal (e.g; skin conductance, heart rate and blood pressure) in social situations, which is mainly expressed in being more responsive to social stressors. To note most of this evidence was found for speech. Next to these indications for physiological problems, social phobia seems to be marked with deficits in social skills and, although the evidence is scarce, with an anxious appearance. This holds primarily for conversations, as those interactions were foremost used in these studies. Regarding speech situations the few studies so far do not indicate general social skills deficits but specific speak disturbances in social phobia. Some evidence is found as well for SPs to appear more anxious than normal controls during a speech. In addition to a social skills deficit and anxious appearance, SPs also suffer from cognitive biases regarding these problems. The majority of the studies show social phobia to be characterized by an underestimation of their skills and an overestimation of their anxious appearance relative to independent observers.

Three remarks across all studies need to be made. First, only eight of the total number of 28 studies addressed used male and female confederates and therefore, accounted for the fact that SPs sometimes have difficulty speaking to the opposite sex or same sex partner. Interestingly, in seven out of these eight studies the experimental group (social phobic or socially anxious individuals) differed from the control group. This suggests that including male and female confederates is more sensitive to detect performance difficulties in social phobia. Second, in 10 out of the 13 patient studies SPs were recruited through advertisements and were not seeking treatment. It could well be that patients referred for treatment are more impaired than patients reacting on advertisements. Third, power problems could have accounted for non-findings, especially for the physiological studies as these assessments suffer from most confounders. Overall the mean participant number was 25 (range 12-36) for the SPs or high socially anxious individuals. Especially given the heterogeneity of social phobia, most studies suffered from insufficient power.

\section{Current study}

In this study referred SPs $(n=48)$, and controls $(n=27)$ were asked to give a 5 -minutes impromptu speech in front of two confederates (male and female) and to get acquainted for 5-minutes with two other confederates (male and female). After each interaction confederates rated sociall skills and anxious appearance of the participant and participants themselves rated their own performance and their estimation of the ratings of the confederates. Two video-raters checked reliability of the confederates ratings. During both 
social interactions blushing (blood flow in cheek and forehead and cheek temperature) and skin conductance were measured at baseline level as well as in response to social challenging tasks. We had the following hypotheses: SPs (Ia) have a higher baseline level and (Ib) are more responsive with respect to blushing and skin conductance to social tasks than normal controls. SPs (IIa) show poorer social skills and (IIb) have a more anxious appearance than normal controls. SPS have a greater discrepancy between their predicted ratings of the confederates and the actual ratings of the confederates for (IIIa) social skills and (IIIb) an anxious appearance than normal controls.

\section{Method}

\section{Participants}

The social phobia group was recruited from the ambulant community mental health centre of Maastricht, the Netherlands. Patients were assessed before they entered treatment. Diagnoses were determined with the Structured Clinical Interview for DSM-IV Axis I disorders (SCID-I, First, Spitzer, Gibbon, \& Williams, 1996). Of the 58 SPs were asked to participate in this study, 49 $(84 \%)$ participated. Reasons for non-participation were: in 5 patients their confidentiality was at risk, as they were students or employees at the university and could be recognized by the student-confederates, 1 patient refused because of the time investment and 3 patients refused because of anxiety. One patient, overwhelmed by anxiety, dropped out during the assessment.

The control group consisted of 27 participants matched on sex, age and education level to the social phobia group. All control participants were screened by telephone with the social phobia and the depression section of the SCID-I. None of the participants fulfilled criteria of social phobia and depression. The group was recruited from a general list of people willing to participate in research at the university.

Due to equipment failure for eight participants (5 SPs and 3 normal controls) all of the physiological data were lost. Besides, during recording for two SPS the equipment failed and some of their data were lost as well.

\section{Procedure}

SPS were asked by their therapists to participate before entering treatment. Order of the tasks, speech and conversation, as well as topic of the speech (see below) was randomly assigned to the participants. Before starting the experimenter asked the participants about medication, caffeine and alcohol use as these factors could influence the physiological assessment. None of the 
participants took anxiolytic medication less than four days previous to the assessment or consumed caffeine or alcohol less than 1 hour previous to the assessment.

After the experimenter attached the participants to the equipment for the physiological recordings participants filled in a questionnaire (used for another study) for 20 minutes in order to get adjusted to the equipment and the temperature of the laboratory. Prior to each task baseline level of physiological arousal was assessed during a 2.5-minutes baseline. After each baseline period participants filled out a baseline anxiety rating concerning their anxiety during the past minutes. The experimenter then instructed the participants for the following task. After explaining the task participants rated their tendency to avoid the next task.

The instruction for the speech was as follows: "We would like you to give a presentation of 5 minutes in front of an audience of two persons. The audience will listen and not react and will judge your social skills afterwards. We ask you to give a presentation about 1) the city/town in which you grew up, 2) a destination of vacation you have been or want to go to." The two topics of the speech were randomized. Before starting the speech participants received a 2.5 -minute preparation period. The instruction for the conversation was as follows: "We would like you to have a conversation with two persons. The purpose of the conversation is to get to know each other. It is up to you to start the conversation and to keep the conversation going." Unlike the speech, participants did not receive a preparation period. In both instances participants were told that the confederates did not know whether they were patients or not and to keep the confederates blind they were asked not to talk about treatment or the study itself.

After each task participants had a recovery period of 2.5-minutes and were instructed to sit quietly and relax. After the recovery period the participants filled out the SSA-rating scale regarding their own performance (self rating) and next the SSA-rating scale regarding their predictions how the confederates would rate them (predicted rating). In the mean time the confederates rated the participants with the same SSA-rating scale (observer rating).

\section{Confederates}

To create a homogeneous group, the confederates were all undergraduate students in the age of 19 to 31 with a mean age of $24(S D=2.72)$. For each assessment four confederates were needed: one male and one female for each of the two tasks. During the course of this study a total of 58 confederates participated. All confederates received a 3 -hour training in rating social skills and anxiety, and were trained to remain neutral during the speech and the 
conversation. During the conversation they were instructed to leave the burden of the conversation with the participant, were not allowed to change the subject of the conversation and were only allowed to take an initiative when the participant was silent for 7 seconds. Furthermore, they were constrained in their responses to three pieces of information per answer (see, Boone et al., 1999; Öst, Jerremalm, \& Johansson, 1981)

\section{General Measure of Social Anxiety}

To assess social phobic symptoms, we employed the social phobic scale of the Social Phobia and Anxiety Inventory (SPAI; Turner, Beidel, Dancu, \& Stanley, 1989; Dutch validation by Bögels \& Reith, 1999).

\section{Social Skills and Anxiety Rating Scale}

The Social Skills and Anxiety Rating Scale (SSA-rating scale) consist of 27 items. Three items (listening, showing interest, responding) only regarded social skills required during the conversation and were not rated for the speech task. Each item of the SSA-scale was rated on a 9-point Likert scale, a high score indicating more anxiety symptoms and better social skills. The participants rated their own performance on the SSA-scale (own rating) and predicted how the confederates would judge them with the SSA-scale (predicted rating). Moreover, two confederates (observer rating) and a videorater (video rating), blind to the diagnoses of the participants, rated the social skills and anxiety of the participants. Fifteen videotapes were independently rated by a second videorater to allow for interrater reliability. Additionally the behavior of the confederates on friendliness, attentiveness, encouragement and discouragement, was rated to estimate the integrity of the confederates. The videoraters received a 1,5 hour training in rating social skills, anxiety symptoms and behavior of the confederates.

The SSA-scale was modelled after the rating scale of Bögels et al. (2002), which was in turn based on an earlier questionnaire developed by Rapee and Lim (1992). This 15-item questionnaire by Bögels et al. (2002) showed a clear two factor structure: the first factor referred to "showing anxiety symptoms" like trembling, stuttering, and appearing nervous, the second factor consisted of items reflecting "skilled behavior", like making eye contact and smiling. This scale was moderated by adding items. For instance, blushing was assessed more precisely: instead of one general item we used three items specifying frequency and intensity of blushing and creeping blush. 


\section{Self-report Anxiety During Baseline}

Prior to each task participants rated their anxiety during a 2,5-minute baseline period on a 9-point Likert scalle. This baseline anxiety rating scale consisted of 9 items concerning, nervousness, physiological responses like, blushing, trembling, sweating, heart rate and the extent of their avoidance tendency for the next task. A high score indicated no anxiety symptoms and no avoidance.

\section{Physiological Measures}

Multi-channel psychological recordings were made with a Vitaport III System. Cheek and forehead blood flow was recorded from a HP model $15230 \mathrm{~A}$ plethysmograph transducer that was modified in such a way that it was dc coupled rather than ac coupled, and sampled at a frequency of 1024 $\mathrm{Hz}$. To assess cheek blood flow the infrared probe for cheek was placed about $5 \mathrm{~cm}$ below the right corner of the right eye. For forehead blood flow the probe was placed in the middle of the forehead $2 \mathrm{~cm}$ above the eyebrow. Cheek temperature was assessed by means of the vitaport temperature transducer that was dc coupled.

Skin conductance level was recorded from two $\mathrm{Ag}-\mathrm{AgCl}$ electrodes $(8 \mathrm{~mm}$ diameter), placed on the medial phalanges of the middle finger and ring finger of participatns nondominant hand, using the method of constant voltage $(0.5 \mathrm{~V})$. The electrodes were filled with an isotonic paste and connected to the vitaport system. Both temperature and skin conductance were sampled with a frequency of $16 \mathrm{~Hz}$. All physiological parameters were analyzed off-line by means of a specifically designed computer program. For each phase in the experiment a mean response for all four physiological parameters was calculated. The temperature of the laboratory was artificially kept a few degrees lower than the temperature of the building.

The social tasks were recorded with a super VHS camera (Sony digital 8) and recorded on Super VHS tapes. For rating of the videotapes we used a Sony Trinitron, monitor.

\section{Data Preparation}

First, $9(12 \%)$ of the participants had few missing values in data collected with questionnaires. These missing values were estimated with the missing value analyses of SPSS, based on regression models using the available data of that measurement moment of the participant and the group mean. The data for the physiological measures that were lost due to equipment failure are represented in the degrees of freedom of the subsequent analyses.

Second, the data collected by the photoplethysmographs, blood flow in cheek and forehead, suffered from common artifacts caused by for instance, 
movement of the probe on the skin or incidence of light. An artifact was defined as an increase or decrease of more than $10 \mathrm{mV}$ within 4 seconds. These artifacts were left out in the calculation of the mean values of the phases of the experiment.

Third, all variables were checked on normality. In the physiological data some outliers were detected. Outliers were transformed by calculating the mean of this variable, without the outlier, and setting the value of the outlier at \pm 3 standard deviations.

Fourth, we investigated whether the two-factor structure of social skills and anxious appearance detected by Bögels et al. (2002) could be replicated. The found structure justified these two factors for the speech and conversation. Explorative factor analyses on the confederate ratings separate for speech and conversation confirmed the existence of an "anxious appearance" and "social skills.s" factor.

Fifth, we checked whether differences between the groups on essential factors existed. The groups did not differ from each other on sex, age and education level. Moreover no differences existed between groups in temperature of the laboratory. Our randomization succeeded, as we found no difference between the groups for order of the two tasks, speech and interaction, and the subject of the speech (place of birth or holiday).

\section{Data Analyses}

Before starting the analyses on the physiological parametters we checked the validity of these measures by correlating self-report and observed ratings of the blushing items (frequency and intensity) and the anxiety scale of the SSA with level and responsiveness (task minus baseline) of the four physiological parameters. These correlations were conducted for first baseline and the data obtained during the speech and conversation, as these measures were used in testing the hypotheses. We repeated this analysis for each group separately. This seemed necessary, as Mulkens et al. (1997) found a relationship between self-perceived blushing and observed blushing for low propensity blushers whereas they did not find this in the high propensity blushers.

For the analysis of differences in physiologicall level between groups (hypothesis Ia) we used the physiological data of the first baseline each participant participated in for the four physiological measures (cheek blood flow, forehead blood flow, cheek temperature, and skin conductance). Depending on the randomization this first baseline was either the baseline before the speech or the baseline before the conversation. With independent $t$ tests differences between the SPs and the normal control group for physiological level were examined. 
To analyze differences in physiological responses to the social tasks between groups (hypothesis Ib) we first analyzed the two tasks (speech and conversation) separately for each of the four plysiological measures. Repeated measures ANOVA was used with phase as within subject variable (for speech: baseline speech, preparation speech, speech, recovery speech; for conversation: baseline conversation, conversation, recovery conversation) and as between subject variable the two groups. Next, to examine whether groups responded differently to the speech versus the conversation task we conducted a repeated measure ANOVA for all four physiological parameters separately with both level and responses to the tasks (differences between baseline and task of speech vs. conversation) as within subject variable and group as between subject variable.

To examine whether the confederates rated the SPs as less skilled (hypothesis II a) and more anxious (hypothesis $\mathrm{Mb}$ ) than the control group across the speech and conversation we used a repeated measures ANOVA with group (SPs vs. controls) as between group variable and task (speech vs. conversation) as within group variable.

Discrepancies between the predicted ratings and the ratings of the confederates on social skills and anxiety symptoms were analyzed to investigate whether SPS showed cognitive biases regarding social skills (hypothesis IIIa) or visible anxiety (hypothesis IIIb). Repeated measure ANOVAs were run for social skills and visible anxiety separately with discrepancy for each task (speech versus interaction) as within group variable and group (SPs versus control) as between group variable.

All post-hoc independent or paired $t$-tests used to unravel interactions were Bonferroni corrected by multiplying the p-value by the number of tests used.

\section{Results}

\section{Reliability}

The consistency of self-reports on the SSA-rating scale was high (range for skills: .91 to .92; anxious appearance: .90 to .92 ). The inter-rater reliability (ICC) for the two confederates on the SSA-rating scale was good for anxious appearance (speech: .76; conversation: .72) and for social skills (speech: 81; conversation: 78 ). Moreover, each of the video-raters showed a good interrater agreement with the average of the two confederates (ICC, mean .84; range .59 to .93 ). The inter-rater reliability of the two video-raters themselves was moderate to good for anxiety (speech: .77; conversation. .63) and good for social skills (speech: .90; conversation: .87). In general we can conclude that the social skills and anxiety ratings of the confederates are reliable. Therefore, 
we used the mean average scores of the confederates for further analysis. Regarding the behavior of the confederates no differences were found between the groups (speech: $t(38)=0.80$, conversation: $t(38)=-0.72$ ).

\section{Validity of Physiological Measures}

As is shown in Table 4-1 forehead blood flow and skin conductance hardly correlated with self-report or observed blush and anxiety during the first baseline, speech and conversation. Cheek temperature showed some correlations but the highest correlations were found between cheek blood flow and the blush and anxiety ratings. All self-report measures, except for first baseline, correlated significantly or borderline significant with cheek blood flow. Moreover, even the observers detected the level or increases in blood flow in the cheek in their blush ratings.

When running the correlations again for each group separately an interesting pattern evoked. In the control group the ratings of observers during the speech correlated highly with cheek blood flow (level: blush: $r=.65, p<.01$; anxiety: $r=.65, p<.01$; responsiveness: blush: $p=.53, p<.01$; anxiety: $r=.45, p$ $<.05$ ). In contrast, no such correlations were found for the SP group (level blush: $r=.08, n s$; observation anxiety: $r=.02$, ns; responsiveness: blush: $r=$ $.05, n s$; observation anxiety: $r=.07, n s)$. Thus, during the speech the observers were more able to pick up the physiological responses of the control group than of the SP group. 
Table 4-1. Correlations between level and responsiveness of the four different physiological measures during first baseline, speech and conversation and self-report and observers rating of blushing and anxiety symptoms

\begin{tabular}{|c|c|c|c|c|c|c|c|c|c|c|}
\hline & \multirow{2}{*}{\multicolumn{2}{|c|}{$\begin{array}{c}\text { First baseline } \\
\text { Self-report }\end{array}$}} & \multicolumn{4}{|c|}{ Speecki } & \multicolumn{4}{|c|}{ Conversation } \\
\hline & & & \multicolumn{2}{|c|}{ Self-report } & \multicolumn{2}{|c|}{ Observers } & \multicolumn{2}{|c|}{ Self-report } & \multicolumn{2}{|c|}{ Observers } \\
\hline & Blush & Anxiety & Blush & Anxiety & Blush & Anxiety & Blush & Anxiety & Blush & Anxiety \\
\hline \multicolumn{11}{|l|}{ Level } \\
\hline Cheek blood flow & .09 & .18 & $.43^{* *}$ & $.42^{\text {*x }}$ & $.26^{*}$ & .17 & $.30^{*}$ & $.30^{*}$ & $.23+$ & .14 \\
\hline Forehead blood tlow & .03 & .00 & -.09 & -.11 & -.03 & -.10 & .05 & .00 & .10 & .08 \\
\hline Cheek temperature & $.26^{*}$ & $.24^{*}$ & $.26^{*}$ & .05 & .10 & .05 & .11 & -.01 & .20 & .20 \\
\hline Skin conduclance level & .07 & .21 & .17 & .18 & .01 & -.02 & .01 & .09 & .03 & .02 \\
\hline \multicolumn{11}{|l|}{ Responsiveness: } \\
\hline Cheek blood flow & & & $.46^{* *}$ & $.33^{* *}$ & $.22+$ & .15 & $.37^{* *}$ & $.26^{*}$ & $.28^{*}$ & $.28^{*}$ \\
\hline Forehead blood flow & & & -.03 & -.11 & -.02 & -.09 & .19 & .16 & .17 & .04 \\
\hline Cheek temperature & & & $.26^{*}$ & .07 & .14 & $.20+$ & $.29^{*}$ & 29 & $.30^{*}$ & $.25^{*}$ \\
\hline Skin conductance level & & & .07 & -.14 & .02 & .06 & -.16 & $-.31 *$ & -.22 & -.04 \\
\hline
\end{tabular}

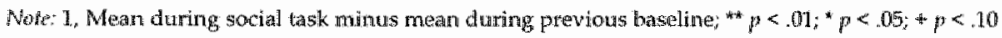

Physiological Baseline Level Differences, Irypothesis Ia

Independent t-tests indicated SPs to have a higher level of cheek blood flow during the first baseline, $t(64)=1.95, \mathrm{p}<.05$, than normal controls. The two groups showed no differences in baseline for forehead blood flow, $t(63)=$ 0.13 , cheek temperature, $t(64)=0.23$, or skin conductance, $t(65)=-.053$. See Table 4-2 for means and standard deviations.

\section{Differences in physiological responses, hypothesis $1 b$}

The means and standard deviations for all physiological parameters during the phases of the assessment are depicted in Table 4-2.

Responses during speech. Except for a trend for cheek blood flow, indicating that the SP group blushed more overall than the control group, $F(3,62)=$ $11.06, p<.08$, no differences between groups were found in the ANOVAs for the four different physiological parameters during the speech. All ANOVAs showed main effects for phase. That is, a significant increase from baseline to preparation for cheek temperature and skin conductance, $p s<.05$, a 
significant increase from baseline to speech for all physiological indices, ps < .05 , and a significant decrease from speech to recovery for cheek blood flow, cheek temperature and skin conductance, $p s<.005$. We found no interaction. effects between phase and group in these speech analyses, except for forehead blood flow, $F(3,60)=4.36, p<.01$. In contrast to expectations, the nommal control group showed a stronger forehead blood flow response from baseline to speech, $t(63)=3.57, p<.005$, and a stronger decrease from speech to recovery speech, $t(63)=2.51, p<.05$ than the SPs.

Table 4-2. Level and responsiveness of the four physiological parameters during first baseline, speech and conversation for the social phobia and normal control group

\begin{tabular}{|c|c|c|c|c|c|c|}
\hline & \multicolumn{2}{|c|}{ First baseline } & \multicolumn{2}{|c|}{ Speech } & \multicolumn{2}{|c|}{ Conversation } \\
\hline & Social phobia & $\begin{array}{l}\text { Normal } \\
\text { control }\end{array}$ & Social phobia & $\begin{array}{l}\text { Normal } \\
\text { control }\end{array}$ & Social phobia: & $\begin{array}{l}\text { Nomal } \\
\text { control }\end{array}$ \\
\hline \multicolumn{7}{|l|}{ Level } \\
\hline Cheek blood flow & $3.57(3.72)$ & $2.18(2.06)$ & $5.93(5.29)$ & $5.11(3.93)$ & $5.67(5.22)$ & $4.85(4.10)$ \\
\hline Forehead blood flow & $3.62(3.46)$ & $3.74(3.33)$ & $4.51(4.53)$ & $7.34(3.85)$ & $4.98(4.39)$ & $6.27(4.16)$ \\
\hline Cheek temperature & $33.43(1.49)$ & $33.36(1.05)$ & $33.98(1.42)$ & $33.92(1.12)$ & $33.90(1.34)$ & $33.93(1.09)$ \\
\hline Skin conductance level & $7.15(3.67)$ & $6.66(3.45)$ & $7.33(3.31)$ & $7.09(3.28)$ & $7.50(3.20)$ & $7.34(3.144)$ \\
\hline \multicolumn{7}{|l|}{ Responsiveness } \\
\hline Cheek bload flow & & & $1.58(2.69)$ & $2.61(3.29)$ & $1.52(2.56)$ & $1.44(3.05)$ \\
\hline Forehead biood flow & & & $1.05(2.03)$ & $3.29(3.00)$ & $1.34(2.58 \mathrm{j})$ & $1.65(2.70)$ \\
\hline Cheek temperature & & & $0.22(0.37)$ & $0.36(0.41)$ & $0.30(0.47)$ & $0.26(0.29)$ \\
\hline Skin conductance level & & & $0.30(0.87)$ & $0.99(1.51)$ & $0.44(0.71)$ & $1.12(0.7 \| 14$ \\
\hline
\end{tabular}

Notw: 1, mean during social task minus mean during previous baseline

Responses during conversation. No main effects for group were found for ANOVAs of each of the four different physiological parameters assessed during the conversation. All ANOVAs showed main effects for phase, that is, a significant increase from baseline to conversation for all physiological indices, $p s<.001$; a significant decrease from conversation to recovery for cheek temperature and skin conductance, $p s<.001$ and a trend for cheek blood flow, $p=099$. Furthermore, we found no interaction effects between phase and group, except for skin conductance, $F(3,60)=4.36, p<.01$. Post-hoc independent $t$-tests indicated, in contrast to expectations, a stronger skin conductance response of the nomal group from baseline to conversation than the SP group, $t(63)=3.79, p<.05$. 
Differences between speech and conversation. No interaction effects between group and task were found for level of the four physiological parameters, except for forehead blood flow, $F(1,63)=7.20, p<.01$. This indicated, in contrast to expectations, that normal controls had a higher forehead blood flow level during the speech, $t(63)=2.54, p<.05$, and the groups did not differ during the conversation, $t(63)=1.18$, ns. Regarding responsiveness, no task interaction effects for temperature and skin conductance but a trend for cheek and forehead blood flow occurred (respectively, $F(1,64)=2.90, p=.09$; $F(1,63)=3.02, p=.09)$. That is, subjects across groups were more responsive to the speech than to the conversation.

\section{Observed Social Skills and Anxiety. Hypothesis Ila and IIb}

See Table 4-3 for means and standard deviations for the two groups. For observed social skills we did not find the hypothesized main effect for group, $F(1,73)=2.08, w s$. Also, no main effect for task was found, $F(1,73)=0.66, n s$, but an interaction effect emerged, $F(1,73)=4.57, p<.05$. Post-hoc independent $t$-tests revealed that the confederates did not detect differences in social skills between the two groups during the speech, $t(73)=0.20, n s$, but rated the SPs as less skilled than the normal controls during the conversation, $t(73)=2.46, p$ $<.05$.

For observed anxiety we did find the expected main effect for group, $F(1,73)=$ $3.92, p<.05$, indicating that SPs were rated as more anxious across speech and conversation than controls. No main effect for task, $F(1,73)=2.87$, ns, nor an interaction effect, $F(1,73)=0.27$, ns, was found.

\section{Cognitive Bias Regarding Social Skills and Visible Anxiety, Hypothesis IIa and Irb}

SPS showed a greater discrepancy between predicted and observed ratings for both social skills and visible anxiety than the normal control group (social skil.Js: $F(1,73)=5.84, p<.05$; visible anxiety: $F(1,73)=6.05, p<.05)$. Also, the analysis for social skills but not for anxious appearance showed a main effect for task, $F(1,73)=11.87, p<.001$, indicating that the discrepancy in the speech condition was greater across the groups than for the interaction condition. No interaction effects between group and task were found. The analysis for discrepancies between own ratings and confederate ratings for social skills and visible anxiety revealed the same pattern. 
Table 4-3. Predicted, observed and discrepancy ratings of social skills and visible anxiety durng spech and conversation for the social phobia and nomal control group

\begin{tabular}{|c|c|c|c|c|}
\hline & \multicolumn{2}{|c|}{ Speech } & \multicolumn{2}{|c|}{ Conversation } \\
\hline & $\begin{array}{c}\text { Social Phobic } \\
\text { Patients }\end{array}$ & Mormal controls & $\begin{array}{c}\text { Social Phobic } \\
\text { Patients }\end{array}$ & Nomal controls \\
\hline \multicolumn{5}{|l|}{ Social skths } \\
\hline Predicted & $5.35(1.51)$ & $6.06(1.15)$ & $5.82(1.13)$ & $6.82(0.97)$ \\
\hline Confederates & $0.70(1.42)^{2}$ & $6.77(1.05)^{2}$ & $6.51(1.18)^{3}$ & $7.19(1.10)^{b}$ \\
\hline Discreparcy & $1.35(1.44)^{\mathrm{a}}$ & $0.70(104)^{3}$ & $0.69(1.23)^{\mathrm{a}}$ & $0.37(1.18)$ \\
\hline \multicolumn{5}{|l|}{ Visible anxiety } \\
\hline Prodicted & $4.39(1.37)$ & $3.82(1.31)$ & $4.09(1.34)$ & $2.88(1.63)$ \\
\hline Confederates & $3.58(1.21)^{0}$ & $3.18(0.95)^{\circ}$ & $3.47(1.02)^{m}$ & $2.96(0.85)$ \\
\hline Discrepancy" & $0.81(1.62)^{3}$ & $-0.06(0.99)^{b}$ & $0.62(1.47)^{a}$ & $-0.00(1.57)^{\mathrm{b}}$ \\
\hline
\end{tabular}

Nofe. Means with different subscript differ significanty from each other. "Diserepancy = confederates ratirg minus predicted ratings of the participants

\section{Discussion}

This study investigated physiological responses, anxious appearance and social skills in social phobia. SPs showed (Ia) a higher blood flow level in their cheek than normal controls during baseline as well as speech. Regarding physiological responses (Ib) no differences between SPs and normal controls were found except that in contrast to expectations, for some indications (forehead blood flow during the speech and skin conductance during the conversation) the normal control group was wore responsive than the SP group. Furthermore, SPS were (Ila) rated less skilled compared to normal controls but only during the conversation and not during the speech. Moreover, SPs were (IIb) rated as more anxious than normal controls during the speech as well as the conversation. Last, SPs (IIIa) underestimated their social skills and (IIIb) overestimated the visibility of anxiety symptoms across both social tasks compared to normal control subjects. These main results are discussed below.

\section{Heighethed bushing level for Social Phobic Patients}

SPs do not only complain about blushing but show actual heightened physiological cheek blush level compared to controls prior to the social tasks and, although only a trend, across the four phases of the speech. No other physiological differences were found between the two groups expect for some 
indications that the normal control group was more responsive to the social tasks. Thus, results of this study indicate that cheek blushing level and not general arousal is a specific marker for social phobia. That blushing is a specific marker for social phobia is plausible as blushing is a social phenomenon that hardly occurs when one is alone (Edelmann, 2001) whereas arousal is a response to a wide variety of stressors. It might well be that cheek blood flow represents social stress whereas forehead blood flow, like skin conductance, represents general stress.

SPs suffered from a higher cheek blood flow before starting the social tasks and during the speech and thus experienced more blushing than normal controls. This blushing might have heightened their awareness of their anxiety response (i.e., being more self-focused, Bögels \& Mansell, 2004) what in turn heightens actual anxiety. This relates well with the heightened visible anxiety observers detected in SPs compared to normal controls across both tasks.

Former studies (Drummond et al., 2003; Drummond, 2001) that differentiated high and low blushing propensity groups on forehead plethysmograph responsiveness used embarrassment-inducing tasks. Why heightened level cheek blood fllow but neither level nor responsiveness of forehead blood flow was a marker for social phobia in current study might be explained by the physiological difference between embarrassment and social anxiety. That is, embarrassment elicits a short blush whereas social anxiety is expected to elicit a more chronic, creeping blush (Leary, Britt, Cutlip, \& Templeton, 1992; Leary \& Kowalski, 1995). Therefore, responsiveness of blushing might represent embarrassment whereas level of blushing represents social anxiety. In addition, forehead blood flow might not be heightened during social anxiety, as the creeping blush starts low, from neck and therefore might not reach forehead regions. More research is needed to understand the difference between blushing in cheek and forehead.

Interestingly, this study did find relations between blood fllow and temperature level and responsiveness of the cheek on the one hand and selfreport and observers rating of blushing on the other hand. This was the first study to report such relations for a physiological blushing parameter. Particularly the finding that observers are able to detect blushing is of interest. This finding is in clear contrast to the study of Mulkens et al. (1997) that found no relations between observers" ratings and cheek blood flow and therefore concluded that people are not able to detect physiological blushing in others. Our data does not support this conclusion and in contrast shows that people are able to detect a blush that corresponds with actual physical contingency in the cheek. The current study and the study of Mulkens et al. (1997) are different in three respects. First, Mulkens et al. (1997) used video fragments to 
induce embarrassment whereas we used social tasks to induced social anxiety. Maybe observers are more able to detect the chronic, creeping blush that would be elicited by social anxiety and not the short blush as elicited by embarrassment. Second, participants in the study of Mulkens et al. (1997) watched video fragments whereas our participants interacted in real life social situations. Such social interactions might be a more valid way to induce blushing and therefore observers could more easily detect blushing. Third, we used a community and a patient sample whereas Mulkens et al. (1997) relied on student samples. Maybe such homogeneous students groups made it more difficult for observers to detect blush differences.

Some caution has to be taken when drawing conclusions from level blood flow differences between groups. The photo-plethysmograph measures the absorption, reflection and scattering of a light beam. Therefore the measurement of blushing level with a photoplethysmograph can be confounded by thickness of the skin, light angle or placement of the probe on the skin. Such confounders do not affect blood flow changes (i.e., responsiveness). Differences in light angel or placement of the probe between groups are due to random error, but we cannot rule out that level differences reflect SPs to have a thinner skin than normal controls. If this were true a higher baseline level measured by the plethysmograph would not necessary reflect more "felt" blushing but a more visible blushing due to a thinner skin. Both explanations for a heightened baseline level blushing, "felt" blushing or visible blushing would add to the anxiety SPs experience in social interaction.

\section{Social Skills Deficit Specific for Condersation and Not for Speech}

Most previous studies showed socially anxious individuals to have a social skills deficit. These studies were foremost conducted with conversation and role-play situations; the few studies that investigated social skills during a speech so far were inconclusive or found specific speak disturbances. In line, in the current study the social skills deficit of SPs did not show in the speech but only in the conversation. Concluding, the social skills deficit of SPs seems specific for conversation. Three differences between speech and conversation situations might be responsible. First, in the general population it is more common to experience anxiety while giving a speech than during a conversation. Second, a speech is more structured than a conversation, as during a speech only the speaker is in control of the situation whereas in the conversation the interaction partners contribute as well. The degree of control might have an impact on the social skills of social phobic patients. In line, Thompson and Rapee (2002) showed that social anxious individuals were more impaired during an unstructured than during a structured conversation. The conversation in the current study, therefore, with its low control might 
have evoked more skills deficits in SPs than the structured speech. Some participants in the social phobia group indeed commented on this difference between the tasks. One patient, for example, stated that he found the speech less difficult than the conversation as nobody lalked back and resulting he experienced more control over the situation. Third, a conversation asks for more complicated skills of interpersonal nature than a speech. For instance, a conversation requires being responsive to what the others have to say. Inspecting the observer-rated items that discriminated SPs from nomals during the conversation, most items referred to interpersonal contact: making contact, listening, showing interest, being responsive and being interesting. This seems to indicate that SPS lack a specific kind of social skills: interpersonal skills that are more important during a conversation than during a speech. Such interpersonal skills deficit may result from lack of knowledge and experience in interpersonal performance, heightened selffocused attention (Bogels \& Mansell, 2004), or safety behaviors (Clark, 2001). Consequences of such interpersonal failure can be extensive (Alden \& Taylor, 2004).

\section{Anxious Appearance Generalizes across Situations}

One of the key features of social phobia is the fear of showing anxicty symptoms. This study shows that part of their fear indeed comes true: others are indeed able to detect their anxiety. Therefore, it is understandable that SPs worry about the visibility of their anxiety symptoms, as these symptoms are indeed detectable. However, SPs are not well able to predict how anxious they come across as we found non-significant correlations between prediction of anxiety and observers ratings (speech: .22; conversation: .25). Normal controls subjects were better able to estimate their anxious appearance, especially during the speech (speech: .66, $p<.001$; conversation: $34, p=.09$ ). SPs foremost fear the consequence of others detecting their anxiety: being disliked. The study of Papsdorf and Alden (1998) shows a negative relation between liking and observed anxiety symptoms. Therefore, these observed anxiety symptoms SPs suffer from probably do have a negative impact on their interaction partner.

\section{Cognitive Biases or Reality?}

This study also shows that, besides this realistic part of the fear of SPs of being detected as more anxious and socially inapt, they also overestimate being seen as anxious and underestimate their socially inadequacy. That is, the discrepancy between observers' actual and predicted ratings was greater in the social phobia group than in the control group. Interestingly, in the conversation these imagined and realistic parts of their fear were almost 
equal. That is, the observed difference between the groups for visible anxiety was 0.51 and overestimation of the SP group was 0.62 (on a scale from 1 to 9). Also, for social skills the observed difference between the groups was 0.68 and the underestimation of the SPs was 0.69. This means that not only intervention in unrealistic cogritions but also changing visible anxiety and social skills, if possible, is of importance. In contrast with the conversation, for the speech the cognitive discrepancy of the SPs exceeded the realistic difference: for visible anxiety the real difference between the groups was 0.40 and the discrepancy of the SPs was 0.81 , and for social skills the actual difference was negligible $(0.07)$ and the discrepancy was the largest of all discrepancies: 1.35 . The therapeutic implication of this might be that while SPs might benefit from interpersonal skills training during conversations, during speeches one should focus on modifying their distorted view on their social performance.

One remark needs to be made regarding the large standard deviations for the discrepancy ratings, especially for the SP group. Apparently, some SPs show great discrepancy ratings, whereas others do not, or even show opposite discrepancy ratings (predicting higher ratings than the observers' ratings). Therefore, in treatment one needs to keep in mind that overestimation of visibility of anxiety and underestimation of social skills does not play a role for all SPs and, for these individuals, cognitive intervention might not be in place, at least when directed at these assumed discrepancies.

\section{Linnitations}

Since this study relied on artificial social tasks, it remains to be investigated to what extend these results can be generalized to real life situations. In certain perhaps essential ways as a result of the artificial situations SPS behavior might have deviated from their natural behavior. For instance, SPs might normally be in a constant approach-avoidance conflict during social situations (e.g., should I mingle in the conversation or not) and as a result become highly self-focused. One could speculate that being confronted with social tasks that they could not avoid, as in this study, they might perform better. Related, SPs may not have had the chance to apply certain safety behaviors that they normally would. For example, excessive preparation of the speech was impossible since it was an impromptu speech. Thus, the SPs might have been more social inapt in their normal life than we have seen during the social interactions in this study. 


\section{Acknowledgments}

This research was supported by a grant from the Netherlands Organization for Scientific Research (NWO: 015.000.069). We would like to thank the experimenters Serife Alakir, Eline Smit, Anja Hendriks and Saskia Nijst and the videoraters Saskia van der Aa and Lotte Bamelis and the research assistants of the DAC, especially Thamare van Roosmalen, Philippe Jacques and Esin Demir. Our gratefulness goes out as well to all the confederates. Besides, we acknowledge Erik Schouten for statistical help and Theo Aerts for his help with the equipment of the lab. Moreover, we would like to thank all the therapists of the anxiety program at the RIAGG Maastricht, especially Guido Sijbers "Stefanie Duijvis, Rene Albers and Hannie van Genderen. 


\section{References}

Alden, L. E., \& Taylor, C. T. (2004). Interpersonal processes in social phobia. Climical Psychology Revieu, 24(7), 857-882.

Alden, L. E., \& Wallace, S. T. (1995). Social phobia and social appraisal in successful and unsuccessful social interactions. Behroiotur Research and Therapy, 33(5), 497-505.

Baker, S. R., \& Edelmann, R. J. (2002). Is social phobia related to lack of social skills? Duration of skill-related behaviours and ratings of behavioural adequacy. British Joumal of Clinical Psychology, 41(3), 243-257.

Beidel, D. C., Turner, S. M., \& Dancu, C. V. (1985). Physiological, cognitive and behavioral aspects of social anxiety. Behowiour Research and Therapy, 23(2), 109-117.

Bögels, S. M., \& Mansell, W. (2004). Attention processes in the maintenance and treatment of social phobia: hypervigilance, avoidance and selffocused attention. Clinical psychology review, $24(7), 827-856$.

Bögels, S. M., \& Reith, W. (1999). Validity of two questionnaires to assess social fears: The Dutch Social Phobia and Anxiety Inventory and the Blushing, Trembling and Sweating Questionnaire. Joumal of Psychopathology and Behaviomal Assessment, 27(1), 51-66.

Bögels, S. M., Rijsemus, W., \& De Jong, P. J. (2002). Self-focused attention and social anxiety: The effects of experimentally theightened self-awareness on fear, blushing, cognitions, and social skills. 26(4), 461-472.

Boone, M. L., McNeil, D. W., Masia, C. L., Turk, C. L., Carter, L. E., Ries, B. J,, \& Lewin, M. R. (1.999). Multimodal comparisons of social phobia subtypes and avoidant personality disorder. foumal of Anxiety Disorders, 13(3), 271-292.

Clark, D. M. (2001). A cognitive perspective on social phobia. In W. R. Crozier \& L. E. Alden (Eds.) (2001). International handbook of social anxiety: Concepts, research and interventions relating to the self and shyness. (pp. 405-430). New York, NY, US: John Wiley \& Sons Ltd.

Clark, D. M., \& Wells, A. (1995). A cognitive model of social phobia. In R. G. Heimberg \& M. R. Liebowitz \& D. A. Hope \& F. R. Schneier (Eds.), Social Phobia: diagnosis, assessment and treatment (pp. 69-93). New York: The Guilford Press.

Clark, J. V., \& Arkowitz, H. (1975). Social anxiety and self-evaluation of interpersonal performance. Psychological Reports, 36(1), 211-221. 
Daly, S., Twentyman, C. T., \& McFall, R. M. (1978). Behavioural correlates of social anxiety

Behavioral training of social skills in shy males. British Jow rial of Social and Clinical Psychology, 17(2), 117-120.

Davidson, R. J., Marshall, J. R., Tomarken, A. J., \& Menriques; J. B. (2000). While a phobic waits: regional brain electrical and autononic activity in social phobics during anticipation of public speaking. Biological psychiatry.

Drummond, P. D. (1997). The effect of adrenergic blockade on blushing and facial flushing. Psychophysiology, 34(2), 163-168.

Drummond, P. D. (2001). The effect of true and false feedback on blushing in women. Personality and Individual Differences, 30(8), 1329-1343.

Drummond, P. D., Camacho, L., Formentin, N., Heffernan, T. D., Williams, F., \& Zekas, T. E. (2003). The impact of verbal feedback about blushing on social discomfort and facial blood flow during embarrassing tasks. Behaviour Resench and Therapy., 41(4), 413-425.

Eckman, P. S., \& Shean, G. D. (1997). Habituation of cognitive and physiological arousal and social anxiety. Behaotout Resenrch and Therapy, 35(12), 1113-1121.

Edelmann, R. J. (2001). Blushing. In L. E. Alden \& W. Crozier (Eds.), International handbook of social awxiety: Concepts, research and interventions relating to the self and shyness (pp. 301-323). Chichester: John Wiley \& Sons, Ltd.

Edelmann, R. J., \& Baker, S. R. (2002). Self-reported and actual physiological responses in social phobia. $41(1), 1-14$.

First, M. B., Spitzer, R. L., Gibbon, M., \& Williams, J. B. W. (1996). Structured Ciinical Interwien for DSM-IV Axis I Disorders - Patient Edition (SCID - I/P, Version 2.0). New York: Biometrics Research Department.

Fydrich, T., Chambless, D. L., Perry, K. I., Buergener, F, \& Beazley, M. B. (1998). Behavioral assessment of social performance: A rating system for social phobia. Behaviour Research and Therapy, 36(10), 995-1010.

Gerlach, A. L., Willhelm, F. H., Gruber, K., \& Roth, W. T. (2001). Blushing and physiological arousability in social phobia. Joumal of Abnommal Psychology, 110(2), 247-258.

Gerlach, A. L. Wilhelm, F. H., \& Roth, W. T. (2003). Embarrassment and social phobia: The role of parasympathetic activation. Jounnal of Anxiefy Disorders, $17(2), 197-210$. 
Halford, K., Foddy, M., Farrell, A. D., Mariotto, M. I., Conger, A. J., Curran J. P., Wallander, J. L. (1982). Cognitive and social skills correlates of social anxiety: Self-ratings and judges' ratings of heterosexual social anxiety and skill: a generalizability study. British Joumal of Cintical Psychology, $21(1), 17-28$

Hofmann, S. G., Gerlach, A. L., Wender, A., Roth, W. T. (1997). Speech disturbances and gaze behavior during public speaking in subtypes of social phobia. Journal of Anxiety Disorders, 11(6), 573-585.

Hofmann, S. G. Newman, M. G., Ehlers, A., \& Roth, W. T. (1995). Psychophysiological differences between subgroups of social phobia. Jowmal of Abnomal Psychology, 104(1), 224-231.

Leary, M. R., Britt, T. W., Cutlip, W. D., \& Templeton, J. L. (1992). Social blushing. Psychological Bulletin, 112(3), 446-460.

Leary, M. R., \& Kowalski, R. M. (1995). Social anxiety. New York, NY, US: Guilford Press.

Levin, A. P., Saoud, I. B., Strauman, T., Gorman, J. M., \& et al. (1993). Responses of "generalized" and "discrete" social phobics during public speaking. Journal of Anxiety Disorders, 7(3), 207-221.

Lewin, M. R., McNeil, D. R., \& Lipson, J. M. (1996). Enduring without avoiding: Pauses and verbal dysfluencies in public speaking fear. Journal of Psychopathology and Behavioral Assessment, 18(4), 387-402.

Mellings, T. M. B., \& Alden, L. E. (2000). Cognitive processes in social anxiety: The effects of self-focus, rumination and anticipatory processing. Behaviour Research and Therapy, 38(3), 243-257.

Mulkens, S., De Jong, P. J., \& Bögels, S. M. (1997). High blushing propensity: Fearful preoccupation or facial coloration? Personality and Individual Differences, 22(6), 817-824.

Mulkens, S., de Jong, P. J., Dobbelaar, A., \& Bogels, S. M. (1999). Fear of blushing: Fearful preoccupation irrespective of facial coloration. Behaviour Research and Therapy, 37(11), 1119-1128.

Öst, L. G., Jerremalm, A., \& Johansson, J. (1981). Individual response patterns and the effects of different behavioral methods in the treatment of social phobia. Behaviour Research and Therapy, 19(1), 1-16.

Papsdorf, M., \& Alden, L. (1998). Mediators of social rejection in social anxiety: Similarity, self-disclosure, and overt signs of anxiety. loumal of Research in Personality, 32(3), 351-369.

Rapee, R. M., \& Heimberg, R. G. (1997). A cognitive-behavioral model of anxiety in social phobia. Behaviour Resenrch and Therapy, 35(8), 741-756. 
Rapee, $\mathbb{R}$. M., \& Lim, L. (1992). Discrepancy between self- and observer ratings of performance in social phobics. Journal of Abnommal Psydrology, $101(4), 728-731$.

Stopa, L., \& Clark, D. M. (1993). Cognitive processes in social phobia. Behaviour Research and Therapy, 31(3), 255-267.

Strahan, E., \& Conger, A. J. (1998). Social anxiety and its effects on performance and perception. Journal of Anxiety Disorders, 12(4), 293-305.

Strauman, T. J. (1989). Self-discrepancies in clinical depression and social phobia: Cognitive structures that underlie emotional disorders? Joumal of Abnormal Psychology, 98(1), 14-22.

Thompson, S., \& Rapee, R. M. (2002). The effect of situational structure on the social performance of socially anxious and non-anxious participants. Joumal of Behavior Therapy and Experimental Psychiatry, 33(2), 91-102.

Turner, S. M., Beidel, D. C., Dancu, C. V., \& Stanley, M. A. (1989). An empirically derived inventory to measure social fears and anxiety: The Social Phobia and Anxiety Inventory. Psychological Assessment, 1(1). 3540 .

Turner, S. M., Beidel, D. C., \& Larkin, K. T. (1986). Situational determinants of social anxiety in clinic and nonclinic samples: Physiological and cognitive correlates. Joumal of Consulting and Clinical Psychology, 54(4), 523-527.

Twentyman, C. T., \& McFall, R. M. (1975). Behavioral training of social skills in shy males. Journal of consulting and clinical psychology, 43(3), 384-395. 



\section{Chapter 5}

Hiding Anxiety versus Acknowledgment of Anxiety in Social Interaction: Relationship with Social Anxiety

Marisol ]. Voncken

Lynn E. Alden

Susan M. Bögels

This section will be published as:

Voncken, M. J., Alden, L. E., Bögels, S. M. Hiding Anxiety versus Acknowledgment of Anxiety in Social Interaction: Relationship with Social Anxiety (in press). Behaviour Research and Therapy 



\begin{abstract}
According to cognitive and interpersonal models, salety behaviors in social phobua (e.g, avoiding eye contact, hiding blushing) erroneously induce negative evaluation by interaction partners. Presumably, a bias about the social outcome of safety behaviors causes this negative interaction cycle. Such a bias might be subject to double standard in social phobia (i.e., having more stringent rules for oneself than for others). Female students $(n=81)$ predicted more negative social outcomes for a prominent type of safety behavior, hiding anxiety, than for the opposite behavior, acknowledgment of anxiety, and ongoing behavior (control condition) in scripts of self- and other-target persons. The relation between social anxiety and double standard was robust. Social anxiety did not relate to a cognitive bias regarding hiding ones anxiety, as we expected, but was associated with the belief that acknowledgment of anxiety has negative social outcomes specifically for them. These results are evaluated in light of the interpersonal consequences anxiety related behaviors have in social interactions.
\end{abstract}




\section{Introduction}

A core feature of social anxiety and social phobia is fear of negative evaluation. For these individuals, an anxious appearance is one of the main sources of this presumed negative evaluation. According to cognitive theorists, this concern leads socially anxious individuals to engage in, what are called, safety (subtle avoidance) behaviors in an attempt to conceal their anxious appearance and thus avoid negative social outcomes (D. M. Clark, 2001; D. M. Clark \& Wells, 1995; Leary \& Kowalski, 1995). A prominent type of these safety behaviors involve actions taken to conceal visible signs of anxiety, for example, using hands to conceal blushing, clasping hands together to hide trembling, or holding arms stiffly by one's side to hide sweating (see, D. M. Clark, 2001).

Sadly, despite those efforts, socially anxious people have been shown to evoke negative responses from others. For example, relative to non-anxious people, socially anxious individuals were judged to be less likeable and less comfortable to be around (Meleshko \& Alden, 1993), less friendly, assertive, relaxed, and attractive (Jones \& Russell, 1982; Pilkonis, 1977), and more sensitive to demands, self-pitying, lacking personal meaning in life, and moody (Creed \& Funder, 1998). At least one study found that the same pattern characterized patients with social phobia (Alden \& Wallace, 1995). Those patients were viewed as less warm, interested, and likable by their partners in a social interaction compared to non-phobic controls.

According to cognitive and interpersonal writers, the use of safety behaviors increases the likelihood of negative social reactions (e.g., Alden, 2001; D. M. Clark, 2001; Rapee \& Heimberg, 1997). For example, some work indicates that socially anxious students who use safety behaviors are liked less than anxious students who do not. (Alden \& Bieling, 1998). Research has yet to examine how the socially anxious people themselves view safety behaviors in social interactions. It may be that these individuals are unaware of their reliance on safety behaviors and therefore unaware of the cause of resulting negative responses. Another possibility is that they recognize the negative effects of safety behaviors but lack the ability to engage in more positive responses. Finally, as assumed by the cognitive model and its treatment recommendations regarding safety behavior (D. M. Clark, 2001) it may be that they believe, incorrectly, that such behaviors will forestall negative responses. The latter explanation implies that socially anxious individuals may be using some safety behaviors in an attempt, albeit ineffective, to prevent negative evaluation. If this bias were indeed present in social phobia, it would be 
valuable to address this in treatment in order to develop more positive interpersonal cycles.

Besides examining how anxious and non-anxious individuals view the effects of safety behaviors, it would be valuable to examine the social consequences. of the opposite behavior, being open about or acknowledging one"s anxiety. It could be that people see this behavior as off-putting, which might indicate that concealing one's anxiety is a sensible response. On the other hand, being open about one's feelings of insecurity might have a positive effect (e.g., an endearing effect) on others. Talking about one's feelings of insecurity may be considered a form of self-disclosure. A large body of studies supports the socalled liking effect, i.e., that people who self-disclose are generally liked more than people who do not (see Collins \& Miller, 1994, for a review). It may be that socially anxious persons fail to reciprocate the disclosures of their interaction partners (Meleshko \& Alden, 1993) and consequently might be viewed as less likable. Moreover, self-disclosure is seen as one of the most important factors in the development of relationships (Altman \& Taylor, 1973). Therefore, being open about one's anxious feelings may have a positive effect on an interaction partner.

A related question pertains to whether socially anxious people misjudge the effects of safety behaviors in general or only when used by themselves. Research indicates that people with social phobia and social anxiety often have a "double standard" in their judgments, specifically that they have more stringent rules judging their own behavior but do not differ from non-anxious people in how they evaluate behavior displayed by others (e.g., J. V. Clark \& Arkowitz, 1975; Rapee \& Lim, 1992). In addition, Amir, Foa, and Coles (1998) found that people with social phobia made the same interpretations of vignettes about a "typical person" as non-phobic people, but showed a negative interpretation bias when judging scripts with themselves as the main character. Cognitive biases about safety behaviors and acknowledgment of anxiety might be similarly subject to a double standard. That is, socially anxious individuals might predict that acknowledging anxiety would result in positive social outcomes for others, but safety behaviors would result in positive outcomes for themselves.

To address these questions, we presented students vignettes in which a target person experiences social anxiety-related symptoms (e.g., trembling. blushing) and either uses safety behaviors to conceal the anxiety, acknowledge the anxiety, or neither" hide or acknowledge the anxiety (ongoing behavior). We then examined participants' predictions about the likely social outcome in the situation concerning themselves as target persons or others. 
We had three hypotheses. (Ia) We expected the participants to predict that hiding anxiety produces more negative social outcomes than acknowledging anxiety or simply continuing the interaction (ongoing behavior). (Ib) In contrast, we expected acknowledging anxiety to be evaluated in the same way or more positively than ongoing behavior. (Ila) We anticipated that a higher level of social anxiety is associated with greater discrepancies between predictions for self and for others, the so-called double-standard effect. (IIb) In addition, we predicted that such a relation between social anxiety and double standard would arise primarily from negative predictions for self and not for others. (IIIa) We expected social anxiety to be associated with a smaller double standard (i.e., self-other discrepancy) for hiding anxiety than for ongoing behavior. (IIIb) In contrast, we anticipated that social anxiety to be associated with a larger self-other discrepancy for acknowledging anxiety than for ongoing behavior. In other words, social anxiety would be associated with the belief that hiding anxiety would make people less critical of them whereas acknowledging anxiety would make people more critical of them, relative to others.

\section{Method}

\section{Participants}

A total of 81 female undergraduates of mental health sciences from the University of Maastricht, the Netherlands participated in this study. All participants completed the 'Way of thinking about social behavior' and the Social Interaction Anxiety Scale (SIAS; Mattick \& Clarke, 1998) (see below). The age of the students ranged from 18 to 24 , with a mean of 21 years, $S D=$ 1.34 .

\section{The Way of Thinking about Soctal Behavior Questionnaire}

The Way of Thinking about Social Behavior Questionnaire consists of nine different scripts. In the scripts the target person ( 5 feminine, 4 masculine) blushes $(n=2)$, trembles $(n=2)$, sweats $(n=2)$ or experiences general anxiety (like shyness) ( $n=3$ ) with one or more interaction partners. Each script has three different versions in which the target person either acknowledges his/ her anxiety toward others (e.g., " saying: I feel a bit embarrassed and even start to blush...'), either conceals his/ her anxiety (e.g. 'turning a bit away and not making eye contact...') or continues the interaction neither concealing nor acknowledging the anxiety (i.e., ongoing behavior). These versions of scripts were randomized in such a way that each participant received three scripts of each type of behavior. As we expected that differences in social status would influence the ratings of the subjects, in all scripts the target person and their 
interaction partmers had the same level of social status ( $2, g_{*}$ colleagues, friends).

The subjects were asked to rate two questions: how they thought the interaction partner(s) in the vignette would perceive a) the target person depicted in the vignette and b) the subject herself were she to behave like the target person. Both questions were in fixed order and rated on 6-point Likert scales that were anchored by the phrases "very negative" to "very positive". (See for an example Figure 5-1.) Each subject read and rated nine different stories. For each subject the behavior displayed by the target person was randomized across the nine stories.

Julia just started with her new job. She is sitting next to a colleague of hers. She got an introduction course but forgot how to start up her computer. She feels that her cheeks are getting very warm.

(Each subject was presented with one of the following endings of the script:)

Hiding anxiety:

She turns slightly away from her colleague to hide her blushing and without making eye contact she asks: "How do I start up my computer?"

Ongoing behavior:

She turns over to her colleague, looks at her and asks: "How do I start up my computer?"

Acknowledgment of anxiety:

She turns over to her colleague, looks at her and says: "I feel a bit embarrassed and even start blushing because of this simple task that I don"t know how to do." Then she asks: "How do I start up my computer?"

What, in your view, would this colleague think of Julia in this situation?

$\begin{array}{cccccc}0 & 1 & 2 & 3 & 4 & 5 \\ \text { very } & \text { moderately } & \text { slightly } & \text { slightly } & \text { moderately } & \text { very } \\ \text { negative } & \text { negative } & \text { negative } & \text { positive } & \text { positive } & \text { positivat }\end{array}$

Imagine that you were Julia and behaved like Juliat in this situation. What would, in your view, this colleague think of you?

$\begin{array}{cccccc}0 & 1 & 2 & 3 & 4 & 5 \\ \text { very } & \text { moderately } & \text { slightly } & \text { slightly } & \text { moderately } & \text { very } \\ \text { negative } & \text { negative } & \text { negative } & \text { positive } & \text { positive } & \text { positive }\end{array}$

Figure 5-1. Example of a script of The Way of Thinking about Social Behavior Questionnaire 


\section{Social Interaction Anxiety Scale (SIAS)}

The Social Interaction Anxiety Scale (SIAS; Mattick \& Clarke, 1998) consists of 20 items that are rated from 0 (not at all characteristic or true of me) to 4 (extremely characteristic or true of me). Items are self-statements describing one's typical cognitive, affective, or behavioral reactions to situations that involve social interaction in dyads or groups. The SIAS is scored by summing the ratings (after reversing the 3 positively-worded items), and total scores range from 0-80. Higher scores represent higher levels of social interaction anxiety. Mattick and Clarke (1998) demonstrated the reliability and validity of the SIAS. Their community sample had a mean of $18.8, S D=11.8$, and the social phobia sample had a mean of $34.6, S D=16$.4. The sample in this study had a mean SIAS of $19.8, S D=10.6$, of which $25 \%$ scored below 12.8 and $25 \%$ scored higher than 24.0 .

Table 5-1. Means and standard deviations for acknowledgment of anxiety, ongoing behavior and hiding of anxiety regarding self- and other evaluations and self-other discrepancies.

\begin{tabular}{lccc}
\hline & & Behawior & \\
\cline { 2 - 4 } & $\begin{array}{c}\text { Acknowledgment of } \\
\text { anxiety }\end{array}$ & Ongoing behavior & Hiding anxiety \\
\hline Other" & $3.19(0.71)$ & $3.10(0.65)$ & $2.44(0.66)$ \\
Self" & $2.86(0.81)$ & $2.77(0.87)$ & $2.20(0.69)$ \\
Self-other discrepancy? & $0.33(0.55)$ & $0.33(0.60)$ & $0.27(0.45)$ \\
\hline
\end{tabular}

Wokt "Higher scores denote more positive evaluations (0-5 Likent scale). 2evaluations for other perscras as target person minus evaluations for ontesalf as target person

\section{Results}

The means and standard deviations for the dependent measures can be seen in Table 5-1. The data were analyzed with a 2-way (target person $X$ type of behavior) within subjects repeated measures ANOVA using the SIAS as a covariate. Significant main effects emerged for type of behavior, $F(2,78)=$ $25.62, p<.001$, and for the SIAS, $F(1,79)=11.76, p<.01$. Bonferroni-corrected paired thests were conducted to compare the three types of behavior. The results indicated that across self- and other-ratings, students believed that, as expected in hypothesis Ia, hiding anxiety would have a more negative social outcome than acknowledging anxiety or ongoing behavior, $t(80)=8.15$ and 9.69 , both $p<.001$. In line with hypothesis $1 b$, no differences emerged 
between acknowledging of anxiety and ongoing behavior, $t(80)=0.92, n$. From the means in Table 5-1 it is clear that, on the average, acknowledgment of anxiety and ongoing behavior is evaluated as slightly positive, whereas hiding anxiety falls just below the negative/positive cutoff line of 2.5 . The significant SIAS main effect indicated that higher levels of social anxiety were associated with more negative ratings across all three types of behawiors and both target people (i.e., self, other), $r=.38, p<.001$.

The analysis also revealed a significant effect for the interaction between target person and the SIAS, $F(1,79)=13.67, p<.001$, and for the 3-way interaction between behavior, target person, and the SIAS, $F(2,78)=3.31, p<$ .05. To understand these interactions, we calculated discrepancy scores by subtracting self-target ratings from other-target ratings across all behaviors and for each behavior separately. Post-hoc bivariate correlations indicated that, as expected in hypothesis IIa, the higher the social anxiety the larger the discrepancy score across the different scripts, $r=.38, p<.001$. To investigate whether self- or other-evaluations mainly explained this correlation, we correlated SIAS with self- and other-evaluations. In line with our hypothesis $\mathrm{IIb}$, these correlations indicated that social anxiety did not relate to expecting negative social outcome for others but only for self (other: $r=-.15$, ns; self: $r=$ $-.38, p<.001$; difference: $z=2.86, p<.005 j$.

To unravel the 3-way interaction between behavior, target person, and the SIAS, we conducted three post-hoc correlations between SIAS on the one hand and the discrepancy score for each of the three different behaviors on the other hand. These correlations revealed, in contrast to our hypothesis IIIa, that the correlations between SIAS and discrepancy concerning ongoing behavior and hiding anxiety did not differ from each other, hiding: $r=.23$; ongoing behavior, $r=.27, z=0.94$, $n s$. However, as expected in hypothesis IITb, the SIAS correlated significantly more strongly with discrepancy for acknowledgment of anxiety than for hiding anxiety, acknowledgment: $r=.42$; $z=1.84, p<.05$, or for ongoing behavior, $z=1.30, p<.10$. To understand the correlation between SIAS and discrepancy for acknowledgment of anxiety, we correlated SLAS separately with self-evaluations and other-evaluations of acknowledgment of anxiety. These correlations indicated that social anxiety did not relate to expecting negative social outcome for others in acknowledgment of anxiety but only for themselves (other: $r=-10$; self: $r=-$ $.37 ; z=3.51, p<.001$ ). To illustrate this complex 3-way interaction we divided the group in high (top 25\%) and low (bottom 25\%) socially anxious subjects. Figure 5-2 shows the self- and other-evaluations of the three types of behaviors for the high and low socially anxious groups. 


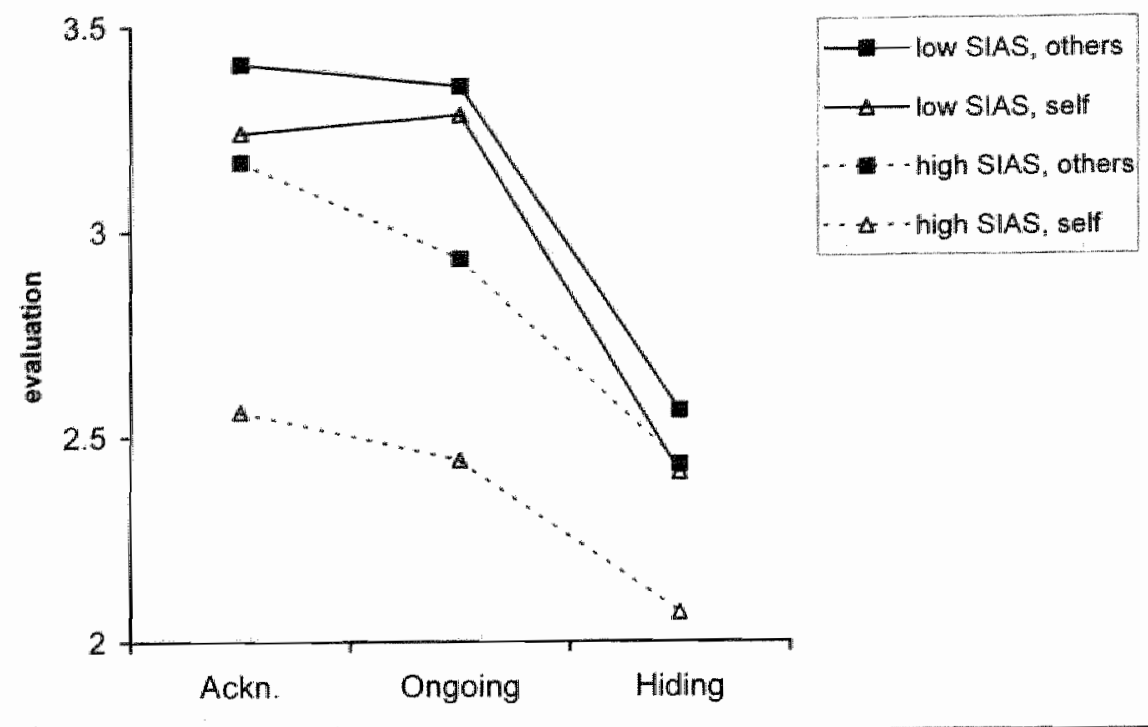

Figure 5- 2. Predicted self- and other-ewaluation regarding acknowledgment of anxiety, ongoing behavior and hiding anxiety divided in high (top 25\%) and low (bottom 25\%) socially anxious students. A higher score on evaluation represents a more positive evaluation.

\section{Discussion}

These participants predicted that actions taken to hide anxiety (overt safety behaviors) would produce more negative social outcomes than either acknowledging anxiety or simply continuing the interaction while feeling anxious. Social anxiety did not affect those predictions, which suggested that the socially anxious participants were as aware as non-socially anxious people of the negative effects of engaging in safety behaviors designed to conceal anxiety. The fact that those safety behaviors were viewed negatively by all participants suggests that attempts to hide social anxiety can backfire, i.e., evoke the negative interpersonal reactions the person was trying to avoid (Alden \& Taylor, 2004; D. M. Clark, 2001; D. M. Clark \& Wells, 1995).

In line with our predictions, social anxiety was related to larger double standards, i.e., discrepancies between the social outcomes predicted for self and those predicted for others engaging in the same behavior. This double standard effect primarily was due to self-related predictions; the more socially anxious the subjects, the more negative their predicted self-outcomes compared to their predictions for others. Thus, socially anxious participants 
expected others to be more critical toward them than they would be toward other people, a finding that is consistent with earlier research (see also, J. V. Clark \& Arkowitz , 1975; Rapee \& Lim, 1992).

We had hypothesized that social anxiety would be associated with a smaller double-standard in situations involving attempts to hide anxiety than situations marked by ongoing behavior, reflecting the belief that concealing anxiety would reduce negative social reactions. In contrast to the hypothesis however, no differences emerged in self-other discrepancies in the two types of scenarios. Hence, social anxiety did not appear to be associated with the belief that hiding one's anxiety would forestall negative evaluation. In line with our hypotheses, social anxiety was associated with a larger discrepancy between expected outcomes for self than others when acknowledging anxiety. Thus, socially anxious individuals appeared to believe that other people would respond even more negatively to them were they to comment on or in some other way acknowledge that they felt anxious. That belief is notable in light of the fact that participants in this study predicted that acknowledging anxiety would produce more positive responses than hiding anxiety, albeit no more positive than simply continuing the interaction without comment.

The current findings have some clinical implications. Prior research and the treatment recommendations in the cognitive model (D. M. Clark, 2001; D. M. Clark \& Wells, 1995) suggest that socially anxious individuals establish negative interpersonal cycles between themselves and others. This study indicates that attempts to hide one's anxiety probably contribute to these negative cycles. Interestingly, these results indicate that socially anxious individuals are able to see the negative social effect of trying to conceal anxiety, which implies that discussing the negative interpersonal consequences of such behaviors indeed seems useful. In what way the belief concerning acknowledging anxiety could be addressed in treatment is speculating. It might have treatment benefits to teach socially anxious patients to causally mention their anxiety as acknowledging anxiety was viewed no more negatively than ongoing behavior. However, this still needs to be established. The results of this study also suggest that it might be beneficial to draw socially anxious patients" attention to the double standard in their social expectations and get them to reflect on why they expect more negative responses for themselves than for others who behave the same way.

The current study had a number of limitations that must be considered when interpreting the results. First, predicted outcomes were assessed in written vignettes, and people may arrive at different predictions during actual social events. Future studies might examine double standards in response to either videotaped or actual social interactions. Second, only a subset of safety behaviors was examined. Research is needed to evaluate the predicted 
outcomes of other types of safety behaviors. Third, only women were included as participants, and the generalizability of these results to men remains to be established, as men might be less accepting in expressions of emotion. Fourth, the study examined a well-educated social oriented group and it might be that these results do not generalize to other social milieus. Last, as the study examined a student population research is needed to determine whether the same patterns would emerge with people with social phobia.

\section{Acknowledgment}

This research was supported by a grant from the Netherlands Organization for Scientific Research (NWO: 015.000.069). We would like to thank the 'Van Walree Fund, Royal Netherlands Academy of Arts and Sciences' for" subsidizing a work visit to the University of British Columbia, Vancouver. 


\section{References}

Alden, L. E. (2001). Interpersonal perspectives on social phobia. In $R . W$. Crozier \& L. E. Alden (Eds.), International Handbook of Social Anviety. Concepts, Research and Interventions Relating to the Self and Shyness (pp. 381-404). Chichester: John Wiley \& Sons, Ltt.

Alden, L. E., \& Bieling, P. (1998). Interpersonal consequences of the pursuit of safety. Behaviour Research and Therapy, 36(1), 53-64.

Alclen, L. E., \& Taylor, C. T. (2004). Interpersonal processes in social phobia. Clinical Psychology Review, 24(7), 857-882.

Alden, L. E., \& Wallace, S. T. (1995). Social phobia and social appraisal in successful and unsuccessful social interactions. Behwoviour Research and Therapy, 33(5), 497-505.

Altman, I., \& Taylor, D. A. (1973). Social penetration: The developnnent of interpersonal relationships. Oxford ${ }_{r}$ England: Holt, Rinehart \& Winston.

Amir, N., Foa, E. B., \& Coles, M. E. (1998). Negative interpretation bias in social phobia. Behaxiour Research and Therapy, 36(10), 945-957.

Clark, D. M. (2001). A cognitive perspective on social phobia. In W. R. Crozier \& L. E. Alden (Eds.), (2001). International handbook of social anxiety: Concepts, research and interventions relating to the self and shyness. (pp. 405-430). New York, NX, US: John Wiley \& Sons Ltd.

Clark, D. M., \& Wells, A. (1995). A cognitive model of social phobia. In R. G. Heimberg \& M. R. Liebowitz \& D. A. Hope \& F. R. Schneier (Eds.), Social Phobia: diagnosis, assessment and treatment (pp. 69-93). New York: The Guilford Press.

Clark, J. V. \& Arkowitz, H. (1975). Social anxiety and self-evaluation of interpersonal performance. Psychological Reports, 36(1), 211-221.

Collins, N. L., \& Miller, L. C. (1994). Self-disclosure and liking: A metaanalytic review. Psychological Bulletin, 116(3), 457-475.

Creed, A. T. \& Funder, D. C. (1998). Social anxiety: From the inside and outside. Personality and Individual Differences, 25(1), 19-33.

Jones, W. H.r \& Russell, D. (1982). The Social Reticence Scale: An objective instrument to measure shyness. Journal of Personality Assessment, 46(6), 629-631.

Leary, M. R., \& Kowalski, R. M. (1995). Social anxiety. New York, NY, US: Guilford Press. 
Mattick, R. P. \& Clarke, I. C. (1998). Development and validation of measures of social phobia scrutiny fear and social interaction anxiety. Behaviour Reserrch and Therapy, 36(4), 455-470.

Meleshko, K. G., \& Alden, L. E. (1993). Anxiety and self-disclosure: Toward a motivational model. Jownal of Personalify and Social Psychology, 64(6). $1000-1009$.

Pilkonis, P. A. (1977). The behavioral consequences of shymess. Joumal of Personality, 45(4), 596-611.

Rapee, R. M., \& Heimberg, R. G. (1997). A cognitive-behavional model of anxiety in social phobia. Behaviour Research and Therapy, 35(8), 741-756.

Rapee, R. M., \& Lim, L. (1992). Discrepancy between self- and observer ratings of performance in social phobics. Journal of Abnormal Psychology, $101(4), 728-731$.

Wells, A., Clark, D. M., Salkovskis, P., Ludgate, J, Hackmann, A., Gelder, M. (1995). Social phobia: The role of in-situation safety behaviors in maintaining anxiety and negative beliefs. Behavior Therapy, 26(1), 153161. 


\section{Chapter 6}

Changing Interpretation and Judgmental Bias in Social Phobia: a Pilot of a Short, Highly Structured Cognitive Treatment

Marisol J. Voncken

Susan M. Bögels

This section will be published as:

Voncken, M. J., Bögels, S. M. (2006). Changing interpretation and judgmental bias in social phobia: a pilot of a short, highly structured cognitive treatment. Journal of Cognitive Psychotherapy 



\begin{abstract}
Interpretation and judgmental biases concerning negative evaluation are considered important maintaining tactors in social phobia. Cognitive models imply that solely changing these core cognitions reduces social anxiety. Standardizing such an intervention in these core biases may simplify and shorten treatment and therefore increase its accessibility. We present pilot data ( $\mathrm{n}=13)$ of a short ( 9 sessions), standardized cognitive therapy developed to directly and solely intervene in interpretation and judgmental biases in social phobia. Described are the design of this therapy and the cognitive techniques. This short therapy was be effective in reducing social phobic complaints (effect-size 1.4) and interpretation and judgmental biases. Besides, we have indications that this treatment has high accessibility because of its short duration and standardization.
\end{abstract}




\section{Introduction}

Fear of negative evaluation is the core fear of social phobic patients. Social phobic patients are found to be more likely than normal controls to pick a negative interpretation in social events (e.g., "Two acquaintances are looking at you: they are gossiping about me." ) but do not show this tendency regarding non-social events (e.g., "Receiving a letter which states "important": a relative died") (Amir, Foa, \& Coles, 1998; Stopa \& Clark, 2000; Voncken, Boggels, \& de Vries, 2003). Related, they also overestimate the probability of a negative evaluation in social events (e.g., "they are gossiping about $\left.m e^{\prime \prime}\right)$ and the cost of this negative evaluation, whereas they do not show this bias in non-social events (Foa, Franklin. Perry, \& Herbert, 1996; McManus, Clark, \& Hackmann, 2000; Voncken et al., 2003). In other words, they show a content specific interpretation and judgmental bias regarding social events. In cognitive models these biases are assumed to play a central role in the maintenance of social phobia (Clark, 2001; Clark \& Wells, 1995). Three studies indeed found that reduction in judgmental bias in social event mediates the recovery from social phobia (Hofmann, 2004; Foa et al., 1996; McManus et al., 2000).

The cognitive model considers distorted cognitions (e.g., interpretation and judgmental biases) about negative evaluation to be the core problem in social phobia and to lead to various other invalidating processes like self-focused attention, safety behaviors and somatic and cognitive symptoms (Clark, 2001; Clark \& Wells, 1995). Hence, solely improvement in cognitive distortions without intervention in these other processes should theoretically lead to improvement of social anxiety. To our knowledge no treatment so far has exclusively intervened in these distorted cognitions in social phobia. Most cognitive-behavioral treatments address other factors as well, like avoidance, self-focused attention, safety behaviors or social skills (Rodebaugh, Holaway, \& Heimberg, 2004; Taylor, 1996). Therefore, evaluating an exclusive intervention in core cognitive distortions allows for a more direct test of the cognitive model. Intervention in interpretation and judgmental biases concerning negative evaluation seem good candidates for such an intervention as former mentioned studies imply. Besides, these biases lend themselves for simple cognitive techniques.

Recently, Clark and Wells developed a highly effective treatment for social phobia (effect-size by Cohen $d$ with pooled SD: 2.5, Clark et al., 2003 and 1.7, Stangier, Heidenreich, Peitz, Lauterbach, \& Clark, 2003) that is remarkably more effective than former cognitive treatments (Rodebaugh et al., 2004; Taylor, 1996). Besides correcting dysfunctional cognitions, this treatment 
intervenes in other factors like dropping of safety behaviors, directing attention externally, modifying distorted self-images, and dealing with post mortem processing. Addressing all these elements resulted in 15-hours (Stangier et al., 2003) and 22-hours (Clark et al., 2003) intervention time. Moreover, therapists need intensive training since the techniques are not standardized.

A treatment that solely focuses on interpretation and judgmental biases with standardized techniques would not only be a more direct test of the cognitive model $_{x}$ but also would also simplify and shorten treatment. This may have important clinical implications as it can increase accessibility of treatment for social phobia. For instance, effectiveness of treatment is highly dependent on training and skills of the therapists (Sperry, Carlson, \& Kjos, 2003) and, as many agree, cognitive treatments require considerable therapeutic skills (e.g., Feske \& Chambless, 1995; van Dam Baggen \& Kraaimaat, 2000). A treatment with standardized techniques can, therefore, increase the number of therapists that can deliver such a treatment. Besides, a shorter intervention fits well in the stepped-care model (Bower \& Gilbody ${ }^{2005}$ ) in which patients are first presented with the simplest intervention and only patients that do not benefit enough receive more intense treatment approaches. Such a steppedcare approach results in an increase of the amount of patients that can be treated and shortens waitlists. All in all this will increase accessibility of cognitive treatment for social phobia that is necessary as the study of Schneier, Johnson, Hornig, Liebowitz \& et al. (1992) shows that only $5 \%$ of patients with social phobia receive treatment. Besides, in the Netherlands only $15 \%$ of patients seeking treatment for their social phobia are treated with some sort of cognitive behavior therapy (based on data of Voncken et al., 2003).

In this pilot study we developed a cognitive treatment for social phobia that only aimed at changing interpretation and judgmental biases. We used standardized cognitive techniques that were intended not to require intensive training and a high level of experience with cognitive therapy. Besides, the treatment was shortened ( 9 hours intervention time). We expected this treatment to reduce interpretation and judgmental biases and social anxiety. 


\section{Participants, method and procedure}

\section{Participants}

The participants were outpatients of the ambulatory mental health center of Maastricht, the Netherlands, and were referred by their general practitioner. After the usual intake, patients, who met the criteria of a primary diagnosis of DSM-IV social phobia, were asked to participate in this study. Diagnoses were assessed by the SCID-I (First, Spitzer, Gibbon, \& Williams, 1996; Dutch translation, Groenestijn, Akkerhuis, Kupka, Schneider, \& Nolen, 1997). The treatment was presented to the patients as an intensive training of nine sessions. As homework assignments were an important part of this therapy, patients were informed that they had to spend at least one hour each day on their homework. None of the patients declined treatment for this reason.

This pilot study was part of a larger treatment outcome study in a regular mental health institute in the Netherlands. Seventy-seven percent ( 39 out of 51) of the patients fulfilling the criteria of a social phobia were willing to participate in this project. Thirteen participants, 6 males and 7 females, were randomly selected for the individual cognitive treatment. Their age ranged from 19 to 51 with a mean of 30.0 years $(S D=10.4)$. The duration of their complaints ranged from 1 to 15 years with a mean of 5.0 years $(S D=4.7)$. See for an overview of their primary and co-morbid diagnoses Table 6-1.

Two males male and one female dropped out during treatment: two after seven and one after three sessions. Two of them did not complete posttreatment assessiment after dropout. In these cases the pretreatment scores were used as the after-treatment scores. Reasons for dropping out were sufficient reduction of social phobic complaints $(n=1)$, inability to complete homework assignments $(n=1)$ and preference for a women's group assertiveness training $(n=1)$. Of the 10 patients who completed the therapy, two did not complete the follow-up assessment after two months. Reasons of refusing were in one case not known and in the other case having severe depressive symptoms, not linked to the social phobia. Analyses of follow-tup only included the 8 patients that completed all assessments. 
Table 6-1. Overview of primary and co-morbid diagnoses of the social phobic patients $(n=13)$

\begin{tabular}{|c|c|}
\hline Type of diagnoses & Specification of diagnoses \\
\hline First diagnosis" & $\begin{array}{l}\text { Generalized social phobia }(n=10) \\
\text { Specific social phobia }(n=3)\end{array}$ \\
\hline $\begin{array}{l}\text { Co-morbid Axis I disorders: } \\
\text { No co-morbid axis I disorders }(n=4) \\
1 \text { co-morbid axis I disorder }(n=1) \\
>1 \text { co-morbid axis I disorder }(n=8)\end{array}$ & $\begin{array}{l}\text { Panic disorder i.x. }(n=1) \\
\text { Post-traumatic disorder partly i.r. }(n=1) \\
\text { Depression }(n=5) \text { : current }(n=1), \text { partly i.r. }(n=2) \text {, } \\
\text { i.r. }(n=1), \text { recurrent i.r. }(n=1) \\
\text { Current dysthymia }(n=1) \\
\text { Anorexia nervosa i.r. }(n=1) \\
\text { Current body dysmorphic disorder }(n=1) \\
\text { Impulse-control disorder NOS i.r. }(n=1) \\
\text { Pathological gambling i.r. }(n=1) \\
\text { Current spastic colon }(n=1), \\
\text { Hallucinogen dependency i.r. }(n=1)\end{array}$ \\
\hline $\begin{array}{l}\text { Comorbid Axis II disorders?: } \\
\text { No co-morbid axis II disorders }(n=7) \\
1 \text { co-morbid axis II disorders }(n=4) \\
>1 \text { co-morbid axis II disorder }(n=2)\end{array}$ & $\begin{array}{l}\text { Avoidant personality disorder }(n=4) \\
\text { Dependent personality disorder }(n=1) \\
\text { Obsessive compulsive personality disorder }(n=1) \\
\text { Personality disorder NOS }(n=3)\end{array}$ \\
\hline
\end{tabular}

\section{Assessment}

As the 13 patients in the current study were the first patients in a larger treatment outcome study, the reported assessments are part of a larger battery of assessments. Two types of measures are reported, a measure to assess social phobic aspects in patient's idiosyncratic phobic social situations and non-idiosyncratic measures to assess general symptoms of social phobia and related constructs. Both types of measures included assessment of judgmental biases.

Patient's Idiosyncratic Social Phobic Aspects:

As the treatment was designed to correct interpretation and judgmental biases in idiosyncratic social situations, we assessed the biases in these specific situations. Therefore, before the first treatment session, the therapist together with the patient constructed five target situations. These situations consisted of patient's idiosyncratic social situations and a corresponding negative interpretation related to rejection by others. Because these target situations were the core element in the treatment the formulations were checked in supervision. Rules and examples of these situations and interpretations are presented in Box 6-1. Patients rated for each assessment 
(among others) the probability and cost of the idiosyncratic interpretation of their target situations and anxiety during the situations on Visual Analogue Scales (VAS) (see for an example Figure 6-1).

Box 6-1. Rules and examples for the construction of target situation and accompanying interpretations:

Rulles for the formulation of the target situations:

1. Formulate the sitwations in the I-form (e.g., not "blushing" but "I talk to someone and I feel that I am blushing" or not "blushing during a conversation with my boss" but "I have a conversation with my boss and I feel that I am blushing")

2. Formulate the situations as objective as possible and make them clear of interpretations (e.g., not "I talk with someone who doesn't like me" but "I talk with someone and this person doesn't ask how I am doing". The interpretation in this case probably is: "this person doesn't like me". Another example: not "I am talking to someone and this person stes that I am trembling" but "I talk to someone and I feel that I am trembling".)

3. In the target situations a certain social interaction has to be stated (e.g. not "I walk on the street", but "I walk on the street and I see that a person is looking at me")

4. Target situations have to consist of the element of a social situation that the patient fears most (e.g. not "I am having a conversation with someone" but "I am having al conversition with someone and there is a 10 seconds silence". If the patient formulates the interpretation as "I will start to tremble", trembling should be formulated in the situation: "I am having a conversation with someone and I feel that I am trembling.").

5. Keep in mind when formulating the target situations that friends and family of the patients have to be able to interpret these situations (see, changing interpretation bias: brainstorm technique).

Rules for formulation of the interpretations in the target sifuations:

1. The interpretations have to concern negative evaluation by others and not their own behavior or their feelings of anxiety or negative evaluation of themselves (e.g., not "I will feel anxious and want to run away" but "this person thinks I am weird" or "I am worthless" but "this person thinks I am worthless".)

2. The interpretations have to be stated as firmly as possible (e.g., not "they might think I am stupid" but "they think I am stupid").

Examples:

II give my opinion in a group and they don't immediately tell me that that they agree with my opinion Itwerpretation: These people think I am stupid

I am in a meeting at work, someone asks me a question and If feel that I am blushing Interpretation: My colleagues think I"m weak

I walk past people who giggle and whisper Interpretation. They laugh at me because they think I look weird.

I am having a conversation with someone and there is a silence of more than 5 seconds Interpretation: This person thinks I am boring

I get money back from a cashier and I feel that my hands are trembling Interpretation: This person thinks I am abnormal 
The following questions concern this situation:

I am in meeting at work, someone asks me question and 1 feel that $I$ am blushing

1. How probable would it be for you that the following interpretation would be trute? These people think I am ateak

$0 \%$

(not probable

at all)

$100 \%$

(very

probable)

2. How bad would it be for you if the former interpretation would be true?

not bad

at all

very bad

3. How fearful are you in this situation?

not fearful

very fearful

Figure 6-1. Example of assessment of judgmental bias and anxiety in an idiosyncratic (farget) situation

\section{Non-idiosyncratic Sociai" Phobic Symptoms and Related Constructs}

To assess changes in non-idiosyncratic social phobic symptoms, we employed the social phobic scale of the Social Phobia and Anxiety Inventory (SPAI; Turner, Beidel, Dancu, \& Stanley, 1989; Dutch validation by Bögels \& Reith, 1999), the brief version of the Fear of Negative Evaluation (FNE; Leary, 1983), the Self-Focused Attention scale (SFA; Bögels, Mulkens, \& Jong de, 1997) and the Social Phobic Beliefs Scale (SPB; Bögels, unpublished). The SPB is based on statements of social phobic patients. Subjects are asked to fill in their conviction of 15 beliefs (0-100\%), for example "If I show my weaknesses in social situations, I will be rejected". In the study of Voncken et al. (2003) the internal consistency was satisfactory (Cronbachs $\alpha: 97$ ).

For assessment of interpretation and judgmental biases in non-idiosyncratic situations we used the Interpretation and Judgmental Questionnaire (Voncken et al., 2003) that consists of 20 social situations. To estimate interpretation bias, subjects are asked in each script to arrange 4 different interpretations in order of likeliness. To assess judgmental bias the profoundly negative interpretation (that is, a negative evaluation) is rated on a Visual Analogue Scale (VAS) on probability and cost. These ratings are computed into threat ratings (probability $x$ cost $/ 100$ ). The Interpretation and Judgmental Questionnaire is shown to have high internal consistency for the social situations (Voncken et al., 2003). 


\section{Therapists}

The therapists were five cognitive-behavior therapists: two with little cognitive therapy experience, two with moderate experience and one with experience on senior level. All of them received an additional training of one day in the present protocol that was mainly focused on formulation of the target situations. We held one-hour supervision meetings a week with all therapists. As this pilot study was part of a larger study the therapists discussed their patients of this treatment condition and of the other treatment condition (mindfulness and task concentration training see Bogels, Sijbers, \& Voncken, this issue). Relatively little supervision time was spent on how to apply the cognitive techniques; most time was spent on organizational problems and the formulations of the target situations.

\section{Dezelopment of the Treatment}

We intended to develop a short treatment that only focuses on core cognitions with standardized techniques. Therefore, we designed three methods to challenge interpretation and judgmental bias concerning negative evaluation (for specific outline see below). The techniques were constructed to be simple and easily applicable by therapists with any level of experience with cognitive therapy. To add, we developed a "guideline book for the therapists" that consisted of a detailed scheme of each session and advises about difficulties during the application of the different techniques. Besides, each patient received a "theory book" in which the rationale and all techniques were explained in simple words. This provided the patients with the same information as the therapists and made them less dependent of the instruction. by the therapists. Throughout the "theory book" we used two different social situations to illustrate the techniques in detail. In the "homework book" forms were provided to practice these techniques on patients' pre-constructed target situations. In this way the homework assignments were independent of the number of and type of difficult social situations experienced by the patients. In result, patients who were avoiding social situations were able to practice all techniques on the five target situations. Since our clinical experience is that often one or two sessions "get lost" because patients avoid social situations and therefore do not make their homework based on idiosyncratic situations. Besides questionnaires for friends or relatives about their target situations, the "homework book" consisted of forms to use for brainstorming or forms on which the pie-chart and the severity-scale were printed (see for these techniques below). 


\section{Treatment Techniques}

Treatment outline. The five pre-constructed target situations were the blueprint of the treatment. The main focus of the treatment was applying the cognitive techniques on the rarget situations. After practicing these techniques together with the therapist and subsequently in homework assignments, the patients learned to apply them in every day social situations (diary situations). Some of the techniques were practiced first on pre-constructed social and non-social situations to get started.

Rationale. Treatment started with explaining that one can have various interpretations in only one situation. For this purpose the example of the burglar is used: imagine waking up because of a hard, breaking noise, what would you think is happening? The main focus is to brainstorm about a variety of different possible interpretations (e.g, a burglar; a cat; the neighbors; a vase; a drunk; a fire; etc.) and that each interpretation is accompanied by a certain feeling and certain behavior.

Changing interpretation bas: brainstorm technique. The first technique patients learn is challenging interpretation bias by widening the variation of their interpretation spectrum. Patients learn to brainstorm about possible interpretations in each of their target situations: they need to produce at least ten different interpretations. To encourage the brainstorm, patients imagine how close friends, family or "famous people" would interpret their target situations (e.g.r "how would your husband, your best friend, the president, Madonna or Ghandi interpret this situation?"). The emphasis is not on the credibility of the different interpretations but on stimulating a wider and more varied spectrum of interpretations. Therefore, these interpretations can be rational but also completely irrational or absurd. Therapists guard that the spectrum of interpretations is varied, that is, that patients not only produce anxious interpretations.

Besides brainstorming alone or with the therapist, patients gather different interpretations from their friends and/or family members. They do so with pre-structured forms in which the friend and/or family members are asked to write down their personal interpretations of the patients' target situations. See Figure 6-1 for an example of an interpretation brainstorm and gathering different interpretations.

Changing judgmental bias. pie-method. After the brainstorm, patients acquire the skill of the "pie method" to decrease their probability estimations of negative interpretations in social situations. First, patients rate the probability of their own negative interpretation in the target situation. Then, the patient puts all the different interpretations of the interpretation brainstorm into a "pie" based on their estimated probabilities. The therapist and patients add an 
interpretation "remaining interpretations" to the list of interpretations. The "pie" represents what the social interaction partner(s) in the situation can think about the patient. See for an example Figure 6-1.

Changing judgmental bias: severity-scale. After challenging probability estimations, patients learn to challenge their cost estimation of the negative interpretation (e.g., negative evaluation). With this method, the severity-scale, the patients are encouraged to brainstorm about "bad" characteristics to widen their narrow perspective of their own presumed "bad" characteristic (e.go, stupid). This method has two variations. In one variation the patient and therapist brainstorm about characteristics that people use to describe each other, ranging from very bad to not bad (e.g." "How can people characterize each other in the world?"). To help the brainstorming process the therapist again introduces various well-known people with bad characteristics (like Hitler, a known criminal, etc.). All the collected characteristics are put on a severity-scale. Finally, the patients put their own "bad" characteristic on the scale. See for an example Figure 6-1. The second variation of this method is to brainstorm about persons who have the characteristic that the patient fears. For instance, brainstorm about different people who are "stupid" (making use of famous people if possible) and putting those persons on a scale from not stupid to very stupid. Finally, the patients put themselves on the scale of the "bad" characteristic. 
Target situation:

I give my opinion in a group and they don t mmediately tell me that they agree with ny opinion.

Interpretation: These people think I am stupid (probability: $85 \%$, costs: 75 )

Interpretation Braimstorm and applying "pie-method":

1. They like my opinion and want to encourage me to say more by being silent. ( $3 \mathrm{w}^{\text {) }}$

2. They weren't expecting me to give my opinion because an I generally not talkative, so now they are stunned that I said something (7\%)

3. They don't dare to react because they are afraid I get angry if they speak up (imagining a dictator) (1\%)

4. They are thinking about what I have said (imagining Ghandi) (14\%)

5. They aren $t$ interested in the opinions of other peopla $(9 \%)$

6. They are amazed by my very interesting opinion (extremely positive interpretation) (3\%)

7. My remark didnt fit very well in the subject of the conversation (13\%) 8. They didn't quite understand what $\mathbb{I}$ said and are thinking about what to ask me to clarify $(7 \%)$

9. These people think I am stupid (38\%)

10. Remaining interpretations ( $5 \%)$

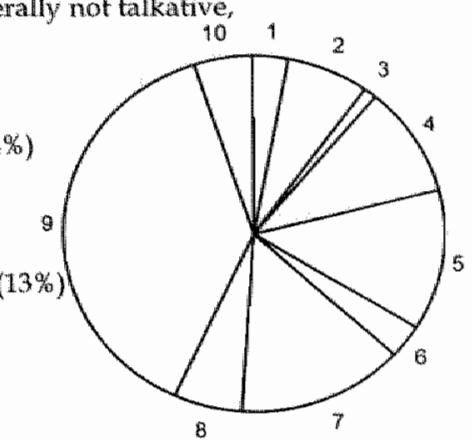

Gathering interpretations:

Mother: They don't like my opinion

Sister: They don't know immediately what to say

Boy friend: They ant thinking of something else

Friend 1: They don't like my opinion and are being polite by not telling me

Friend 2: They agree with my opinion, there is no need to add something more

Evaluation probability:

How probable would it be for you that these persons really think you are stupid?

Probability-score by patient in the "pie": $38 \%$

Probability-score by patient after applying the "pie-method": $60 \%$

Brainstorm for: "severity-scale":

How can people characterize each other in the world?

Sweet

Sociable

Spontaneous

Mean

Vulgar

Dominating

Spiteful

Racist:

Murderous

Intimidating

Severity scale: not bad

0

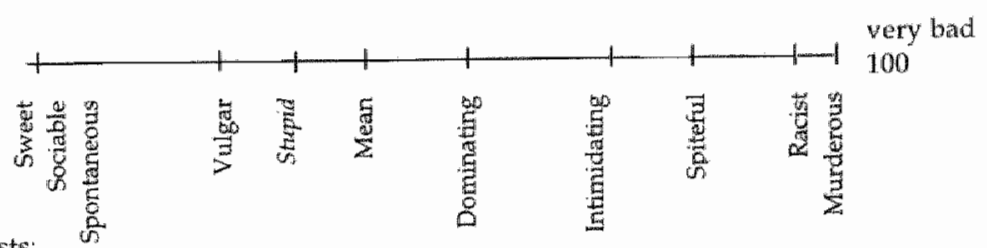

Evaluation costs:

Evaluationcosts:
How bad would it be for you if person actually thinks you are stupid?
Cost-score by patient on severity scale 30
Cost-score by patient after applyng the "severity-scales technique: 65

Figure 6-2. Example of the different cognitive techniques 
Changing judgmental bias: What if your worst scenario comes true? In addition to the former technique to challenge costs, the patient the therapist and patient brainstorm about what someone can do if this worst scenario actually happened to them. In Box 6-2 a conversation illustrates this technique.

Box 6-2. Example of a comversation between a therapist: (T) and a patient (P) to illustrate the technique of "What can I do if my worst scenario comes true."

T: Imagime that someone says 'no' to a friend and this friend in response thinks that this person is very stupid: in other words your worst scenario comes true. What sort of behaviors can people show if this happens to them?

P. I would never dare to talk to him again.

$T$ : You mean you would never talk to him again? $O k$, that is one kind of behavior (and puts "not talking to him any more" on the white board).

T: What else? What for instance would Mohammed Ali do if he knew somebody finds him stupid?

P: He would knock him out! (laughing)

(T: puts 'knocking him out' on the white board)

P: But 1 would never do that?

T: No (laughing), actually I hope not! In this exercise we are only collecting different kinds of behaviours. So you don't have to actually perform them. But..., what else? What for instance would your mom do if this happened to her?

P: She would phone my aunt and talk to her on the phone for hours and hours.

T: Ok (and puts "talking to friends or family" on the white board). What else?

P.....

T: I know a friend of mine who always confronts other people. She would ask this friend why he thinks she is stupid.

P: I would never dare to do that!

T: Well, this exercise is only to brainstorm about what different behaviors are possible, not about what behaviors you dare to perform. Can I put 'confronting the friend' one the whiteboard?

P: Yes. I know a friend of mine, he never cares if others like him or not.

T: Oh, that: sinteresting. How does he behave?

P. Well, he would talk to this friend as if nothing happened.

"T: Ok. So he behaves the same as he always did toward this friend? Can I put "behaving the same on the whiteboard?

P: Yes

Ete. 
Behavior experiments. Around session 6 the therapists introduces the behavior experiments that are based on the work of Clark and Wells (1995). In these behavior experiments patients test out their negative interpretations and probability estimates in real life. For example, a patient tests out the negative interpretation "everybody thinks I am stupid" in the situation "I give my opinion" by giving his/her opinion. Then the patient observes if others respond in a way indicating that they think the patient is stupid. Before starting the behavior experiment the patients makes estimations about the probability of their interpretation being true, and rate it after the experiment again. In the "theory book for patients" examples of different types of behavior experiments are given, like observation of others' behavior, observation of others ${ }^{n}$ responses to their own behavior, or interviewing other people.

Relapse prevention. To prevent relapse, patients make a homework assignment in which they list learned techniques that they can use if they feel socially anxious in the future. If necessary the therapist encourages to brainstorms about more or different techniques the patient can use.

\section{Results}

For each of the outcome measures mean scores and standard deviations at each assessment time and effect-sizes from pre- to post-treatment and followup are given in Table 6-2. The Social Phobia Composite was generated with the procedure followed by Clark et al. (2003) based on the means of standardized Z-scores across pre- post- and follow-up assessment. Included in this composite were the measures of the SPAI, FNE, SFA and SPB. Paired ttests indicated that changes from pre to post and from pre to follow-up are significant.

Effect sizes were computed according to Cohen (1987) d statistic. For each questionnaire the magnitude of change form pre- to post treatment was defined as $\left(M_{\text {pre }}-M_{\text {post }}\right) / S D_{\text {pooled, where }} S D_{\text {proded }}=\sqrt{ }\left[\left(S D_{\text {pre }}{ }^{2}+S D_{\text {post }}{ }^{2}\right) / 2\right]$. The magnitude of change from post-treatment to follow-up was defined by replacing $\mathrm{M}_{\text {prost }}$ with $\mathrm{M}_{\text {sollowup }}$ and $\mathrm{SD}_{\text {post }}$ with $\mathrm{SD}$ followup. Effect-sizes are high, ranging from 0.66 to 2.02 , with lowest effect-sizes for self-focused attention and fear of negative evaluation (respectively, 0.66 and 0.96 ) and highest effectsizes for judgmental biases and anxiety in idiosyncratic situations (target situations: respectively, 1.56 and 2.02). 
Table 6-2. Ouforme measures and effect-sizes for each assessment

\begin{tabular}{|c|c|c|c|c|c|c|c|c|}
\hline & \multicolumn{2}{|c|}{ Pre-treatment $(n=13)$} & \multicolumn{2}{|c|}{ Post-treatment $(n=13)^{3}$} & \multicolumn{2}{|c|}{$\begin{array}{l}\text { 2-Months Follow-up } \\
\qquad(n=8)\end{array}$} & \multicolumn{2}{|c|}{ Effect-size } \\
\hline & $M$ & SD & $M$ & $\mathrm{SD}$ & $M$ & $\mathrm{SD}$ & $\begin{array}{c}\text { Treatment } \\
(n=13)\end{array}$ & $\begin{array}{l}\text { Follow-up } \\
(n=8)^{4}\end{array}$ \\
\hline Social phobia conposite & 0.51 & 0.50 & -0.53 & 0.95 & -0.93 & 0.98 & 1.37 & 1.53 \\
\hline SPAI & 133.67 & 18.67 & 97.03 & 34.79 & 71.41 & 46.25 & 1.31 & 1.36 \\
\hline FNE & 40.77 & 5.12 & 30.76 & 13.78 & 25.75 & 13.42 & 0.96 & 1.46 \\
\hline SFA & 27.23 & 8.72 & 20.23 & 12.23 & 16.38 & 12.73 & 0.66 & 1.04 \\
\hline SPB & 59.02 & 16.85 & 31.42 & 22.88 & 28.39 & 19.62 & 1.37 & 1.70 \\
\hline Target situations, judgmental bias? ${ }^{2}$ & 66.25 & 21.90 & 27.50 & 27.34 & 14.21 & 18.10 & 1.56 & 3.05 \\
\hline Target sifuations, anxiety & 82.06 & 9.89 & 39.09 & 28.34 & 37.10 & 26.38 & 202 & 218 \\
\hline${ }_{N} Q_{2}$ Interpretation bias & 2.27 & 0.95 & 1.42 & 0.52 & & & 1.11 & \\
\hline $1 \mathrm{JQ}_{2}$ Judigmental bials: & 33.31 & 17.05 & 14.43 & 11.74 & & & 1.29 & \\
\hline
\end{tabular}

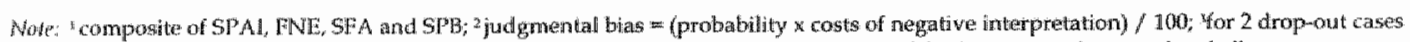

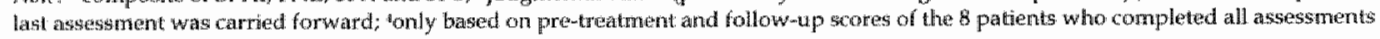

At follow-up the diagnosis of social phobia was re-assessed with SCID-I interviews. No patients who completed follow-up assessments ( $n=8$ ) fulfilled the criteria of a social phobia. Six out of the 10 patients $(60 \%)$ who completed treatment were below the SPAI cut-off at post-test and 5 out of 8 patients $(63 \%)$ who completed follow-up were below this cut-off at follow-up. Eight patients out of the $10(80 \%)$ who completed the treatment requested no further treatment for social phobia; two patients received additional cognitive therapy (respectively 6 and 7 sessions). Four patients (40\%) received followup treatment for other Axis-I disorders $(n=3)$ and Axis-II disorders $(n=1)$.

\section{Discussion}

\section{Effectionemess}

The short, highly structured cognitive treatment that we evaluated effectively reduces social phobic complaints in this pilot of thirteen patients (effect-size 1.4 for the social phobic composite). Although the effect-sizes were not as strong as in the recent studies of Clark et al. (2003) and Stangier et al. (2003), it should be noted that our treatment consisted of only 9 hours intervention time. Considering the length of the treatments in the mentioned studies (respectively: 22 hours and 15 hours), the current treatment seems as effective or even more effective. To add, eight patients $(80 \%)$ who completed our 
treatment did not need further treatment for their social phobic complaints. Moreover, none of the patients that completed follow-up assessments $(n=8)$ fulfilled the DSM-IV criteria for social phobia anymore.

To test the cognitive model we aimed to exclusively intervene in core cognitions (e.g., interpretation and judgmental biases) in social phobia. The highest effect-sizes of all outcome measures were indeed found in the change of threat-scores (probability $x \cos t$ ) for the target situations, that is, the idiosyncratic social situations. However in comparison, the effect-sizes of interpretation and judgmental biases in the non-idiosyncratic situations measured by the lJQ (Voncken et al., 2003) were lower. This could indicate that patients have difficulties in generalizing the learned skills to non-target situations. Nevertheless, these data seem to support the cognitive model as core biases in the idiosyncratic situations decreased and social phobic complaints reduced. The positive correlation $(42, \mathrm{~ns})$, in this small population, between the reduction in these biases and social phobic complaints from pre to post treatment does indicate such a relationship. This is in line with the studies of Hofmann (2004) Foa et al. (1996) and McManus (2000) that found changes in judgmental bias to mediate improvement of social complaints.

Whether the cognitive techniques actually caused a reduction in social phobic complaints is difficult to unravel. It is possible social phobic complaints reduced through other interventions. Although our main techniques (interpretation brainstorm, pie-method and severity-scale) were solely aimed at changing core cognitions, giving a questionnaire to friends is for some patients already exposure. Besides, in spite of the fact that the behavior experiments were framed to test cognitions it might be that avoidance, selffocused attention and social skills were addressed as well. Also general factors might have added to the increased the effectiveness, like the structured homework assignments and the high structure of each session. In contrast with our previous clinical experience most of the patients did their homework seriously (2.4 hours a week) and a number of studies found a positive relationship between compliance with homework and improvement during treatment (see for a review Karantzis \& Lampropoulos, 2002). The high structure in each session could have increased effectiveness as almost no room was left for therapists to spent time on other complaints besides social phobia. This would be in line with the study of Schulte, Kuenzel, Pepping, and Schulte Bahrenberg (1992) in which standardized treatment was superior over individualized treatment. Future research has to resolve whether the cognitive techniques solely caused the reduction in social phobic complaints, for instance in a study that compares this cognitive treatment to other treatments, like exposure or social skills training. 


\section{Follow-up Results}

At 2 months follow-wp the treatment gains showed some increase for the 8 patients $(65 \%)$ that completed all assessments. Of the patients who completed the treatment, no patients sought treatment during this 2 months follow-up period. Future results of our larger treatment outcome study have to clarify whether patients indeed improve from after-treatment to follow-up and how many patients require additional treatment after this 2 months follow-up period.

\section{Accessibility}

Besides being effective, we expected this treatment to be more accessible due to its simplicity and short intervention time. We can indeed conclude that the treatment is effective despite the short intervention time. However, it is difficult to conclude that therapists from our pilot data easily acquired the techniques, as we did not use direct measures to assess this. Besides, in our study we did not use novice therapists; three of our therapists had moderate experience with cognitive therapy. Future studies have to investigate the accessibility of this treatment more thoroughly.

Nevertheless, compared to the highly effective treatment of Clark et al. (2003) and Stangier et al. (2003) our therapists were less experienced and received less training and supervision. In the study of Clark et al. (2003) all therapists were experienced, conducted the treatments after two pilot treatments and received regular supervision. Also in the study of Stangier et al. (2003) all therapists were well advanced in or completed a behavioral treatment certification training, received a two times two-day workshop, and were required to complete one or more pilot treatments. In our study therapists were trained in one day and most of that day was spent on discussion how to formulate the target situations. Besides, therapists did not treat patients with this protocol before entering this study. Moreover, the one-hour supervision, hell once a week with five therapists, was mostly spent on organizational problems rather than on cognitive techniques.

Drawing from our experience we noticed that the two novice therapists and all patients easilly adopted the cognitive techniques, especially the simple brainstorm principal, which was the base of most used techniques. Another advantage of the brainstorming technique was as well that therapists did not get into conflict with their patients about the credibility of their negative automatic thoughts, which is known as one of the major pitfalls for beginning therapists. Besides we learned that brainstorming made the therapy "funny", especially when using "famous people"; it takes the edge of the severity of the patients' problems. 


\section{Difficulties}

We found that a precise formulation of the target situations was of great importance for the interpretation brainstorm and following cogritive techniques (see Box 1 for the rules). Target situations that were formulated in a too general way or not objective (included interpretations) were not suitable for the interpretation brainstorm. Besides, poorly formulated situations were not able to elicit an interpretation from family and friends of the patients when gathering other interpretations. We consider the formulation of these target situations as the main difficulty of this treatment. Though, during the treatment of these thirteen patients we learned how to formulate these situations more precisely to heighten the simplicity of the treatment for future treatments.

\section{Clinical Implications}

The short treatment we developed seems effective and addresses the core of social phobia: interpretation and judgmental biases concening negative evaluation. Besides, the treatment appears more accessible for therapists due to the standardization of the treatment and its shorter duration. We consider this treatment to be less therapist-dependent because of the strong focus on homework and an elaborate handbook for the patients, which makes the treatment transparent. Moreover, our experience was that the treatment does not require intensive training because the cognitive techniques, especially the brainstorm technique, are simple to apply and can be used by therapists with little experience in cognitive therapy. Our experience with the brainstorming principal was that the more people gave imput (like friends or family of the patients) the better the technique worked. Therefore, brainstorming seems to be a technique that would thrive in a group treatment. Currently, we are running group treatments with this protocol and our first experiences are very positive.

\section{Acknowledgments}

This research was supported by a grant from the Netherlands Organization for Scientific Research (NWO; 015.000.069). The authors are grateful to the therapists: Guido Sijbers, René Albers, Stefanie Duijvis, and Sanne Tinga. Furthermore the authors wish to thank Thamare van Roosmalen, Philippe Jacques, Jill Lobbestael, Joke Opdenacker and Esin Demir for their help as research assistants. 


\section{References}

Amir, N., Foa, E. B., Coles, M. E. (1998). Negative interpretation bias in social phobia. Behaviour Research and Therapy, 36(10), 945-9.57.

Bögels, S. M. Mulkens, S., \& fong de, P. J. (1997). Task concentration training and fear of blushing, Clinical Psychology and Psychotherapy, vol. 4(4), 251258.

Bogels, S. M., \& Reith, W. (1999). Validity of two questionnaires to assess social fears: The Dutch Social Phobia and Anxiety Inventory and the Blushing, Trembling and Sweating Questionnaire. Joumal of Psychopathology and Behaoioral Assessment, 21(1), 51-66.

Bogels, S. M., Sijbers, G., \& Voncken, M. J. (2004). Mindfulness- and task concentration training for social phobia: A pilot study of 10 patients. Jourral of Cognitive Psychotherapy.

Bower, P., \& Gilbody, S. (2005). Stepped care in psychological therapies: access, effectiveness and efficiency: Narrative literature review. $\mathrm{Br}$ J Psychiatry, 186, 11-17.

Clark, D. M. (2001). A cognitive perspective on social phobia. In W. R. Crozier \& L. E. Alden (Eds.), (2001). International handbook of social anxiety: Concepts, research and interoentions relating to the self and shyness. (pp. 405-430). New York, NY, US: John Wiley \& Sons Ltd.

Clark, D. M., Ehlers, A., McManus, F., Hackmann, A., Fennell, M., Campbell, $H_{\text {., }}$ et al. (2003). Cognitive Therapy Versus Fluoxetine in Generalized Social Phobia: A Randomized Placebo-Controlled Trial. Journal of Consulting and Clinical Psychology, 71(6), 1058-1067.

Clark, D. M., \& Wells, A. (1995). A cognitive model of social phobia. In R. G. Heimberg, M. R. Liebowitz, D. A. Hope \& F. R. Schneier (Eds.), Social Phobia: diagnosis, assessment and treatment (pp. 69-93). New York: The Guilford Press.

Cohen, J. (1987). Statistical pouter analysis for the behavioral sciences (rev. ed.). Hillsdale, NI, England: Lawrence Erlbaum Associates, Inc.

Feske, U., \& Chambless, D. L. (1995). Cognitive behavioral versus exposure only treatment for social phobia: A meta-analysis. Behavior Therapy, 26(4), 695-720.

First, M. B., Spitzer, R. L., Gibbon, M., Williams, G. B. W., \& Benjamin, L. (1997). Structured Clinical Interview for DSM-IV Personality Disorders (SCID-II). Washington, DC: American Psychiatric Press. 
First, M. B., Spitzer, R. L., Gibbon, M., \& Williams, J. B. W. (1996). Structured Clinical Interview for DSM-IV Axis I Disorders - Pattent Edition (SCID-1/P, Version 2.0). New York: Biometrics Research Department.

Foa, E. B., Franklin, M. E., Perry, K. J. \& Herbert, J. D. (1996). Cognitive biases in generalized social phobia. Joumal of Abnorwal Psychology, 105(3), 433439.

Groenestijn, M. A. C., Akkerhuis, G. W. Kupka, R. W., Schneider, H. \& Nolen, W. A. (1997). Gestructureed Klinisch Intenonew woor de tonststling van DSM-IV As I Stoomissen, Nederlandse vertaling. SCID-I. Lisse: Swets \& Zeitlinger.

Hofman, S. G. (2004. Cognitive Mediation of Treament Change in Social Phobia. Joumal of Consulting Psychology, 72(3), 392-399

Karantzis, N., \& Lampropoulos, G. K. (2002). Reflecting on homework in psychotherapy: What can we conclude from research and experience? Journal of Clinical Psychology, 58(5), 577-585.

Leary, M. R. (1983). A brief version of the Fear of Negative Evaluation Scale. Personality and Social Psychology Bulletin., 9(3), 371-375.

McManus, F., Clark, D. M., \& Hackmann, A. (2000). Specificity of cognitive biases in social phobia and their role in recovery. Behavioural and Cognitive Psychotherapy, 28(3), 201-209.

Rodebaugh, T. L., Holaway, R. M., \& Heimberg, R. G. (2004). The treatment of social anxiety disorder. Clmical Psychology Reovew, 24(7), 883-908.

Schneier, F. R., Johnson, J., Hornig, C. D., Liebowitz, M., R., \& et al. (1992). Social phobia: Comorbidity and morbidity in an epidemiologic sample. Archives of General Psychiatry, 49(4), 282-288.

Schulte, D., Kuenzel, R., Pepping, G., \& Schulte Bahrenberg, T. (1992). Tailormade versus standardized therapy of phobic patients. Advances in Behaviour Research and Therapy, 14(2), 67-92.

Sperry, L., Carlson, J., \& Kjos, D. (2003). Becoming an effective therapist. Needham Heights, MA, US: Allyn and Bacon.

Stangier, U., Heidenreich, T., Peitz, M., Lauterbach, W., \& Clark, D. M. (2003) Cognitive therapy for social phobia: Individual versus group treatment. Behaviour Research and Therapy, 41(9), 991-1007.

Stopa, L., \& Clark, D. M. (2000). Social phobia and interpretation of social events. Behaviour Research and Therapy, 38(3), 273-283. 
Taylor, S. (1996). Meta-analysis of cognitive-behavioral treatment for social phobia. Joumal of Behwoior Therapy and Experimental Psychiatry, 27(1), 19.

Tumer, S. M., Beidel, D. C., Dancu, C. V., \& Stanley, M. A. (1989). An empirically derived inventory to measure social fears and anxiety: The Social Phobia and Anxiety Inventory. Psychological Assessment, 1(1), 3540 .

van Dam Baggen, R., \& Kraaimaat, F. (2000). Group social skills training or cognitive group therapy as the clinical treatment of choice for generalized social phobia? Joumal of Anxiety Disorders, $14(5), 437-451$.

Voncken, M. J., Bógels, S. M., \& de Vries, K. (2003). Interpretation and juldgmental biases in social phobia. Behatiour Research and Therapy. $41(12), 1481-1488$.

Weertman, A., Arntz, A., \& Kerkhofs, M. (2000). Gestructureerd Klinisch Interview woor DSM-IV As-II Persoonlikheidsstoomissen. Lisse: Swets test publishers. 


\section{Chapter 7}

\section{Conclusion and Discussion}



In this thesis cognitive models of social phobia were investigated. Since 1976 , when the cognitive model of emotional disorders was first proposed by Beck, researchers have investigated the model's key assumptions, and new, highly specified models of various disorders were developed. Beck's basic assumptions were that distortions in information processes maintain emotional disorders and that correcting such distortions would reduce complaints. This thesis examined three types of cognitive biases that are assumed to play an important role in the maintenance of the behavioral and cognitive problems of social phobic patients (SPs). Moreover, a cognitive treatment developed to change core cognitions in social phobia was evaluated. The findings can be summarized as follows.

First, despite the overlap of symptoms between social phobia and depression and in line with the content-specificity model of Beck (1976), social phobic and depressed patients showed distinct pattern in interpretation and judgmental biases: depressed patients showed general biases across social and non-social situations whereas the biases in SPs were content-specific to social situations (chapter 2 and 3). Second, as expected by cognitive models of social phobia (Clark, 2001; Clark \& Wells, 1995; Rapee \& Heimberg, 1997) SPs showed an overestimation of their anxious appearance and an underestimation of their social skills compared to normal controls. That is, $\mathrm{SPs}^{\prime}$ predictions of how they were evaluated by their interaction partners were more negative than the ratings of the interaction partners about the SP's performance compared to normal control participants (chapter 4). Third, cognitive biases concerning behaviors that might have a negative (safety behaviors) or positive (selfdisclosure) effect on one's interaction partner were explored in chapter 5. Such biases are assumed to contribute to negative interpersonal cycles in social phobia (Alden, 2001; Clark, 2001). In contrast to expectations, social anxiety was not related to a manifest belief that hiding ones anxiety (e.g., safety behavior) would forestall a negative evaluation by others. However, social anxiety seemed to be associated with the belief that acknowledgment of anxiety (e.g, being self-disclosive) has negative social outcomes specifically for them. Finally, a short, cognitive treatment aimed at core interpretation and judgmental biases in social phobia was evaluated. The study in chapter 6 showed the treatment to be effective in reducing social anxiety symptoms in referred patients with social phobia. The conclusions regarding the three cognitive biases and treatment investigated are presented and discussed in this chapter. 


\section{Interpretation and judgmental biases}

Although interpretation and judgmental biases seem interrelated as both refer to how threatening a certain situation is perceived, cognitive theorists propose that they are distinct (Amir \& Foa, 2001; Hirsch \& Clark, 2004). Interpretation bias refers to a distortion in the meaning assigned to an event (Heinrichs \& Hofman, 2001) whereas judgmental bias relers to the level of perceived threat assigned to a negative event. The latter can be subdivided into judgments of the probability that the negative event will happen and the cost if the negative event would occur (Carr, 1974). Contemporary cognitive models of social phobia regard negative interpretation of a social event as the starting point for various cognitive and behavioral problems in social phobia (Clark, 2001; Clark \& Wells, 1995; Rapee \& Heimberg, 1997)

One problem that pervades studies of interpretation and judgmental biases is catusal status. Cognitive writers assume that these biases produce certain negative feelings, however until recently few studies investigated this issue thoroughly. Mathews and Mackintosh (2000) developed a method of inducing interpretation bias in healthy participants, and found that even these participants experienced heightened anxiety due to this induction. So far, two studies were able to replicate this finding (Salemink, Kindt, \& wan den Hout, submitted; Yiend, Mackintosh, \& Mathews, 2005). Moreover, work is underway to determine whether correcting interpretation biases through computerized tasks reduces anxiety symptoms. Preliminary results in 9 social phobic patients are promising (Amir, 2004). "Taken together, these findings indicate that cognitive biases are not merely a side effect of anxiety disorders but play a causal role.

Three features of interpretation and judgmental biases. To gain more insight in interpretation and judgmental biases, this discussion highlights three features of these cognitive biases. The first feature regards the type of sitwation that is interpreted or judged in a biases way. This feature of interpretation and judgmental biases was investigated chapter 2 and 3 . Chapter 2 showed, in line with previous studies (Amir \& Foa, 2001; Constans, Penn, Then, \& Hope, 1999; Stopa \& Clark, 2000; Foa, Franklin, Perry, \& Herbert, 1996; Lucock \& Salkowskis, 1988; McManus, Clark, \& Hackmann, 2000; Poulton \& Andrews, 1996), that SPs interpreted social events as more negative and judged social events as more threatening but do not differ from normal controls in their ratings of non-social events. Chapter 3 shows that SPs not only differ from normal controls but also from depressed patients in type of situations in which they show distortions. Depression was characterized by general biases across social and non-social situation whereas social phobia was marked by distortions specific to social situations. This finding supports Beck's 
assumption that the type of situations in which information processing is disturbed differentiates between social phobia and depression. This is in line with Rapee (submitted) and Taylor and Wald (2003) who found biases in social but not in non-social events to be related to social anxiety symptoms whereas depressive symptoms were related to biases in both social and nonsocial events.

The second feature of interpretation and judgmental biases regards the content of the biases. It is notable in chapter 3 that, although the interpretation and judgmental biases for depressed patients are not specific to either social or non-social events, both depressed patients and SPs show biases in social events. This pattern raises the question of whether biases regarding social events have the same features in both groups or whether the biases of SPs differ in content from those of depressed patients. For instance, it is proposed that cognitions in anxiety in general are more future-oriented whereas cognitions in depression are more past-oriented and cognitions in anxiety are related to threat whereas cognitions in depression are related to loss and hopelessness (see overview by Beck \& Perkins, 2001). In addlition to these differences in content between general anxiety and depression, the literature derived from self-discrepancy theory (Higgins, 1987) provides interesting findings concerning differences in content of biases between SPS and depressed patients. In this research, Strauman (1989) found depression to be marked by discrepancies between one's "actual self" (the attributes one beliefs to possess) and one's "ideal self" (the attributes one hopes or aspires to), whereas social phobia was marked by discrepancies between one's "actual self" and "ought other" (the attributes a person beliefs others want them to obtain). Interestingly, Higgins (1987) demonstrated that activating "actual seli" versus "ideal self" discrepancies produces feelings of dejection in normal participants whereas activating "actual self" versus "ought other" discrepancies produces agitation. Thus, cognitive biases in social phobia and depression seem distinct in content: SPS are bothered by a distorted view about others" expectations about them whereas depressive patients are bothered by distorted expectations of themselves and not per se by others. More research is needed, however, to establish that self-discrepancies lead to feelings of dejection and agitation.

A third aspect of interpretation and judgmental biases is the variety of meanings that one can assign to a certain situation. Amir and Foa (2001) proposed that interpretations of events compete with each other and that interpretations that are repeatedly accessed dominate this competitive process. Thus, one characteristic of patients with emotional disorders could be their inflexibility in generating multiple interpretations of a situation, i.e., they tend to stick to only one possible (and negative) interpretation. If so, widening 
the interpretation possibilities would be helptul. In chapter 5, this approach, called "the brainstorm", was used to reduce interpretation bias in SPs and was received well by both therapists and patients. Moreover, this treatment was found to be effective in reducing social phobia symptoms (chapter 6).

Differentiation between two types of judgmental binses In addition to addressing various general features of interpretation and judgmental biases in social phobia, the differentiation between two kinds of judgmental biases in social phobia needs to be addressed in this discussion. This differentiation is critical to treating the core dysfunction in social phobia. In the subsequent paragraphs this distinction between these two judgmental biases is addressed. In Figure 7-1 this distinction is illustrated.

Type I

Anticipatory anxiety

Judgmental bins:

threat of social mishap
Type II

Core fear

Judgwemtal bias: threat of negatioe evaluation
Interpretation bias: content of outcome
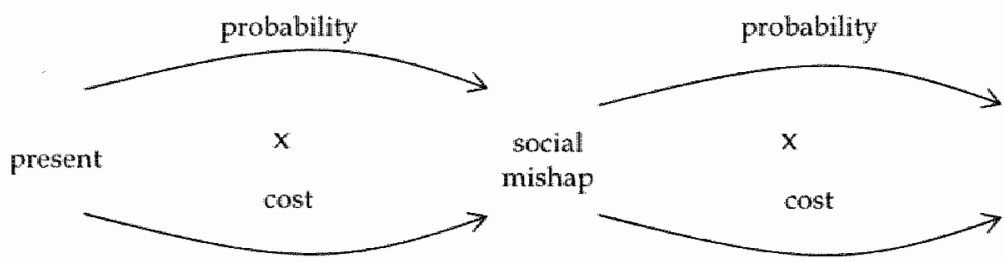

sociall

mishap $x$

-negative evaluation -various other outcomes

$\cos t$

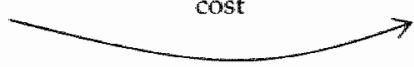

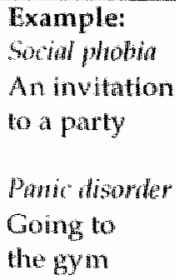

Going to the gym

Increased

heart beat
Possible oulcones

- Others think I"m weak

- Others think I'm charming

- I am having a heart. attack

- My exercise is intense

Figure 7-1. Illustration of interpretation and type I and type II judgmental biases in social phobia 
The first type of judgmental bias was assessed in prior studies (Foa, Franklin, Perry, \& Herbert, 1996; Lucock \& Salkovskis, 1988; McManus, Clark, \& Hackmann, 2000; Poulton \& Andrews, 1996), and reflects judgments about events that might happen in the (near) future: i.e., estimations of probability and costs of certain social minor mishaps that SPs fear. Such mishaps include voluntary behavior like saying something stupid or asking an improper question and involuntary behavior like blushing, stuttering or having a blackout. High estimations of probability and cost of such minor social mishaps lead to anticipatory anxiety. For instance, Jane could be thinking of the birthday party she is invited for next week; "I will blush". If her estimations of both probability and cost of blushing during this party were high this party would be highly threatening for her and subsequently she would experience anticipatory anxiety for the party. In line, going to the gym will provoke anticipatory anxiety in a panic patient if this patient has high estimations of both the probability and cost of experiencing increased heart rate during the workout. As argued in chapter 2 viewing this type of judgments, as assessed in previous studies of judgmental bias in social phobia, as central to social phobia (and other anxiety disorders) is problematic. Heightened probability ratings in those patients might be accurate, as SPs indeed do experience more anxiety-related symptoms like blushing (see chapter 4), and heightened cost ratings in SPs might reflect negative interpretations of such social events.

The second type of judgmental bias reflects the probability and cost estimations of a negative outcome because of a social mishap (e.g., "If I actually blush during the party people will think I am weak"), as investigated in chapter 2. This second type of judgmental bias differentiates between the minor social mishap and the feared negative outcome of such a mishap. For instance, for panic disorder the feared outcome of an increased heartbeat (i.e., minor physical problem) is a heart attack (i.e., negative outcome) and for social phobia the feared outcome of blushing is being regarded as weak or being evaluated in some other negative way. The overestimation of probability and cost of negative evaluation due to a social mishap, rather than the overestimation of probability and cost of the social mishap itself (i.e., blushing) is argued to represent the core anxiety of social phobia, as it is in panic disorder. Two other studies next to the study presented in chapter 2 investigated such type II judgments. The study of de Jong and Peters (2005) found blushing phobics to overestimate the probability and costs of undesirable outcomes of social mishaps and Roth, Antony and Swinson (2001) showed SPs to be marked with the belief that others would evaluate their anxiety symptoms negatively (e.g., having a psychiatric condition). 
Before arguing why the probability and cost of negative evaluation due to a social mishap (type II threat perception) is the core fear of social phobia, one theoretical reflection regarding the difference between type I (probability and cost of a social mishap) and type II judgmental bias (probability and cost of negative evaluation due to a social mishap) needs to be discussed. One can wonder whether in type I judgmental bias the cost estimation of a social mishap, like blushing, does not merely represent the product of cost and probability of a negative evaluation due to this social mishap, the type II judgmental bias. In other words, the cost estimations of blushing might simply reflect estimations of probability and costs of a negative outcome due to this blush (e.g." "other people think I am weak because of my blush").

Returning the issue to which judgmental bias, type I or type II, reflects the core fear in social phobia, one can ask oneself which judgmental bias needs to be addressed in treatment. A therapist can correct type 1 probability overestimations of a social mishap like blushing happening to the social phobic patient. This would correct the tendency of SPs to overestimate their anxious appearance, demonstrated in chapter 4 . However, the data in chapter 4 also show SPs to blush more frequently than normal controls, not only as assessed by a physiological parameter but as well by independent observers. Therefore, it can be questioned whether addressing type I probability estimations of blushing or other social mishaps would be helpful for SPs. In support of this reasoning, Foa et al. (1996) found the cost estimations, more precisely the type $I I$ judgments, of mildly negative social events to mediate social phobic complaints. In other words, when a patient is able to perceive a social mishap like blushing as non-threatening, an overestimation of probability of blushing in the near future is not relevant for reduction of social anxiety symptoms. Following this line of reasoning, the core of social phobia consists of perceiving negative evaluation due to a social mishap as highly probable and costly (type II judgments) but does not consist of overestimating the probability of social mishaps happening (type I judgments).

Subsequently, it needs to be established. what elements, probability or cost, of the core (type II) judgmental biases concerning negative evaluation due to a social mishap, mediates reduction of social phobic complaints. Foa et al. (1996) concluded that cost estimations mediate recovery in social phobia, however, they measured type I judgmental biases. The data of McManus et al. (2000) seem to point in the direction of probability over cost ratings of negative evaluation due to social mishaps to mediate reduction in social phobic complaints. However, in their assessment they included both type I judgmental bias, estimates of social mishaps ("I will freeze during a job interview") and type II judgmental bias, the negative outcome of a social mishap ("I will be ridiculled for voicing my opinion"). This makes it difficult 
to draw firm conclusions from their data concerning type II probability and cost judgments of negative evaluation due to social mishaps. The study by Voncken and Bögels (in preparation-a) did specifically study such type II judgments. This study shows that reduction in probability and not in cost estimations of negative evaluation predicts a drop in social anxiety at 2 months after treatment. As the treatment used in this study is fairly short ( 8 to 9 sessions, see chapter 6 and Bögels, Sijbers, \& Voncken, in press) one can speculate that probability estimations of negative evaluation due to social mishaps are highly flexible and primarily represent changes in level of complaints (Axis I). Changes in cost estimations of negative evaluation due to a social mishap might be less flexible than probability estimations, and therefore could represent more difficult changes like changes on personality level (Axis II). More research is needed to establish which bias, or maybe both, are important in the reduction of complaints in social phobia and whether probability or cost estimations of negative outcomes due to social mishaps represent a different level of pathology.

\section{Biases in Perception of Own Social Performance}

Cognitive models of social phobia assume that social phobia is marked by cognitive biases concerning their anxious appearance and social performance (Clark, 2001; Clark \& Wells, 1995; Rapee \& Heimberg, 1997). Integrating biases concerning anxious appearance and performance with the model presented in previous paragraph (see Figure 7-1), biases regarding how anxious and socially inept one comes across reflect type I judgmental biases of social mishaps. That is, such performance problems can be seen as social mishaps that only become threatening if one predicts high probability and cost of negative evaluation due to these performance deficits (type II judgmental bias).

In line with expectations, chapter 4 shows that SPs overestimated their anxious appearance and underestimated their social skills compared to normal controls. That is, SPs' predictions of how they were evaluated by their interaction partners were more negative than the ratings of the interaction partners about the SP's performance compared to normal control participants. In addition to biases concerning social performance, SPs also suffered from actual deficits in performance. That is, SPS showed a higher cheek blush level, as recorded with a photo plethysmograph, prior to the social tasks and during the speech than normal controls. Since this result was not found for other physiological measures, this implies that blushing is a specific marker for social phobia. In addition to this physiological blush problem, SPs were rated by independent observers as appearing more anxious in both speech and conversation tasks than did control participants. Finally, SPs were rated as 
less socially skilled during the conversation but not during the speech relative to their non-social phobic counterparts. Thus, although SPs showed biases concerning their social performance, they also displayed actual social inadequacy indicating that part of the negative predictions of SPs was accurate. This conclusion is especially true for the conversation as the overestimation of SPs and actual differences between the two groups were almost equal.

The finding that SPS suffer from actual performance problems in social interaction supports the idea that biases concerning social mishaps such as appearing anxious (e.g, blushing) or being socially inadequate (e.g., being silent for a few seconds) might not represent the core anxiety in social phobia. Rather, the predicted outcomes of such social mishaps, negative evaluation by others due to these behavioral problems, type II judgments, is the core fear in social phobia and needs to be addressed in treatment.

One essential point should be made about the model shown in Figure 7-1. The model assumes that SPs erroneously believe that social events like blushing, appearing anxious, and being socially inadequate leads others to negatively evaluate them (type II judgmental bias). However, just as the fear of SPs that they come across as anxious is realistic part of their fear of being negatively evaluated due to social inadequacy might be realistic. There are some indications in the literature that displaying anxiety symptoms is associated with being less well liked by interaction partners (Papsdorf \& Alden, 1998). Moreover, various analogue studies (Creed \& Funder, 1998; Jones \& Russell, 1982; Meleshko \& Alden, 1993; Pilkonis, 1977) and one patient study (Alden \& Wallace, 1995) demonstrate that socially anxious individuals are less liked than non-socially anxious individuals. Therefore, there might be actual negative consequences to the inadequate behavior that SPs display. Research is needed to establish how the physiological signs and performance problems of SPs affect their interaction partners. For instance, independent observers could rate the likeability of SPs and normal control participants during social interactions, thereby testing whether these likeability ratings are related to observed performance problems during interactions.

\section{Biases Regarding Interpersonal Behazior}

In chapter 5 cognitive biases concerning the impact of two interpersonal behaviors, safety behavior and self-disclosure, on evaluation by one's interaction partner were investigated. As the core fear in social phobia is to be negatively evaluated, SPs are assumed to engage in behaviors to reduce the likelihood of negative evaluation. According to the model presented in Figure 7-1, such attempts arise from type II judgmental biases, probability and cost estimates of being negatively evaluated due to social mishaps. These 
behaviors, which SPs believe to forestall negative evaluation; are labeled safety behaviors in cognitive models of social, phobia (Clark 2001. Clark \& Wells, 1995).

Concealing ones anxiety is believed to be a prominent type of safety behavior in social phobia. In chapter 5 participants, anxious or not agreed that hiding anxiety evokes negative responses. As a result, socially anxious individuals seem to be in a difficult position: they are aware of the negative effect of behaviors designed to conceal anxiety, yet they continue to engage in this behavior. Three reasons can be put forward to explain why socially anxious individuals continue hiding their anxiety what seems to evoke negative responses. First, they may hide their anxiety because they lack the ability to engage in more positive behavior. Second, safety behaviors like hiding anxiety might be learned responses in social phobia that occur automatically, i.e., without conscious thought. Third, concealing anxiety is part of a conscious strategy socially anxious individuals use to reduce negative evaluation. However, in chapter 5 no evidence was found that social anxiely related with a manifest believe that hiding anxiety will forestall negative evaluation. This might implicate that hiding ones anxiety is not part of a conscious strategy used by SPs to reduce the probability of a negative evaluation. Another explanation might be that SPs do belief hiding anxiety reduces the probability of a negative evaluation in comparison with explicitly showing their anxiety symptoms, e.g., vividly blushing or having an anxious look in their eyes. It this were true, SPs use hiding anxiety strategically to prevent a vivid expression of their anxiety what they believe results in negative evaluation. This condition of explicitly showing anxiety symptoms was not assessed in the study in chapter 5 . Future research needs to establish whether hiding anxiety is used in social phobia as conscious strategy to reduce critical evaluation.

Following the so-called liking effect of self-disclosure (see Collins \& Miller, 1994 for a review) acknowledging one's anxiety, seems a way to create more positive responses than hiding anxiety. Chapter 5 provides evidence for this assumption: subjects predicted that acknowledging anxiety results in more positive responses than hiding anxiety. Acknowledging anxiety therefore could provide a good alternative for socially anxious individuals. Unfortunately, the socially anxious participants (chapter 5) seemed to belief that acknowledgment of anxiety has negative social outcomes specifically for them. Such a belief might lead SPs to be less open than others about their anxiety feelings. It might even be considered that SPs are afraid of being open about personal topics in general what lead them to be less self-disclosive toward others. The study of (Alden \& Bieling, 1998) provides evidence that SPs are indeed less reciprocal to others" self-disclosure than normal controls. 
If future studies are able to confirm that social phobia is characterized by a belief that acknowledging anxiety or in some other way being open about oneself evokes negative responses, failing to self-disclose could be part of a strategy of SPs to prevent negative social outcomes.

\section{Modifying the Core Arxiety in Social Phobia}

In chapter 6 a short, highly structured treatment for social phobia is presented. This treatment is aimed at changing interpretation bias by widening the interpretation spectrum of $\mathrm{SP}_{\mathrm{s}}$ and altering the core (type II) threat perception by reducing overestimations of probability and cost of negative evaluation due to social mishaps, like blushing or being silent during a conversation (see the model presented in Figure 7-1). The study showed the treatment to be effective in reducing social anxiety symptoms in referred patients with social phobia. Special effort was taken to not address type I probability estimations of social mishaps but only type II estimations of probability and cost of negative evalluation due to social mishaps. The choice to only intervene in type II judgmental bias might have increased the effectiveness of the treatment, as therapists did not invest time addressing the presumed nonessential type I biases. Research is needed to investigate the assumption that changes in type II judgments mediate reduction in social anxiety over changes in type l judgments.

Chapter 6 indicates that solely intervening in core (type II) biases in social phobia strongly reduces social anxiety and strengthens the assumption that these biases have an important role in the maintenance of social phobia. In spite of the effort to solely address these core biases, it might be that other factors caused the reduction in social anxiety. For instance, avoidance, selffocused attention or social skills might have been indirectly addressed by the techniques as well. Therefore, a treatment study is being conducted (Voncken \& Bogels, in preparation-b) that assesses changes in these possible maintaining factors in social phobia. This study may identify which factor(s) contributes most to reduction in social anxiety. In line with the cognitive model of social phobia, it is hypothesized that reduction in social anxiety is primarily mediated by reduction in core (type II) biases.

\section{Towards a Cognitive Interpersonal Model of Social Phobia}

The aim of this thesis was to investigate different cognitive biases in social phobia that are believed to maintain the disorder and to develop a treatment to intervene in core biases in social phobia. On the whole, evidence was found for these biases, and a new treatment solely intervening in core biases in social phobia showed to be effective. However, during this investigation other interesting features of social phobia emerged that lead to the consideration of 
a cognitive interpersonal perspective on social phobia. First, SPs were observed to suffer from actual social inadequacy and this inadequacy seemed to concern a subset of social skulls: interpersonal oriented behavior like making contact and being responsive to ones interaction partiner (chapter 4). Second, hiding anxiety, submissive behavior that characterizes SPs, manifested itself as behavior that evokes negative responses in ain interaction partner (chapter 5). Third, showed social anxiety to be related with a biased view of the effect of acknowledgment of anxiety in social interaction; socially anxious individuals seemed to believe that acknowledgment of anxiety evoked more criticism for themselves than for others (chapter 5). Precisely this behavior appeared to have more positive effects on ones interaction partner than hiding anxiety. Last, during the development of this thesis studies were found that showed socially anxious individuals to be less liked than their nonsocially anxious counterparts (Alden \& Wallace, 1995; Creed \& Funder, 1998; Jones \& Russell, 1982; Meleshko \& Alden, 1993; Pilkonis, 1977). Linking all these findings in this thesis together leads to a conceptualization of social phobia as not only characterized by cognitive biases regarding social events or social performance but also as characterized by an interpersonal inadequacy that might lead other people to disengage from them. Consequences of interpersonal inadequacy in SPS can be huge (see Alden \& Taylor, 2004 for an excellent overview) and might contribute to their feelings of social isolation, difficulties in development of friendships and intimate relationships (Lipsitz \& Schneier, 2000), and distress in intimate relationships (Heinrichs, Hahlweg, \& Fiegenbaum, 2003). Such problems with social connectedness have a strong impact on well-being and quallity of life (Myers, 1999).

Four factors in social anxiety that contribute to negatioe evaluation. Future research needs to focus on the underlying mechanisms that contribute to the relation between social anxiety and the negative impression they leave on others. Four factors that contribute to this relation can be put forward. First, SPs may lack knowledge and experience in interpersonal performance. The overview of Rapee and Spence (2004) suggests that in shy children the development of social skills is stagnated already at young age, as childhood social anxiety is already accompanied by a lack in social skills what leads to negative social interaction and limits opportunities to further develop their social skills. Second, social phobia is accompanied by heightened self-focused attention, what refers to directing too much attention toward themselves in social interaction (Bögels \& Mansell, 2004). Besides intensifying feelings of anxiety, self-focused attention is assumed to increase disengagement in social interaction (e.g., not attending to what is said; absent-minded impression) what in turn might lead the social interaction partner to believe the other person is not interested. Third, socially anxious individuals seem to have 
difficulties with self-disclosure and the reciprocity of self-disclosure (Alden \& Bieling, 1998). This discussion puts forward that underlying beliefs that being open evokes criticism might lead SPs to be less self-disclosive than nonsocially anxious individuals. Being less self-disclosive is suggested to have a negative impact on ones interaction partner. For instance, a large amount of studies indicate the so-called liking effect: people who self-disclose are more liked than people who do not (see for a review Collins \& Miller, 1994). In addition, self-disclosure and the reciprocity of self-disclosure are seen as the key factor in development of friendships (Altman \& Taylor, 1973; Jourard, 1971). Fourth, cognitive models of social anxiety assume socially anxious individuals to show safety behaviors such as concealing ones anxiety (Clark, 2001; Leary \& Kowalski, 1995). In chapter 5 participants predict negative social outcomes for hiding anxiety and therefore such behavior could contribute to the negative interpersonal cycles SPs are involved in. Although, in chapter 5 no evidence was found that social anxiety is related to a manifest believe that hiding anxiety prevents from negative evaluation, such behavior might also be part of learned responses that occur automatically or SPS simply lack the ability to engage in more positive behavior.

Treatment in an interpersonal perspective. Overall, studies in this thesis and other studies point in the direction of social phobia to be marked with inadequate interpersonal behavior and as a consequence are involved in negative interpersonal cycles (see overview of Alden \& Taylor, 2004). Subsequently, it is of importance to investigate whether treatment in social phobia changes their inadequate interpersonal behavior. Although Öst, Jerremalm and Johansson (1981) investigated change in anxious appearance due to treatment, no studies have explicitly studied changes in social skills due to treatment in social phobia. Preliminary analyses in Voncken and Bögels (in preparation-b) show hardly any change in social skills during conversation in SPs $(n=24)$ from pre to post treatment (effect size 0.2 ) whereas social anxiety complaints measured by the SPAI effectively reduced (effect size 1.4). This indicates that an effective treatment did not succeed in changes in interpersonal behavior. Subsequently, inadequate interpersonal behavior could still maintain negative interpersonal cycles in treated SPs.

Following from this discussion, it can be considered to add to current cognitive-behavioral treatment by addressing two types of behaviors in order to correct negative interpersonal cycles in SPs. First, it would be valuable to teach social phobic patients about the negative social outcome of hiding anxiety or submissive behavior in order to improve their social interactions. As the results in chapter 5 show that socially anxious individuals are quite able to see the negative effect that hiding anxiety has in others, explaining this effect of hiding anxiety would be possible by projecting their own behavior on 
somebody else (e.g." 'Imagine that you meet someone who doesn't make eyecontact and hardly talks to you, how would you interpret his/her behavior?"). Our clinical experience supports this idea. Besides making social phobic patients aware of their self-perpetuating negative interpersonal cycles, it would be valuable to teach them how to establish more positive interpersonal cycles. From chapter 5 and the current discussion it can be concluded that being more open about ones anxiety or other personal topics could be useful for this purpose. Chapter 5 also shows that social anxiety is related to a double standard concerning acknowledgment of anxiety: socially anxious individuals seem to perceive acknowledgment of their own anxiety to evoke criticism. Therefore, this double standard needs to be addressed in treatment when motivating patients to use this behavior.

\section{Conclusion}

This thesis identified three types of biased cognitions that play an important role in the maintenance of social phobia: interpretation and judgmental biases regarding social events, the overestimation of an anxious appearance and underestimation of social skills, and the belief that being open about ones social anxiety leads to a critical evaluation by others. Moreover this cognitive approach to social phobia led to the development of an effective treatment that addresses core biases cognitions in social phobia. This thesis did not only add to the development of the cognitive model of social phobia but also suggests critical interpersonal problems social phobic patients suffer from. This gives rise to a cognitive interpersonal approach to social phobia and proposes for intervention in negative interpersonal cycles of social phobic patients. 


\section{References}

Alden, L. E. (2001). Interpersonal perspectives on social phobia. In R. W. Crozier \& L. E. Alden (Eds.), International Handbook of Social Anxiety. Concepts, Research and Interventions Relating to the Self and Shyness (pp. 381-404). Chichester: John Wiley \& Sons, Ltd.

Alden, L. E., \& Bieling, P. (1998). Interpersonal consequences of the pursuit of safety. Behaviour Research and Therapy, 36(1), 53-64.

Alden, L. E., \& Taylor, C. T. (2004). Interpersonal processes in social phobia. Clinical Psychology Review, 24(7), 857-882.

Alden, L. E. \& Wallace, S. T. (1995). Social phobia and social appraisal in successful and unsuccessful social interactions. Behaviour Research and Therapy, 33(5), 497-505.

Amir, N. (2004). Unlearning interpretation bias in social phobia. Paper presented at the European Association for Behavioural and Cognitive Therapies, Manchester.

Amir, N., \& Foa, E. B. (2001). Cognitive biases in social phobia. In P. M. DiBartolo \& S. G. Hofmann (Eds.), From social anxiety to social phobia: Multiple perspectioes (pp. 254-267). Needham Heights, MA: Allyn and Bacon.

Beck, A. T. (1976). Cognitive therapy and the enotional disorders. Oxford, England: International Universities Press.

Beck, R., \& Perkins, T. (2001). Cognitive content-specificity for anxiety and depression: A meta-analysis. Cognitive Therapy and Research, 25(6), 651663.

Bogels, S. M., Sijbers, G., \& Voncken, M. J. (in press). Mindfulness- and task concentration training for social phobia: $\mathrm{A}$ pilot study of 10 patients. Journal of Cognitive Psychotherapy.

Carr, A. T. (1974). Compulsive neurosis: A review of the literature. Psychological Bulletin, 81(5), 311-318.

Clark D. M. (2001). A cognitive perspective on social phobia. In W. R. Crozier \& L. E. Alden (Eds.), (2001). International handbook of social anxiety: Concepts, research and interventions relating to the self and shyness. (pp. 405-430). New York, NY, US: John Wiley \& Sons Ltd.

Clark, D. M., \& Wells, A. (1995). A cognitive model of social phobia. In R. G. Heimberg \& M. R. Liebowitz \& D. A. Hope \& F. R. Schneier (Eds.), 
Social Phobia: diagnosis, assessntent and treatment (pp. 69-93). New York: The Guilford Press.

Collins, N. L., \& Miller, L. C. (1994). Self-disclosure and liking: A metaanalytic review. Psychological Bulletin, 116(3), 457-475.

Constans, I. I., Penn, D. L. Then, G. H., \& Hope, D. A. (1999). Interpretive biases for ambiguous stimuli in social anxiety. Behaviour Research and Therapy, 37(7), 643-651.

Creed, A. T. \& Funder, D. C. (1998). Social anxiety: From the inside and outside. Personality and Individual Differences, 25(1), 19-33.

de Jong, P. J., \& Peters, M. L. (2005). Do blushing phobics overestimate the undesirable communicative effects of their blushing? Behaviour Resentrch and Therapy, 43, 747-758.

Foa, E. B., Franklin, M. E., Perry, K. J., \& Herbert, J. D. (1996). Cognitive biases in generalized social phobia. Journal of Abnormal Psychoiogy, 105(3), 433439 .

Heinrichs, N., \& Hofman, S. G. (2001). Information processing in social phobia: A critical review. Clinical Psychology Review, 21(5), 751-770.

Higgins, E. (1987). Self-discrepancy: A theory relating self and affect. Psychological Review, 94(3), 319-340.

Hirsch, C. R., \& Clark, D. M. (2004). Information-processing bias in social phobia. Clinical Psychology Review, 24(7), 799-825.

Jones, W. H., \& Russell, D. (1982). The Social Reticence Scale: An objective instrument to measure shyness. Journal of Personality Assessment, 46(6), 629-631.

Leary, M. R., \& Kowalski, R. M. (1995). Social anxiety. New York, NX, US: Guilford Press.

Julicock, M. P., \& Salkovskis, P. M. (1988). Cognitive factors in social anxiety and its treatment. Behnoiour Research and Therapy, 26(4), 297-302.

Mathews, A., \& Mackintosh, B. (2000). Induced emotional interpretation bias and anxiety. Joumal of Abnormal Psychology, 109(4), 602-615.

McManus, F., Clark, D. M., \& Hackmann, A. (2000). Specificity of cognitive biases in social phobia and their role in recovery. Behowioural and Cogritive Psychotherapy, 28(3), 201-209.

Meleshko, K. G., \& Alden, L. E. (1993). Anxiety and self-disclosure: Toward a motivational model. Journal of Personality and Social Psychology, 64(6), 1000-1009. 
Ost, L. G., Jerremalm, A., \& Johansson, J. (1981). Individual response patterns and the effects of different behavioral methods in the treatment of social phobia. Behowiour Research and Therapy, 19(1), 1-16.

Papsdorf, M., \& Alden, L. (1998). Mediators of social rejection in social anxiety: Similarity, self-disclosure, and overt signs of anxiety. Journal of Research in Personality, 32(3), 351-369.

Pilkonis, P. A. (1977). The behavioral consequences of shyness. Journal of personality, 45(4), 596-611.

Poulton, R. G., \& Andrews, G. (1996). Change in danger cognitions in agoraphobia and social phobia during treatment. Behaviour Research and Therapy, 34(5-6), 413-421.

Rapee, R. M. (submitted). Underestimation of Personal Performance in Social Anxiety: Replication and Examination of the Role of Dysphoria.

Rapee, R. M, \& Heimberg, R. G. (1997). A cognitive-behavioral model of anxiety in social phobia. Behaviour Research and Therapy, 35(8), 741-756.

Rapee, R. M., \& Spence, S. H. (2004). The etiology of social phobia: empirical evidence and an initial model. Clinical psychology review, 24(7), 737-767.

Roth, D., Antony, M. M., \& Swinson, R. P. (2001). Interpretations for anxiety symptoms in social phobia. Behaviour Research and Therapy, 39(2), 129138.

Salemink, E., Kindt, M., \& van den Hout, M. (submitted). The causal effects of induced interpretative bias in anxiety.

Stopa, L., Clark, D. M. (2000). Social phobia and interpretation of social events. Behaviour Research and Therapy, 38(3), 273-283.

Strauman, T. J. (1989). Self-discrepancies in clinical depression and social phobia: Cognitive structures that underlie emotional disorders? Joumal of Abnormal Psychology, 98(1), 14-22.

Taylor, S, \& Wald, J. (2003). Expectations and attributions in social anxiety disorder: Diagnostic distinctions and relationship to general anxiety and depression. Cogwitive Behaviout Therapy, 32(4), 166-178.

Voncken, M. I. \& Bögels, M. S. (in preparation-a). Mediation of probability and cost of negative evaluation in treatment for social phobia.

Voncken, M. J., \& Bögels, M. S. (in preparation-b). Mediators of change in treatment for social phobia.

Yiend, I., Mackintosh, B., \& Mathews, A. (2005). Enduring consequences of experimentally induced biases in interpretation. Behaviour Research and Therapy. $43,779-797$. 

Social phobia, or social anxiety disorder, is a persistent and excessive anxiety about being disliked by others. Patients are highly concerned about the impression they leave on others and presume that this impression is negative. Social phobia is the most prevalent anxiety disorder and the third most prevalent mental disorder after depression and alcohol abuse. According to cognitive models, patients with emotional disorders process information in a distorted way. Such problems in information processing would maintain the disorder and, if corrected, reduce complaints. In this thesis, three different types of cognitive biases in social phobia are investigated, interpretation and judgmental biases, biases regarding social performance and biases concerning interpersonal behavior. In addition, a cognitive treatment is evaluated that was developed specifically to address the core cognitive biases in social phobia.

\section{Interpretation and Judgmental Biases}

One basic assumption of the cognitive model is that cognitive biases are content specific. That is, these biases are restricted to key areas related to the disorder, for instance in social phobia: the social situations. In line with previous studies, the study presented in chapter 2 shows this content specificity to be present in social phobia. That is, patients with social phobia interpreted social situations more negatively and estimated higher probability and costs for negative social situations than participants without social phobia. In contrast, the non-social situations were interpreted and judged in the same way by both groups. Thus, the biases in the social phobia group were specific for social situations and not for non-social situations.

Comorbid depression, one of the major comorbid disorders in social phobia, might have accounted for the content specific biases in social phobia found in chapter 2. The fact is that depression is also characterized by cognitive distortions in social situations. Nevertheless, chapter 3 demonstrates that social phobic and depressed patients do show a distinct pattern in biases across social and non-social situations. Depressive symptoms related to general biases, i.e., the biases were both present in social as well as in nonsocial situations. In contrast, social phobic symptoms related to biases for social situations but not for non-social situations. Moreover, depressive symptoms in social phobic patients increased biases in both social and nonsocial situations. This implicates that establishing a primary diagnosis in patients with mixed depression and social anxiety is meaningful. Furthermore, treatment for patients with social phobia with co-morbid depression should also address biases in non-social situations. 


\section{Biases Regarding Sacial Performance}

Not only do recent cognitive models of social phobia assume that social phobic patients suffer from interpretation and judgmental biases, they also propose that social phobic patients suffer from a biased perception regarding their social performance. In the study described in chapter 4 , social phobic patients conversed with two confederates and gave a speech in front of two confederates. The confederates rated anxiety symptoms and social skills of the participants and the participants estimated how the confederates would judge them. As expected, the social phobic patients underestimated their social skills and overestimated their anxious appearance.

The study did not only find that social phobic patients suffer from biases regarding their social performance but also that social phobic patients show actual performance deficits. That is, during both conversation and speech, the confederates detected more anxiety symptoms in the patient group than in the normal control group. In addition, patients with social phobia were rated as less socially skilled than the normal control group during the conversation. This was not the case during the speech; the skills of both groups were equal. Remarkably, the social skill problem of the patients with social phobia during the conversation specifically concerned interpersonal skills such as, making contact, listening, showing interest and being responsive. This indicates that the social phobic patients lack a specific kind of social skills: interpersonal skills.

Next to the social performance problems, social phobic patients also showed to suffer from physiological problems. That is, patients with social phobia blushed more prior to the social tasks than the normal control group. This was surprising as prior studies were not able to detect differences in physiological blushing between participants with and without social phobia. Moreover, this was the first study to find a relation between physiological responses on the one hand and self-report and observers ratings of blushing on the other hand. This shows, in contrast to prior studies, that people are able to detect their own physiologicall blush response and that others are able to observe blushing in others.

In short, this study shows that, next to biases regarding to their own social performance, social phobic patients suffer from actual performance deficits. Thus, the belief of social phobic patients of being detected as more anxious and socially inapt is partly realistic. Therefore, this implies that treatment should not only aim at changing biases regarding social performance but also aim at changes in anxious appearance and social skills. 


\section{Biases Regarding Interpersonal Behavior}

As patients with social phobia are essentially afraid of being negatively evaluated, it is assumed that they engage in behavior to forestall such negative evaluations. Such behaviors are defined as safety behaviors. A prominent type of safety behavior is hiding ones anxiety, such as avoiding eye contact or hiding trembling hands. The cognitive model proposes that such safety behaviors have the contradictory effect of eliciting negative evaluations in others. It may be that socially anxious individuals believe, incorrectly, that such safety behaviors will forestall negative responses.

The opposite behavior of hiding ones anxiety is acknowledging anxiety. A body of studies has shown that people who are self-disclosive are liked more than people who are not. Acknowledging ones anxiety, like making a remark about ones blush, might therefore elicit a positive response in others. There are indications that patients with social phobia are less self-disclosiwe than others. Possibly, socially anxious indiwiduals erroneously belief that acknowledging ones anxiety evokes negative responses.

Chapter 5 investigates biases regarding the two mentioned kinds of interpersonal behavior, hiding ones anxiety and acknowledging ones anxiety. Participants teceived written scenarios in which a target person experiences social anxiety and either tries to hide the anxiety or acknowledges the anxiety. The participants rated in each scenario how others would judge themselves as target persons or others. As expected, the safety behavior hiding anxiety elicited a negative evaluation by the participants. In contrast, acknowledgment of anxiety elicited a positive evaluation. Against expectations, no relation was found between social anxiety and a bias regarding hiding anxiety. However, social anxiety did relate to a bias regarding acknowledgment of anxiety. Apparently, socially anxious participants believed that when others were open about their anxiety this would not elicit a negative evaluation. Yet, when they themselves were open about their anxiety this would elicit a negative evaluation. This belief might lead social phobic patients to be less open than others about their anxiety feelings. Correcting this bias in treatment may contribute to mote positive interaction patterns of patients with social phobia.

\section{Modifying the Core Anxiety in Social Phobia}

Chapter 6 presents a short (nine sessions), highly structured cognitive treatment for social phobia. This treatment aims at changing the core anxiety in social phobia. In the discussion (chapter 7) it is argued that the core fear in social phobia consists of biases regarding the social consequences of social mishaps (for example: people think I am weak if I blush or people think I am. stupid if I stutter). 
Prior to treatment, each patient together with the therapist formulates five idiosyncratic social situations. Each social situation consists of a social mishap the patient fears, such as blushing, stuttering or a silence in conversation. Next, the patient describes how others would, in their view, interpret this behavior (e.g, others think 1 am weak, weird, boring). The treatment exists of three basic techniques that aim at changing interpretation bias regarding the consequences of social mishaps, the probability of negative evaluation and the cost of negative evaluation. Furthermore, the treatment focuses on behavioral experiments in which patients test their interpretations and judgments in the reall world.

The first results with thirteen social phobic patients shows that the treatment effectively reduced social anxiety (effect-size 1.4). This effect was especially high considering that this treatment only consisted of nine sessions. This result seems to indicate that a solely intervention in interpretation and judgmental biases in social phobia is able to reduce social anxiety complaints. Next to the effectiveness of the treatment, the treatment seemed highly accessible for patients due to its simplicity and short duration.

\section{Discussion}

In chapter 7 the findings of the previous chapter are discussed. An important conclusion in this thesis is the necessity of differentiating between two types of biases in social phobia. The first bias (type l) refers to biases regarding the occurrence of social mishaps as blushing or stuttering. The second bias (type II) refers to the negative consequences of these social mishaps (type II). It may not be the overestimation of the occurrence of social mishaps (type I) that reflects the core fear in social phobia. After all, chapter 4 shows that social phobic patients do make more social mishaps, as they were judged as more anxious and less skilled than the normal control subjects. It is argued that the core fear of social phobia would primarily consist of the overestimation of the consequences of these mishaps: the overestimation of probability and cost of negative evaluation due to social mishaps as blushing and stuttering (type II). Such overestimations of the consequences of social mishaps would be the core fear in social phobia as, for instance, blushing will only become fear evoking if one estimates that the negative consequences of blushing are high.

Another important topic in the discussion is the interpersonal view on social phobia. In this thesis four notable findings emerged that lead to the consideration of a interpersonal problem in social phobia. First, patients with social phobia mainly showed a skills deficit in interpersonal behavior (chapter 4). Second, hiding ones anxiety (a behavior social phobic patients often use) was negatively evaluated by others (chapter 5). Third, a relation was found between social anxiety and biases regarding being open about ones anxiety 
(chapter 5). Such a bias could have interpersonal consequences as openness, e.g., self-disclosure, is related to being liked by others. Last, previous studies show that socially anxious individuals are less liked than their non-socially anxious counterparts. Linking all these findings together lead to a conceptualization of social phobia as not only characterized by cognitive biases but also characterized by an interpersonal inadequacy. Such an interpersonal inadequacy might lead social phobic patients to elicit a negative impression in others. Changing the interpersonal problems of social phobic patients might add to the current cognitive treatment of social phobia. Such changes could be achieved by making patients with social phobia more aware of the negative effect of their safety behaviors on others and the positive effect of self-disclosure in social interaction.

\section{Conclusion}

This thesis identified three types of cognitive biases that play an important role in the maintenance of social phobia: interpretation and judgmental biases regarding social events, the overestimation of an anxious appearance and underestimation of social skills, and the belief that being open about ones social anxiety leads to a critical evaluation by others. Moreover, this cognitive approach to social phobia led to the development of an effective treatment that addresses core biases in social phobia. This thesis did not only add to the development of the cognitive model of social phobia but also suggests critical interpersonal problems social phobic patients suffer from. This gives rise to a cognitive interpersonal approach to social phobia and proposes for intervention in negative interpersonal cycles of social phobic patients. 


Sociale fobie, ofwel sociale angststoornis, is een buitensporige, aanhoudende angst om negatief geẻvalueerd te worden door anderen. Cliënten met deze angststoornis zijn buitengewoon bezorgd welke indruk ze op anderen achterlaten en veronderstellen dat deze indruk negatief is. Sociale fobie is de meest voorkomende angststoornis en de derde meest voorkomende mentale stoornis na depressie en alcoholmisbruik. Cognitieve modellen stellen dat cliënten met emotionele stoornissen informatie op een verstoorde manier verwerken. Deze verstoorde informatieverwerking zou de klachten in stand houden en, wanneer gecorrigeerd, de klachten verminderen. In dit proefschrift worden drie verschillende typen denkfouten in sociale fobie onderzocht: denkfouten in het interpreteren en beoordelen van situaties, denkfouten over sociale prestaties en denkfouten over interpersoonlijk gedrag. Daarnaast wordt een behandeling geëvalueerd die tot specifiek doel heeft kern denkfouten in sociale fobie te veranderen.

\section{Denkfouten in Interpreteren en Beoordelen oan Situaties}

Een van de basis aannames van het cognitieve model is dat denkfouten inhoudsspecifiek zijn. Dat wil zeggen dat denkfouten beperkt blijven tot het specifieke domein van de stoornis, bijvoorbeeld in geval van sociale fobie: de sociale situaties. In aanvulling op eerder onderzoek werd dit in hoofdstuk 2 inderdaad gevonden. Cliënten met een sociale fobie verwachtten in sterkere mate een negatieve evaluatie door anderen in sociale situaties en overschatten de kans op en de ernst van deze negatieve evaluatie in vergelijking met mensen zonder sociale fobie. Echter de niet-sociale situaties werden door de mensen met en zonder sociale fobie op dezelfde manier gënterpreteerd en beoordeeld. De denkfouten van de cliënten met sociale fobie waren dus specifiek voor sociale situaties en waren niet aanwezig in niet-sociale situaties.

Comorbide depressie, een van de meest voorkomende comorbide stoomissen bij sociale fobie, zou de inhoudsspecifieke denkfouten in sociale fobie gevonden in hoofdstuk 2 kunnen verklaren. Depressieve cliënten vertonen namelijk ook denkfouten in sociale situaties. Desondanks laat hoofdstuk 3 toch zien dat cliênten met een sociale fobie duidelijk anders reageren op sociale en niet-sociale situaties dan cliënten met een depressie. Depressieve symptomen hingen samen met algemene denkfouten. Dat wil zeggen dat de denkfouten in zowel de sociale als de niet-sociale situaties aanwezig waren. Sociale fobie symptomen hingen echter samen met denkfouten die specifiek waren voor sociale situaties en niet voor de niet sociale situaties. Depressieve symptomen bij cliënten met een sociale fobie verhoogden daarnaast de sterkte van de denkfouten in zowel de sociale als niet sociale situaties. Dit impliceert dat het stellen van een primaire diagnose zinvol is bij cliënten met een mix 
van sociale angst en depressieve symptomen. Bovendien zou in behandeling van cliênten met een hoofddiagnose sociale fobie en een co-morbide depressie ook wandacht gegeven moeten worden aan denkfouten in niet-sociale situaties.

\section{Denkfouten ower Sacinle Prestatie}

Cognitieve modellen van sociale fobie veronderstellen niet alleen dat cliènten met sociale fobie last hebben bij het interpreteren en beoordelen van sociale situaties, maar dat ze ook denkfouten maken over hun eigen sociale prestaties. In de studie beschreven in hoofdstuk 4 voerden cliënten met sociale fobie en menisen zonder sociale fobie een gesprekje met twee onbekenden en gaven zij een presentatie woor een publiek van twee onbekenden. Deze onbekenden beoordeelden hoe angstig de deelnemer op hen overkwam en hoe sociaal vaardig zij hem of haar vonden. De deelnemers op hum beurt werd gevraagd te voorspellen welke scores ze van hum beoordelaars zouden krijgen. Zoals verwacht voorspelden de sociale fobie cliénten, in vergelijking met mensen zonder sociale fobie, een negatievere beoordeling wan hun beoordelaars dan de beoordelaars werkelijk gaven. Oftewel, de cliënten met een sociale fobie overschatten de zichtbaarheid van hun angst en onderschatten hun sociale vaardigheden.

In dit onderzoek werd niet alleen gevonden dat cliënten met een sociale fobie last hadden van denkfouten over hun sociale prestatie, er werd ook gevonden dat zij werkelijk slechter presteerden dan hun niet sociaal fobische tegenhangers. Tijdens de speech en het gesprek werden de cliënten met sociale fobie als angstiger beoordeeld dan de mensen zonder sociale fobie. Daarnaast werden de cliënten met sociale fobie slechter beoordeeld op sociale vaardigheden tijdens het gesprek dan de mensen zonder sociale fobie. De clienten met socialle fobie werden echter niet negatiever beoordeeld tijdens de speech. Daarin verschilden de sociale vaardigheden van beide groepen niet van elkaar. Opmerkelijk was dat de sociale vaardigheidsproblemen van clienten met sociale fobie tijdens het gesprek vooral interpersoonlijke vaardigheden betroffen, zoals contact leggen met de ander, luisteren, interesse tonen en doorvragen. Mogelijk ligt hun vaardigheidstekort vooral op interpersoonlijk vlak.

Naast problemen in sociale prestatie werd ook gevonden dat cliênten met een sociale fobie fysiologische problemen hadden. De fysiologische apparatur laat zien dat cliênten met sociale fobie meer bloosden voordat ze begonnen met de sociale interacties dan de deelnemers zonder socialle fobie. Dit was vooral opmerkelijk omdat eerder onderzoek naar fysiologisch blozen geen verschillen aantoonde tussen mensen met en zonder sociale fobie. Bovendien was dit ook het eerste onderzoek dat samenhang vond tussen de fysiologisch 
bloosmetingen enerzijds en eigen rapportage van de deelnemer en de rapportage van beoordelaars over blozen en angst van de deelnemer anderzijds. Dit geeft aan, in tegenstelling tot eerder onderzoek, dat mensen hun eigen bloosrespons kunnen voelen en dat anderen deze bloosrespons bij hen ook kunnen waarnemen.

Kortom, naast denkfouten over eigen sociale prestaties toont dit onderzoek aan dat cliënten met een sociale fobie ook werkelijk sociaal slechter presteren. Oftewel, de overtuiging van cliènten met een sociale fobie dat ze sociaal slechter presteren, is ten dele realistisch. Dit lijkt er dan ook op te wijzen dat niet alleen verandering in denkfouten maar ook de verandering in zichtbare angst symptomen en sociale vaardigheden nodig zijn bij behandeling van sociale fobie.

\section{Denkfouten in Interpersoonlijk Gedrag}

Aangezien cliënten met een sociale fobie in essentie bang zijn negatief geëvalueerd te worden, wordt verondersteld dat zij zich op een bepaalde manier proberen te gedragen om zo deze negatieve evaluatie te voorkomen. Zulke gedragingen worden veiligheidsgedragingen genoemd. Het verbergen van angst, zoals wegkijken, je trillende handen verbergen of jezelf klein maken, wordt gezien als een belangrijke vorm van veiligheidsgedragingen. Het cognitieve model van sociale fobie oppert dat juist deze veiligheidsgedragingen een averechts effect hebben en juist een negatieve evaluatie zouden uitlokken. Mogelijk maken sociaal angstige mensen de denkfout dat veiligheidsgedragingen een negatieve evaluatie voorkomen, terwijl deze gedragingen in werkelijkheid juist een negatieve evaluatie uitlokken.

Een tegenhanger van het verbergen van angst is het open zijn over je angst. Duidelijk is uit eerder onderzoek dat mensen die opener zijn over wie ze zijn en wat ze voelen aardiger worden gevonden dan mensen die daarover gesloten zijn. Openheid over je eigen angst, door bijvoorbeeld een opmerking te maken over je blos, zou daarom misschien juist een positieve reactie van anderen kunnen ontlokken. Er zijn aanwijzingen in de literatuur dat cliënten met een sociale fobie minder open zijn dan mensen zonder sociale fobie. Misschien denken sociaal angstige mensen dat open zijn over je angst een negatieve evaluatie uitlokt terwijl het in werkelijkheid juist tot positieve evaluaties leidt.

In hoofdstuk 5 worden denkfouten over de sociale consequenties van de twee eerder genoemde soorten interpersoonlijk gedrag, veiligheidsgedragingen en openheid, onderzocht. Deelnemers beoordeelden verhaaltjes waarin hoofdpersonen zich sociaal angstig voelden. In de verhaaltjes probeerden de hoofdpersonen hun angst te verbergen of waren deze hoofdpersonen juist 
open over hun angst of reageerden ze niet op hun angst. Zoals verwacht bleek dat het veiligheidsgedrag van het verbergen van je angst een negatieve evaluatie ontlokte bij de deelnemers. Open zijn over je angst werd daarentegen positief beoordeeld. Tegen de verwachting in was er geen samenhang tussen sociale angst en denkfouten over veiligheidsgedragingen. Wel werd er samenhang gevonden tussen sociale angst en denkfouten over open zijn over je angst. Sociaal angstige deelnemers leken te geloven dat wanneer anderen open zijn over hun angst dit geen negatieve reactie uitlokt. Echter als zijzelf open zijn over hun angst zou dit wel een negatieve reactie uitlokken. Het is dan ook voor te stellen dat mensen met sociale angst zich minder open zullen opstellen over hun angst. Het corrigeren van deze denkfout in behandeling van sociale fobie zou wellicht kunnen bijdragen aan meer positieve interactie patronen van cliënten met een sociale fobie.

\section{Verandering wan de Kern Angst in Sociale Fobie}

In hoofdstuk 6 wordt een korte (negen sessies), sterk gestructureerde cognitieve behandleling voor sociale fobie gepresenteerd die er specifiek op gericht is om de kern angst van sociale fobie te veranderen. In de discussie (hoofdstuk 7) wordt beargumenteert dat de kern angst bij sociale fobie bestaat uit denkfouten over de sociale gevolgen van sociale foutjes (bijvoorbeeld: mensen vinden me zwak als ik bloos, mensen vinden me dom als ik stotter of mensen vinden me saai als ik een stilte laat vallen).

Voor de aanvang van de therapie formuleert elke cliënt samen met de therapeut wijf verschillende sociale situaties die hij/zij specifiek vreest. In elke sociale situatie komt een bepaalde sociaal foutje voor zoals blozen, stotteren of een stilte laten vallen. Daarnaast beschrijft de cliënt hoe hij/zij denkt dat anderen dit gedrag interpreteren (bv. de ander vindt mij zwak, raar, saai). De therapie bestaat uit drie basis technieken die zich richten op het veranderen van interpretatie fouten van de consequenties van sociale foutjes, het overschatten van kans op een negatieve beoordeling en het overschatten van ernst van een negatieve beoordeling. Verder wordt in deze therapie aandacht besteed aan gedragsexperimenten waarin cliënten hun eigen interpretaties en oordelen gaan testen in de werkelijke wereld buiten de behandelkamer.

De eerste resultaten met dertien sociale fobie cliënten laten zien dat de therapie effectief was in het reduceren van sociale angst (effect-size 1.4). Dit resultaat is bijzonder voor een therapie van zo'n korte duur (negen sessies). Het lijkt daarom ook dat het enkel ingrijpen in kern interpretatie en oordeelsfouten in sociale fobie sociale angst klachten kan reduceren. Naast de effectiviteit van de therapie, leek de therapie ook verhoogd toegankelijk door zijn eenvoud en korte behandelingsduur. 


\section{Discussie}

In hoofdstuk 7 worden de bevindingen in de voorgaande hoofdstukken bediscussieerd. Een belangrijke conclusie van dit proefschrift is dat er onderscheid gemaakt moet worden tussen twee typen denkfouten in sociale fobie. De eerste denkfout (type I) betreft denkfouten over het maken van sociale foutjes zoals blozen, stotteren of een stilte laten vallen. De tweede denkfout (type II) betreft denkfouten over de negatieve consequenties van deze sociale foutjes. De kern angst in sociale fobie zou niet zo zeer liggen in de overschatting van het maken van sociale foutjes (type I). Immers clienten met een sociale fobie bleken, zoals de studie in hoofdstuk 4 laat zien, inderdaad meer sociale foutjes te maken aangezien ze angstiger overkomen dan anderen en tijdens een gesprek minder goede sociale vaardigheden laten zien. Het zou dan vooral ook de overschatting van de gevolgen van zulke sociale foutjes zijn die sociale fobie kenmerken: het overschatten van de kans en ernst van negatieve evaluatie als gevolg van deze sociale foutjes (type II). Immers, alleen als iemand negatieve consequenties verbindt aan een sociaal foutje, zoals blozen, zal blozen ook angstaanjagend worden.

Een ander belangrijk thema in de discussie is de interpersoonlijke kijk op sociale fobie. In dit proefschrift zijn vier opvallende bevindingen gedaan die wijzen in de richting van een interpersoonlijk probleem in socialle fobie. Ten eerste bleek dat cliènten met een sociale fobie vooral tekort schoten in interpersoonlijke vaardigheden zoals contact leggen (hoofdstuk 4). Ten tweede, werd het verbergen van sociale angst, zoals mensen met sociale angst plegen te doen, door anderen negatief beoordeeld (hoofdstuk 5). Ten derde hing sociale angst samen met denkfouten over het open zijn over je angst, terwijl openheid juist gerelateerd is aan aardig gevonden worden (hoofdstuk 5). Als laatste zijn er in de literatuur onderzoeken die laten zien dat sociaal. angstige mensen minder aardig worden gevonden dan mensen die niet sociaal angstig zijn. Deze vier bevindingen samenvoegend, lijkt sociale fobie niet alleen gekarakteriseerd te worden door cognitieve denkfouten maar ook door een interpersoonlijk tekortkoming. Zo'n interpersoonlijk gebrek zou ertoe kunnen leiden dat mensen met een sociale fobie een negatieve impressie achter laten op anderen. Mogelijk zouden interventies die ingrijpen op interpersoonlijk gedrag van cliënten met een sociale fobie een toevoeging kunnen zijn op de huidige cognitieve behandeling van sociale fobie. Bijvoorbeeld door hen bewust te maken wan het negatieve effect van hun veiligheidsgedragingen op anderen en het positieve effect die zelfonthullingen hebben in sociale interactie. 


\section{Conchusie}

Dit proefschrift identificeerde drie typen denkfouten die een belangrijke rol spelen bij de in stand houding van sociale fobie: interpretatie en beoordelingsfouten in sociale situaties, de overschatting van een angstig uiterlijk en de onderschatting van sociale vaardigheden en de overtuiging dat een opmerking maken over je sociale angst leidt tot een kritische evaluatie. Daarnaast is een effectieve behandeling ontwikkeld om kern denkfouten in sociale fobie te veranderen. Dit proefschrift heeft niet alleen het begrip verhoogd van cognitieve processen bij sociale fobie, maar oppert ook essentiêle interpersoonlijke problemen waar cliënten met een sociale fobie last van hebben. Deze interpersoonlijke problemen in sociale fobie wijzen erop dat niet alleen een cognitieve maar ook een interpersoonlijke benadering meer inzicht geeft in de instandhouding van sociale fobie. Voorgesteld wordt om ook in behandeling in te grijpen op deze negatieve interpersoonlijke patronen van cliênten met een sociale fobie.. 


\section{Dankwoord}


De afgelopen jaren ben ik wijzer geworden als onderzoeker maar ook als mens. Mijn dank gaat uit naar al die mensen die daaraan hebben bijgedrager.. Allereerst wil ik mijn co-promotoren, Susan Bögels en Lynn Alden en mijn promotor Arnoud Arntz bedanken.

Susan, jij hebt deze jaren naast mij gestaan en mij rondgeleid in de wereld van het onderzoek. Je bent een zeer bevlogen onderzoeker en jouw passie voor het onderzoek heeft op mij zeer aanstekelijk gewerkt. $\mathrm{lk}$ keek altijd uit naar ons vaste uurtje in de week waarin we de essentie van sociale fobie probeenden te vangen. Ik vond het bijzonder dat je mij de ruimte gaf en aanmoedigde om. mijn eigen visie te ontwikkelen. Wat ik verder erg heb gewaandeerd is dat ik ook persoonlijke dingen waar ik tegen aan liep met jou kon bespreken. Je kon altijd goed luisteren en helder, doortastend advies geven. Verder wil ik je bedanken voor de rol die je in de start van het project had toen het plotselinge verlies van mijn vader mijn werk in de weg stond. Je hebt me toen de ruimte gegeven, maar me ook laten zien hoe je met zo'n ingrijpende gebeurtenis om kan gaan. Susan, ik heb me vaak gelukkig geprezen dat jij me begeleidde. Ik hoop dan ook dat we in de toekomst kunnen blijven samenwerken.

Lym, I would like to thank you for your part in my development as a researcher. Your interpersonal view on social phobia inspired me. The first time I met you was at our ambulant mental health centre in Masticht in 2002 (around the EABCT in Maastricht that year). You talked about the interaction between 'the aggressive type' of social phobia and therapists. This was the first time such an interactional problem in social phobia became apparent to me. Months later, I was reading about the fascinating concept of selfdisclosure and discovered your experimental work on self-disclosure in social phobia. You made it possible for me to work for 3-months at the UBC, Vanvoucer, in 2003. This was a very special and important experience for me: working in your lab and treating social phobic patients with the concepts of self-disclosure. These 3 months showed me some interesting cultural differences between our countries but foremost added to my interest in the interpersonal view on social phobia.

Arnoud, voor ik hier met mijn promotie traject begon ben ik bij jou afgestudeerd en heb ik voor je gewerkt als onderzoekassistent bij het DAC. IK heb je leren kennen als iemand die gefascineerd is door een breed scala van onderzaek binnen de psychopathologie. Jouw rol als promotor startte op het moment dat mijn proefschrift zo goed als af was. Je had het op dat moment erg druk en ik vind het geweldig dat je de tijd nam om zo uitgebreid naar mijn proefschrift te kijken.

De basis van dit proefschrift zijn de vele cliënten van de RIAGG Maastricht. leden van de VVM (Vereniging an Verlegen Mensen) en proefpersonen die 
ellenlange lastige vragenlijsten invulden en het engste van het engste moesten doen: onder het oog van een camera, volgeplakt met elektroden in een klein hokje een speech en een gesprek voeren met twee afwachtende onbekenden. Ik heb grote bewondering voor jullie moed, niet alleen om mee te doen aan dit onderzoek maar ook om behandeling te zoeken voor de klachten waar jullie al jaren last van hebben. Daamaast wil ik de stoet van zo'n 60 rollenspelers bedanken die tijdens de afgelopen jaren trouw kwamen opdagen bij de gedragsmetingen en zeer betrouwbaar elke keer het gedrag van weer de volgende proefpersoon beoordeelden. Jullie hebben een geweldige klus geklaard waar ik jullie bijzonder dankbaar voor ben. Deze ingewikkelde gedragsmetingen zijn voortreffelijk geleid door verschillende stagiaires en assistenten: Serife, Eline, Anja en Saskia. Veel dank voor jullie zorgvuldigheid en stressbestendigheid.

Een van de fundamenten van dit proefschrift ligt daarnaast bij het dwarsverband academisering (DAC) van de RLAGG Maastricht. Deze bijzondere onderzoeksstructuur maakte het mogelijk om reguliere cliênten te betrekken in dit onderzoek. Daarom wil ik in de eerste plaats Amoud en zijn opvolger Marcus als coördinatoren van het DAC bedanken. Verder wil ik alle onderzoeksassistenten die betrokken waren bij SF6 bedanken, met name Esin en Thamare. Jullie betrokkenheid en zorgvuldigheid heb ik de afgelopen jaren zeer gewaardeerd. Elke keer als ik voorzichtig kwam informeren of bepaalde data misschien al binnen waren kreeg ik te horen dat alles al lang was ingevoerd en binnen 1 minuut in SPSS kon worden omgezet. Mijn complimenten. Daarnaast wil de ik therapeuten van het angstteam van de RIAGG onder leiding van Hannie van Genderen bedanken. Door jullie zorgvuldige manier van motiveren van cliënten voor deelname aan onderzoek waren velen van hen bereid om aan het SF6 protocol en de gedragsmetingen mee te doen. Grote dank gaat vooral uit naar Guido, Stefanie en René, het sociale fobie 'A-team', die zo dapper met 101 formulieren weer ten strijde gingen om de cliènten met sociale fobie te behandelen. Ons intervisie uurtje elke week was altijd warm en vrolijk en ik hoop nog veel van zulke uurtjes met jullie door te brengen. Ook veel dank voor al de organisatorische beslommeringen rondom het onderzoek die jullie altijd weer wisten te tackelen.

Verder wil ik mijn collega's bij het DMKEP bedanken voor jullie gezelligheid en ping-pong hoogte en diepte punten. Met name wil ik Nicole en Ellin, mijn paranimfen, bedanken. Nicole, we hebben 4 jaar naast een kamer ook veel persoonlijke dingen met elkaar gedeeld. Bedankt daarvoor. Ellin, vanaf het eerste moment dat we elkaar leerden kennen ('s nacht in een enge buurt in Manchester tijdens het $E A B C T$ ) waren we goede vriendinnen van elkaar. Bedankt voor al het lief en leed dat ik met je kan delen. De leden van de 
WWW (Wijze Wielren Wijoen) bedankt voor de fiets vakanties op de dinsdagavond. Verder wil ik ook Theo bedanken voor zijn inzet rondom het lab op de RIAGG en Erik voor al die '5-minuutjes' Spoedeisende Hulp bij Statistiek.

Naast iedereen die ik via het onderzoek ken zijn ook daarbuiten een aantal mensen die ik graag wil bedanken. Marionne, Sonja, Danielle, Charlotte en Marjan wil ik bedanken voor jullie fijne vriendschap door de jaren heen. Ook wil ik Lumière bedanken voor de prachtige films die ik heb kunnen zien en de vrijdagavond-gang en vele anderen bedankt voor de leuke tijd die ik al meer dan 10 jaar bij Lumière heb. Daarnaast wil ik mijn nicht Addy bedanken. voor de prachtige omslag. Je hebt dit boekje helemaal compleet gemaakt.

In het bijzonder will ik de mensen die heel dicht bij me staan bedanken. Lieve papa, ook al ben je er niet meer, jouw nieuwsgierigheid heb ik van je meegekregen. Je vond het mooi voor me dat ik begon met mijn promotie onderzoek. Het is nu af en ik had je graag dit boekje willen geven en je zien glimmen van trots. Lieve mama, ik vind het heel bijzonder hoe wij de afgelopen jaren naar elkaar toe zijn gegroeid. Bedankt voor je fijne tijd die we met elkaar hebben. Lieve zus, als grote zus was je, ben je en zul je altijd een belangrijk deel in mijn leven zijn. Op moeilijke momenten in mijn leven heb je bijzonder veel voor mij betekent. Bedankt daarvoor. Allerliefste Marcel, hoe kan ik jou bedanken voor alles wat je voor me betekent? Er is niemand zoais jij bent voor mij. Jouw rust en realiteitszin hebben me vele malen met mijn benen op de grond gezet.

Marisol 


\section{De boktor}

De boktor was zo nueuwsgierig naar wat hij nu eigenlijk voelde, ergens binnen in zich, dat hij zich binnenstebuiten keerde om daar achter te komen. Onder veel gehijg en gesteun, duwde de boktor zijn binnenste naar buiten, terwijl hij zijn buitenste naar binnen verdween. 'Kun je mijn gevoel zien, mier?', vroeg de boktor. 'Het ziet er eigenaardig uit', zei de mier, 'maar het lijkt nergens op'. "En mijn gedachten?" vroeg de boktor benauwd. De mier haalde zijn schouders op en schudde zijn hoofd. De boktor vroeg of de mier nog een keer heel goed wilde kijken of hij zijn gevoel zag en ook bepaalde gedachten die hij soms zo maar tegen zijn zin had. Maar de mier zag niets. Toen keerde de boktor zich met veel gehijg en rumoer weer buitenstebinnen. 'En toch,' zei de boktor, 'toch had je mijn gevoel moeten zien. Want nu zit het weer hier.' Hij tikte op zijn borst. 'Hier.' 'Ik denk dat mijn gevoel rood is,' zei de boktor, 'lichtrood. Dat denk ik. Maar ik zou dat zó graag eens zeker willen weten. 'De mier knikte terwijl hij een hap uit zijn potje honing nam. 

Marisol Voncken was born on the 8th of June in 1976 in Huesca, Spain. Until 8 years of age she lived in various countries over the world as her father worked as a soil expert in developmental projects. She finished secondary school (VWO, Scholengemeenschap 't Wagenings) in Wageningen, the Netherlands. In 1994, she started with her study Health Sciences (Mental Health Sciences) and, in 1998, Psychology (Biological Psychology). She received her Masters Degree for both studies at Maastricht University in 2001. From 2001 until 2005 she was a PhD student at the Department of Medical, Clinical, and Experimental Psychology at Maastricht University, and carried out the studies included in this dissertation. During this period, she conducted research at the University of British Columbia, Vancouver for three months with Professor Lynn Alden. In 2001 she began with her training as a behavioral and cognitive therapist at the RIAGG Maastricht for the registration as a member of the Association of Behavioral and Cognitive Therapy (VGCt). In 2005 she received a scholarship from the faculty of Health Sciences of Maastricht University for young talent (Talent voor de toekomst) to further develop her interpersonal ideas in social phobia research. In 2006 she will start as an Assistant Professor at the Department of Medical, Clinical, and Experimental Psychology at Maastricht University.

\section{Publication list}

\section{Intemational Publications}

Voncken, M.J., Bögels, S. M. de Vries, K. (2003). Interpretation and judgmental biases in social phobia. Behaviour Research and Therapy, 41 , 1481-1488

Voncken, M. J., Bögels, S. M. (in press). Changing interpretation and judgmental bias in social phobia: a pilot of a short, highly structured cognitive treatment. Journal of Cognitive Psychotherapy

Voncken, M. J., Alden, L. E., Bögels, S. M. (in press). Hiding Anxiety versus Acknowledgment of Anxiety in Social Interaction: Relationship with Social Anxiety. Behaviour Research and Therapy

Bögels, S.M., Sijbers, G., Voncken, M. (in press). Mindfulness- and task concentration training for social phobia: A pilot study of 10 patients. Journal of Cognitive Psychotherapy

Voncken, M. J., Bögels, S.M. (submitted). Specificity of Interpretation and Judgmental Biases in Social. Phobia versus Depression

Voncken, M.J., Bögels, S.M. (submitted). Physiological Responses, Anxious Appearance and Social Skills in Social Phobia 
Arntz, A. Voncken, M.I., Goosen, A.C.A. (submitted). Responsibility and Obsessive Compulsive Disorder: An experimental test

\section{National Publications}

Voncken, M.]., Bogels, S.M. (2005). Specifieke preoccupaties bij sociale fobie: theorie en mieuwe behandeltechnieken. Directieve Therapie 25 (2), 165175

Voncken, M.J., Bügels, S.M. (2004). Persoonlijkheidsstoornissen geen stoorzenders. (Bespreking van: C. van Velzen, Social Phobia and Personality Disorders: comorbidity and treatment issues) De Psycholoog $39,261-263$.

\section{List of presentations}

\section{International Presentations}

Voncken, M. J., Hoffart, A. (2005). Symposium: Content of dysfunctional beliefs and processes of change in social phobia. European Congress for Behaoiour and Cognitioe Therapies, Thessalonica, Sept 21-24.

Voncken, M. J., Alden, L. E., Bögels, S. M. (2005). Hiding and being open about ones social anxiety. European Congress for Behaviour and Cognitive Therapies, Thessalonica, Sept $21-24$.

Voncken, M. J., Boggels, S. M. (2005). Mediators of change in social phobia: Cognitive biases and self-focused attention during actual social interaction. European Congress for Behaviour and Cognitive Therapies, Thessalonica, Sept 21-24.

Bogels, S. M., Voncken, M. J. (2005). Attention processes as mediators of change during treatment for social phobia. Association for Behnvional and Cognitive Thernples, Washington, DC, Nov 17-20

Voncken, M. J., Bögels, S. M. (2004). Cognitive processes during treatment in social phobia. European Congress for Behaviour and Cognitive Thermpies, Manchester, Sept 8-11.

Voncken, M. J., Bögels, S. M. (2004). Actual and self-perceived differences in social performance and anxious appearance between social phobic patients and normal controls. European Congress for Behoviour and Cognitive Therquies, Manchester, Sept 8- 11 .

Bögels, S. M., Voncken, M. J. (2004). Attention processes in the maintenance of social phobia. Europen Congress for Behaviour and Cognitive Therapies, Manchester; Sept 8-11. 
Voncken, M. J. \& Bogels, S.M. (2003). Changing interpretation and judgmental biases in social phobia. European Congress for Cogmine and Behnowour Therapies, Prague, Sept 10-13.

Voncken, M. J. \& Bögels, S.M. (2003). Process of cognitive change during treatment of social phobia. British Conference for Cogntioe and Behasiour Therapies, York, July 17-19.

Voncken, M. J., Bögels, S. M. (2002). Interpretation and judgemental biases in social phobia. Europen conference for Cognitive and Behnowon Therapies, Maastricht, Sept 18-21.

\section{National Presentations}

Voncken, M.J. (2005). Symposium: Sociale fobie: Nieuwe inzichten in cognitieve processen en de implicaties hiervan voor behandeling. Najaarsconferentie on de Verenging voor Gedragstherapit en Cognilieve Therapie, Eindhoven, 10-11 november

Voncken, M.J. (2005). Hoe voorkom ik een negatieve indruk: Verbergen van je angst of juist open zijn over je angst? Najaarsconferentie zan de Vereniging woor Gedragstherapie en Cognitieve Therapie, Eindhoven, 10-11 november

Voncken, M. I., Albers, R. (2004). Workshop: Gestructureerde cognitieve gedragstherapie bij sociale fobie. Najaarsconferentie wan de Vereniging voor Gedragstherapie en Cognitieve Therapie, Eindhoven, 18-19 november

Voncken, M. J., Bögels, S. M. (2004). Symposium: Socialle fobie: Hoe verraderlijk is hun lichaam? Najaarsconferentie van de Vereniging woor Gedragstherapie en Cognitieve Therapie, Eindhoven, 18-19 november

Voncken, M. J., Bögels, S. M. (2004). Sociaall fobici: Verraden zij hun sociale angst door een angstig tuiterlijk of door het verbetgen daarvan? Najansconferentie wan de Vereniging voor Gedragstherapie en Cogntitiete Therapie, Eindhoven, 18-19 november

Voncken, M. J., Bögels, S. M. (2004). Workshop: Korte, gestructureerde cognitieve therapie voor socialle fobie. Afdeling psychotherapit Rotterdam, 5 juli

Voncken, M. J., Bögels, S. M. (2004). Workshop: Korte, gestructureerde cognitieve therapie voor sociale fobie. Geestgronden, Bennebroek, 3 Juni.

Voncken, M. J. (2001). Blozen, je kunt er iets aan doen. Landelijke dag oan de Vereniging an Verlegen Mensen, Utrecht, 9 Juni. 